University of Szeged

Faculty of Humanities and Social Sciences

Doctoral School of Education

Programme of Learning and Instructions

\title{
Development, adaptation and validation of instruments for assessing Namibian students' beliefs about nature of science
}

PhD Dissertation

by

Simson Ndadaleka Shaakumeni

Supervisor: Prof. Dr. Benő Csapó

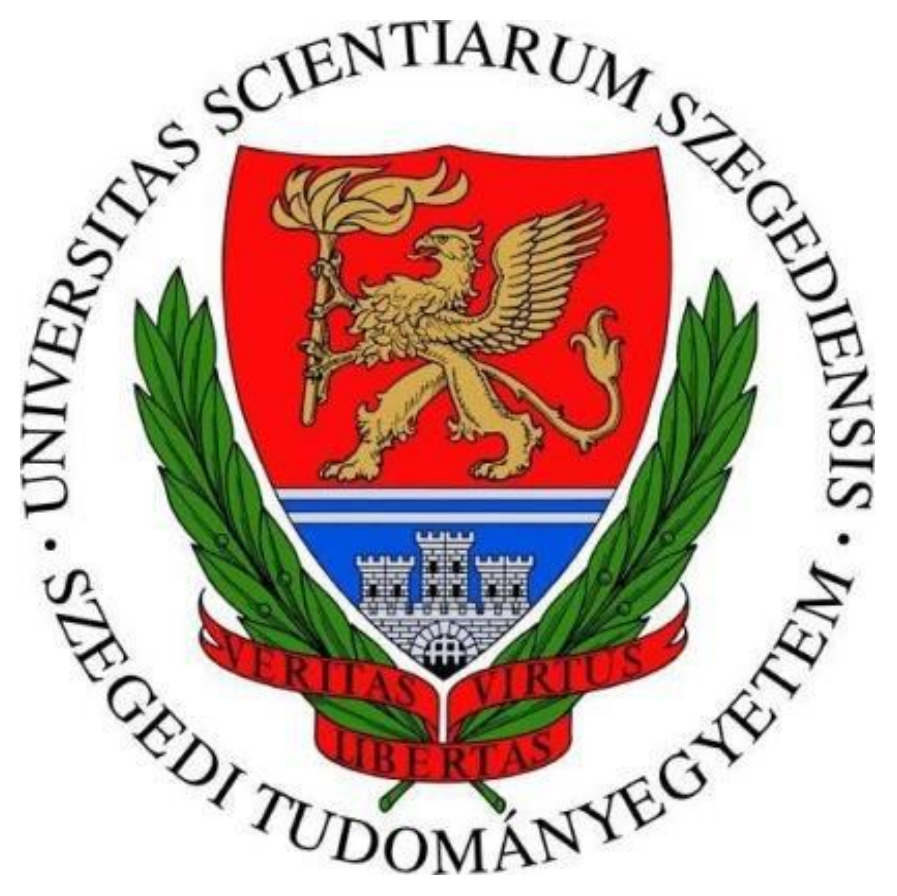

SZEGED, HUNGARY 2020 


\section{Table of Contents}

DEDICATION

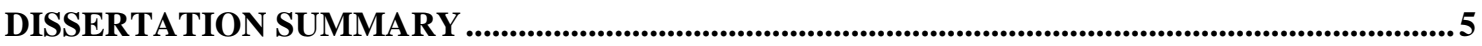

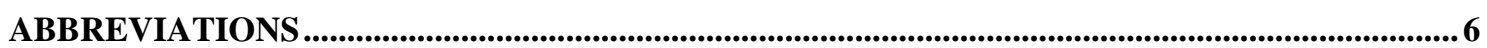

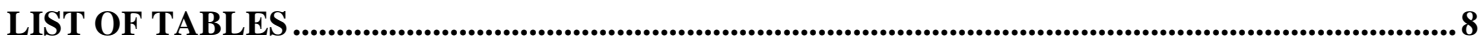

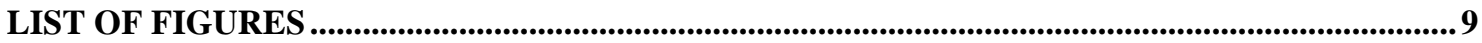

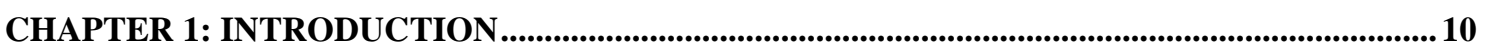

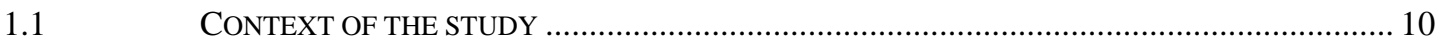

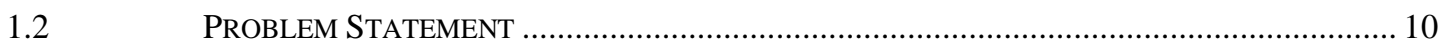

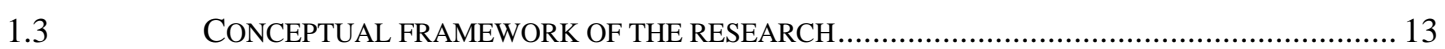

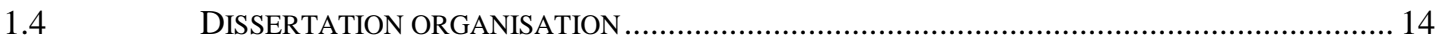

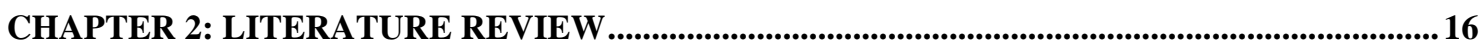

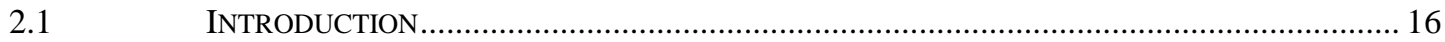

2.2 THE STRUCTURE OF BASIC EDUCATION IN NAMIBIA ………………………................. 17

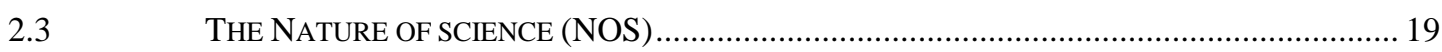

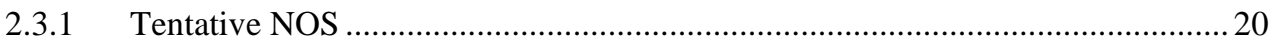

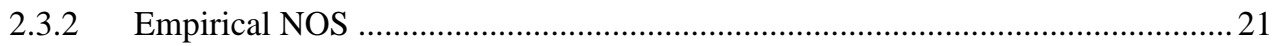

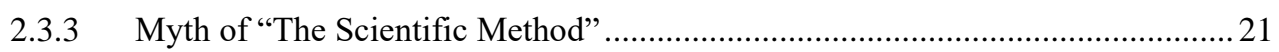

2.3. 4 Subjective/theory-laden nature of scientific knowledge ...................................... 21

2.3.5 Imaginative and creative nature of scientific knowledge....................................22

2.3.6 Social and cultural embeddedness of science ………........................................22

2.3.7 Difference between observations and inferences..............................................23

2.3.8 Difference and relationship between theories and laws of science ...................... 23

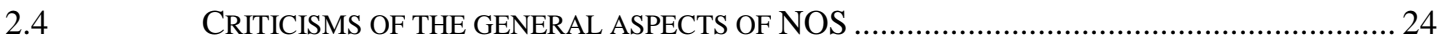

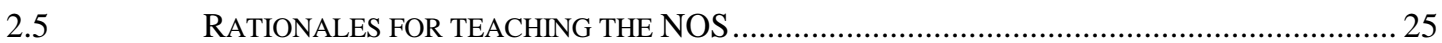

2.6 NOS IN THE NAMIBIAN SCIENCE CURRICULUM: A CRITICAL APPRAISAL...........................226

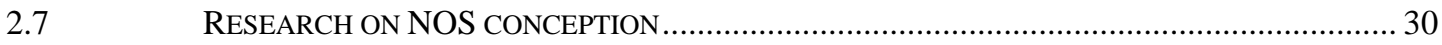

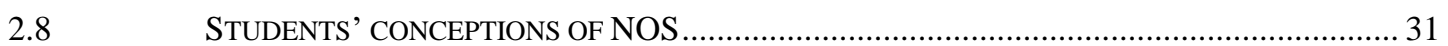

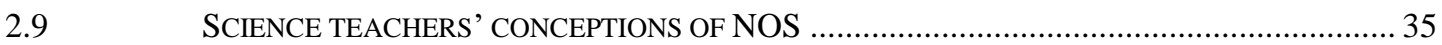

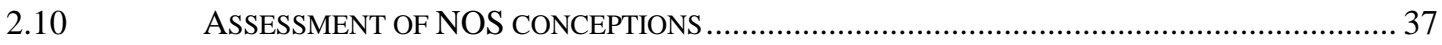

2.11 SCIENTIFIC EPISTEMIC BELIEFS: TERMINOLOGY ................................................................ 40

2.12 STUDENTS’ SCIENTIFIC EPISTEMIC BELIEFS ........................................................... 41

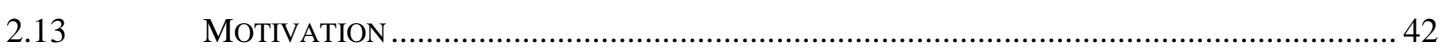

2.13.1 Science academic self-concept, self-efficacy and mastery motivation ................. 43

2.13.2 Motivation towards science learning ............................................................... 45

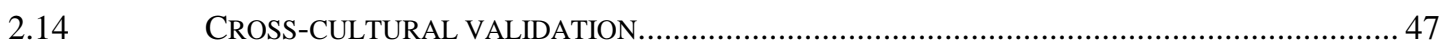


CHAPTER 3: AIMS OF THE RESEARCH AND EMPIRICAL STUDIES ....................................50

RESEARCH AIMS AND EMPIRICAL STUDIES ............................................................... 50

RESEARCH QUESTIONS AND HYPOTHESES.............................................................. 51

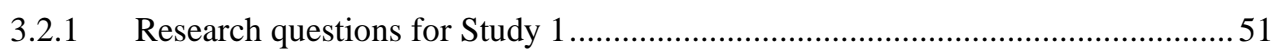

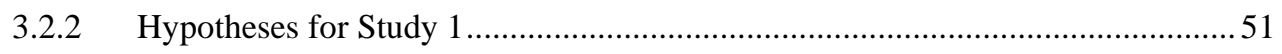

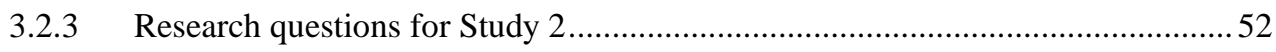

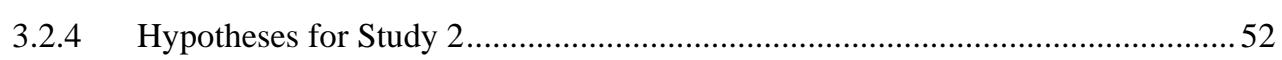

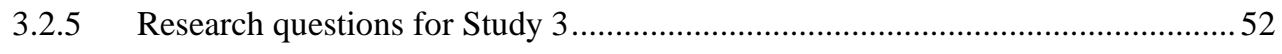

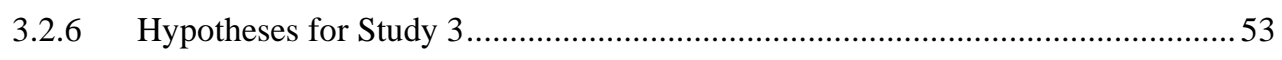

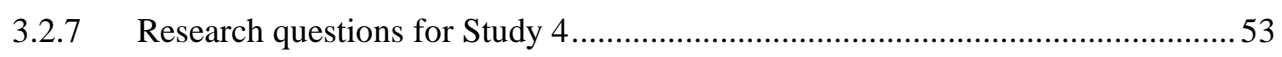

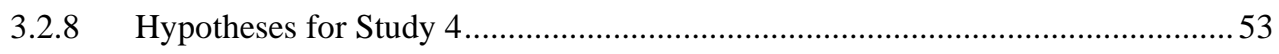

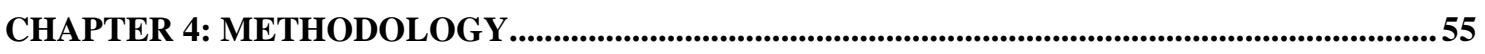

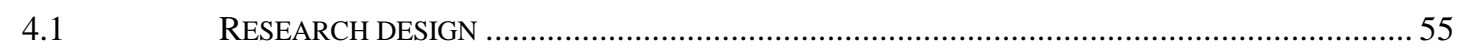

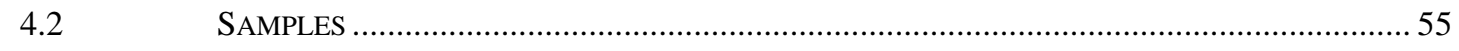

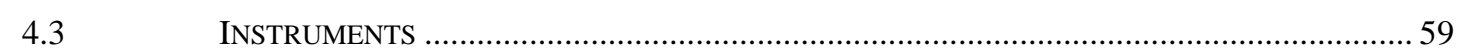

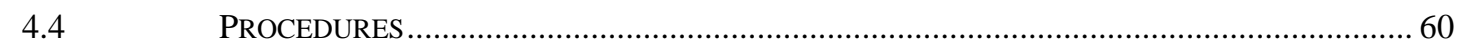

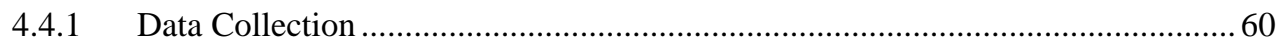

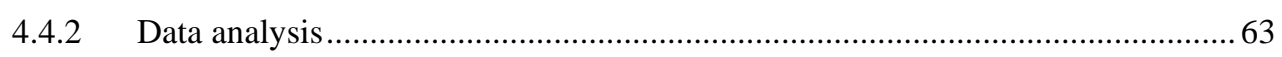

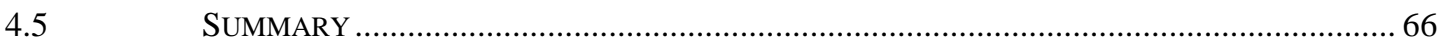

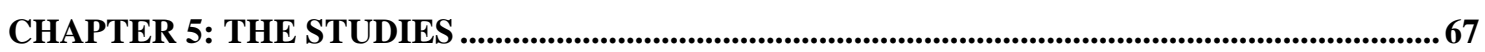

STUDY 1: VALIDATION OF AN INSTRUMENT TO ASSESS BELIEFS ABOUT NATURE OF

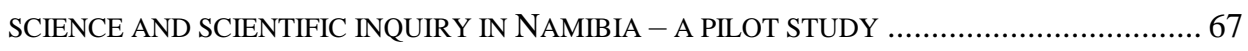

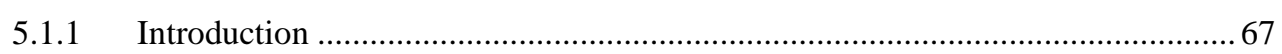

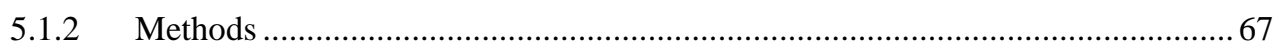

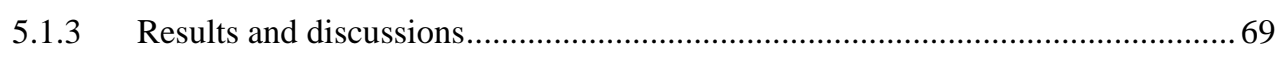

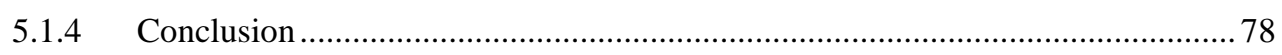

5.2 STUDY 2: EXPLORING THE FACTORIAL VALIDITY OF THE BELIEFS ABOUT NATURE OF

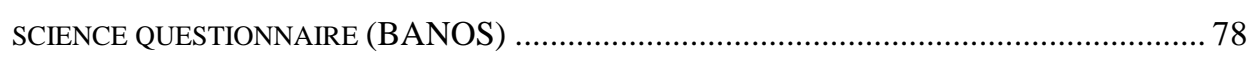

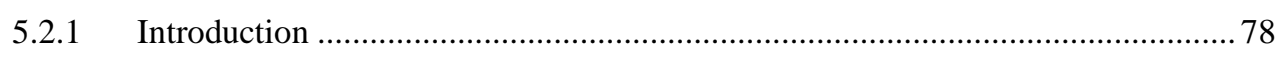

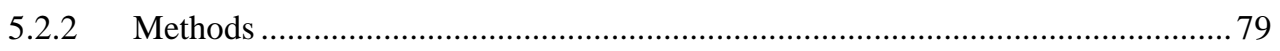

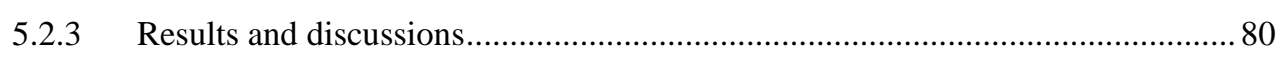

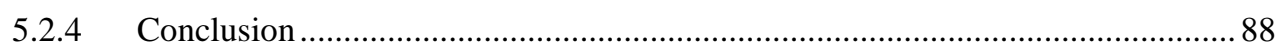

5.3 STUDY 3: A CROSS-CULTURAL VALIDATION OF ADAPTED QUESTIONNAIRE FOR ASSESSING MOTIVATION TO LEARN SCIENCE AMONG GRADE 12 STUDENTS IN NAMIBIA ................... 88

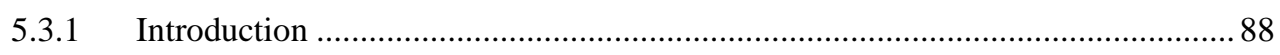

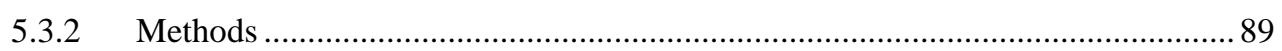

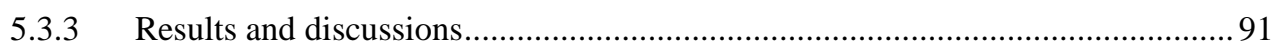

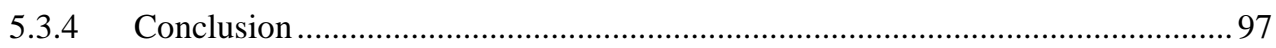




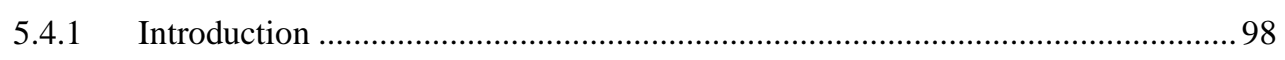

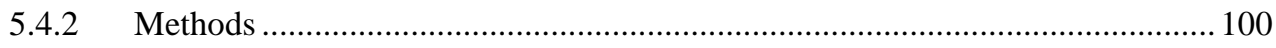

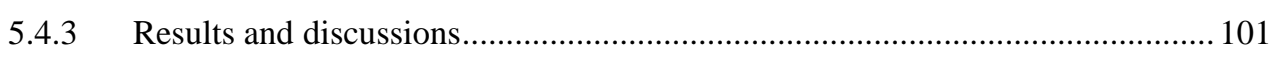

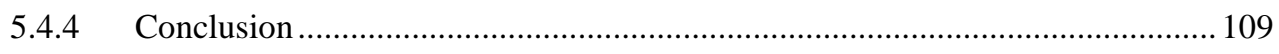

CHAPTER 6: CONCLUSIONS AND RECOMMENDATIONS .................................................. 113

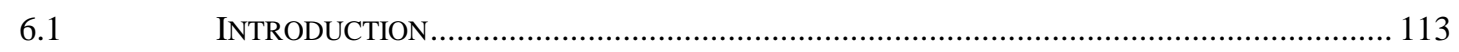

6.2 DEVELOPMENT AND VALIDATION OF THE BELIEFS ABOUT NATURE OF SCIENCE

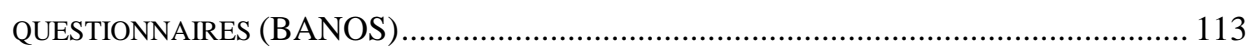

CROSS-CULTURAL VALIDATION OF ADAPTED QUESTIONNAIRES ................................. 115

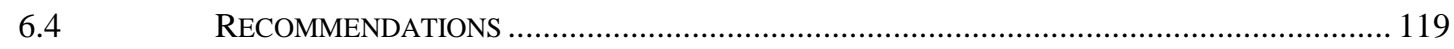

6.4.1 Development of the beliefs about nature of science questionnaire (BANOS) ... 119

6.4.2 Cross-cultural validation studies.............................................................. 120

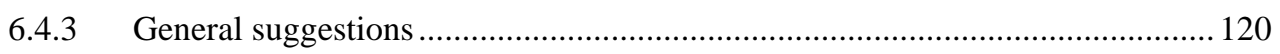

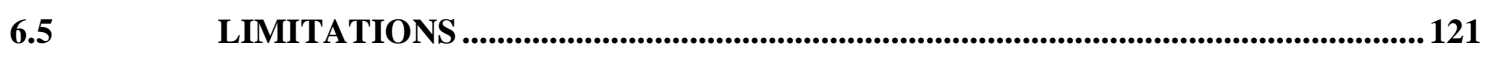

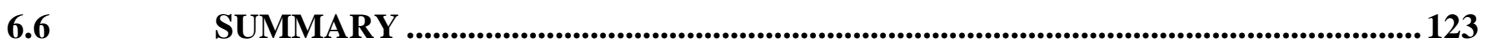

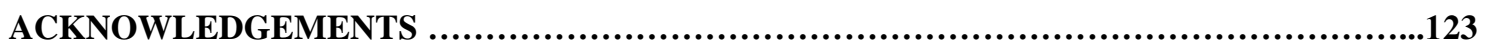

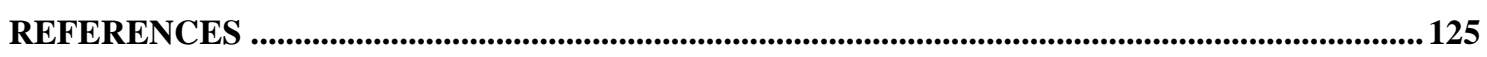

PUBLICATIONS RELATED TO THE DISSERTATION............................................................... 139

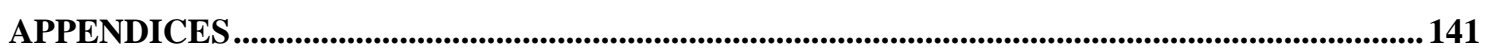

APPENDIX 1: BELIEFS ABOUT NATURE OF SCIENCE QUESTIONNAIRE AND SCIENTIFIC INQUIRY (STUDY

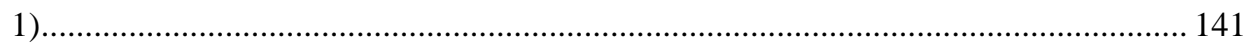

APPENDIX 2: BELIEFS AbOUT NATURE OF SCIENCE QUESTIONNAIRE (BANOS) (STUDY 2) ............... 144

APPENDIX 3: AdAPTED STUdENTS’ Motivation TOWARdS SCIENCE LEARNing (STUdy 3) ............. 146

APPENDIX 4: ADAPTED SCIENTIFIC EPISTEMIC BELIEFS QUESTIONNAIRE (SEBS) (STUDY 4).............. 148

APPENDIX 5: ETHICAL CLEARANCE LETTER FROM THE INSTITUTIONAL REVIEW BOARD ..................... 151

APPENDIX 6: PERMISSION LETTER FROM THE MiNISTRY OF EDUCATION, ARTS AND CULTURE ............ 152

APPENDIX 7: PERMISSION LETTER FROM THE REGIONAL EDUCATION OFFICE ................................... 153

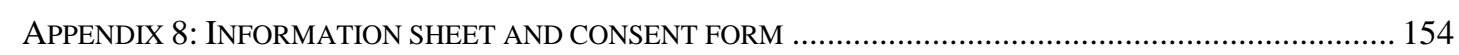

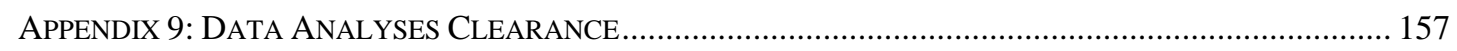




\section{Dedication}

This dissertation is dedicated to my father Nehemia "Kamwiya" Shaakumeni (08.06.1938-26.10.2013) who would have appreciated this Doctoral thesis. He believed in education despite not having had the same opportunities to study due to the injustices of the apartheid rule that prevailed during his youthful days. He taught me how to write my name in the sand before I started school, while we were looking after the cattle in the fields. That act inculcated in me the desire to learn and I have never looked back ever since. I will forever cherish him. Rest in peace dad! 


\section{Dissertation Summary}

The overall aims of this research were to develop, adapt and psychometrically validate questionnaires for assessing senior secondary students' beliefs about the nature of science and motivation to learn science in the cultural context of Namibia. Namibia as a developing nation needs to keep abreast with the rest of the world in terms of educational reforms particularly in science education. Although the national curriculum recognises the importance of scientific literacy, the current assessment practices in Namibian secondary education phase do not include the epistemic aspect of scientific inquiry. Subsequently, there are no ways of ascertaining the realisation of the goals of the national curriculum, related to the understanding of the nature of scientific knowledge. Four empirical studies were carried out in this research. The first two studies pertained the development of a new questionnaire termed 'Beliefs About the Nature of Science' (BANOS). The other two studies were concerned with adaptation and cross-cultural validations of questionnaires for assessing motivation to learn science and scientific epistemic beliefs in the Namibian cultural context. The research followed a descriptive cross-sectional design. In total, 124 science teachers and 2559 students constituted the samples of the research. Data analysis employed both parametric and non-parametric statistical analyses. Findings from the first two studies revealed that the new questionnaire had good reliability and thus showed potential to become psychometrically valid although it had poor model fit for the data. Results from the two adaptation studies showed that the questionnaires were suitable for use in the cultural context of Namibia, at least for the sample used; owing to their reliabilities and good measurement model fit for the data. Further revision and qualitative validations are needed to ascertain whether respondents understand and interpret items in the questionnaires accurately. Furthermore, due to the pioneering nature of this research, a multitude of suggestions for further research in the Namibian context has been made. 


\section{Abbreviations}

NDP National Development Plan

HPP Harambee Prosperity Plan

NCBE National Curriculum for Basic Education

SAT Standardised Achievement Tests

VNOS Views of Nature of Science

NOS Nature of Science

SEB Scientific Epistemic Beliefs

VOSTS Views on Science-Technology-Society

VOSE Views on Science and Education

BANOS Beliefs about Nature of Science

SMTSL Students' Motivation Towards Science Learning

CR Composite Reliability

AVE Average Variance Extracted

MSV Maximum Shared Variance

SES Socioeconomic Status

SPSS Statistical Package for Social Sciences

AMOS Analysis of a Moment Structures

EFA Exploratory Factor Analysis

CFA Confirmatory Factor Analysis

RMSEA Root-Mean-Square Error of Approximation 
SRMR Standardised Root Mean Square Residual

TLI Tucker-Lewis Index

CFI Comparative Fit Index

IQR Interquartile Range

Mdn Median

SD Standard Deviation

KMO Kaizer-Meyer-Olkin

LES Learning Environment Stimulation

SE Self-Efficacy

ALS Active Learning Strategies

AG Achievement Goal

SLV Science Learning Value 


\section{List of Tables}

Table 1: A comparison of aggregated aims of the Namibian science curriculum with a consensus view of international science standards objectives .....................................28

Table 2: Demographic information of the science teachers .........................................57

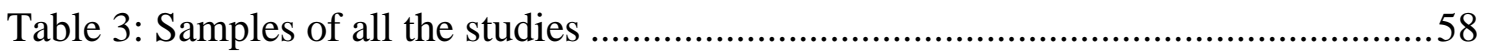

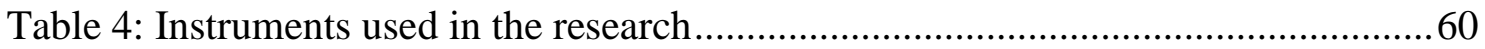

Table 5: Mother's level of education and gender of students ....................................61

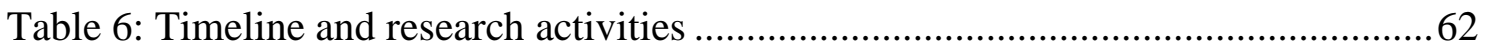

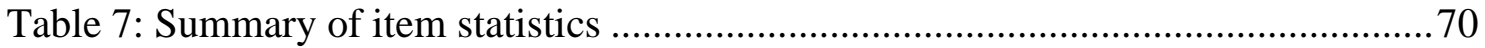

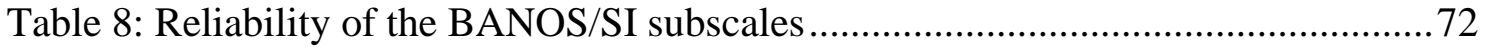

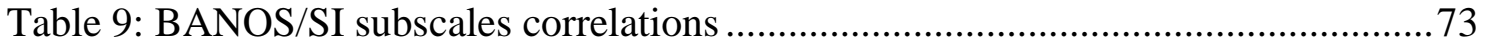

Table 10: Reliabilities of the five factors retained in EFA ......................................... 81

Table 11: Five-factor BANOS model CR, AVE, MSV and correlations ....................... 81

Table 12: Four-factor BANOS model CR, AVE, MSV and correlations........................ 82

Table 13: Rotated factor matrix showing the structure of the resultant BANOS

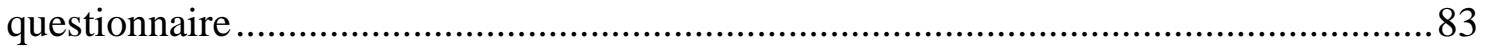

Table 14: Raw data eigenvalues, means and percentile random data eigenvalues .........84

Table 15: Reliability analyses of the scales and the questionnaire ..............................91

Table 16: Factor correlations and square root of the average variance extracted...........92

Table 17: Rotated factor matrix of the five factors of motivation .................................93

Table 18: Comparison of items composition of original and adapted SEB questionnaire 
Table 19: Reliabilities comparison of original and adapted SEB questionnaires 101

Table 20: Correlation of adapted SEB dimensions 102

Table 21: Factor loadings, composite reliability and average variance extracted values of the four dimensions SEB model

Table 22: Correlation matrix for adapted SEB dimensions 105

Table 23: Mean differences of beliefs in terms of gender 107

Table 24: Mean difference of beliefs in terms of grade 108

Table 25: Mean difference of beliefs in terms of socioeconomic status 109

\section{List of Figures}

Figure 1: Relationship between NOS understanding, scientific epistemic beliefs and motivation towards science learning....

Figure 2: Structure of Basic Education in Namibia 17

Figure 3: Regions of Namibia .56

Figure 4: Boxplot of responses to subscales showing the median scores. .74

Figure 5: Scree plot comparing raw and random data eigenvalues for factor retention. 85

Figure 6: The standardised factor loadings and correlations of the five-factor NOS aspects model .86

Figure 7: The standardised factor loadings and correlations of the four-factor NOS aspects model

Figure 8: Standardised loadings and correlations of the five factors of motivation .96

Figure 9: Standardised factor loading and correlations of the four dimensions of beliefs model 104

Figure 10: Linear regression of SEBs and achievement in science 106 


\section{CHAPTER 1: INTRODUCTION}

\subsection{Context of the study}

Science, technology and innovation have increasingly become more important for economic well-being and for the quality of a $21^{\text {st }}$ century life (Bybee, McCrae, \& Laurie, 2009; Turiman, Omar, Daud, \& Osman, 2012). For this reason, students need to develop scientific skills in order to effectively deal with twenty first century challenges in a modern society. In response to this demand, Namibia has set itself a vision, that is, to be an industrialised nation by the year 2030 (Eita, Appolus, \& Ndimbira, 2004). Namibia Vision 2030 envisages seeing the country developing from a literate society to a knowledge-based society. A knowledge-based society is one where knowledge is created, transformed, and used for innovation to improve the quality of life (Ministry of Education, 2010). Namibia recognises the importance of scientific literacy by making science, technology and innovation a priority in its development endeavours (Vision 2030, NDP3, NDP4, NDP5). The National Curriculum for Basic Education (NCBE) states that Natural Sciences are part of the main drivers of the transformation of society and the world. According to the NCBE, scientific literacy which is the understanding of scientific processes, the nature of scientific knowledge, and the ability to apply scientific thinking and skills, is "indispensable today" (Ministry of Education, 2010, p. 12). Therefore, Natural Sciences area of learning contributes to the foundation of a knowledge-based society by empowering learners with the scientific knowledge, skills and attitudes to formulate hypotheses, to investigate, observe, make deductions and understand the physical world in a rational scientific and sustainable way.

\subsection{Problem Statement}

Several reforms have taken place in the Namibian education system since independence in 1990, particularly in curriculum and assessment areas. However, such reforms did not fully address scientific literacy assessment at any level of schooling despite calls to prioritise science, technology and innovation in the country. In primary education, the only scientific and reliable diagnostic assessment that attempts to measure students' science literacy are the Standardized Achievement Tests (SAT) that were introduced in 2009 (Iipinge \& Likando, 2012). However, these tests too fell short of 
assessing scientific literacy in the broader sense of the concept (Wenning, 2006) as they only assess students' achievement of disciplinary science upon completion of Grade 7 science curriculum and not on scientific inquiry and the nature of science neither on the application of scientific literacy needed for success in everyday life (Nemeth \& Korom, 2012). In secondary education, there are two certification examinations at Grades 10 and 12. Contrary to primary education there is no diagnostic assessment of scientific literacy taking place in the secondary education phase. Furthermore, scientific inquiry and nature of science are not taught directly in the science curriculum. Science teachers are required to incorporate these skills in the teaching of the content.

Moreover, the current forms of inquiry are viewed as over-simplified thus making students think of science as the accumulation of simple facts rather than the construction and revision of models and theories about the natural world (Gu \& Belland, 2015). In response, there has been a shift of learning goals in recent years, from content knowledge to understanding of the nature of science. This shift emphasises the epistemic aspect of scientific inquiry needed to help students develop $21^{\text {st }}$ century skills. Students need to develop sophisticated understanding of the nature of scientific knowledge and how such knowledge is constructed (Gu \& Belland, 2015). However, the assessment of science knowledge in Namibian schools does not include this aspect of scientific literacy despite that the National Curriculum for Basic Education (NCBE) advocate for students to develop into scientific literate citizens (Ministry of Education, 2010). According to the $\mathrm{NCBE}$, one of the components of scientific literacy is the understanding of the nature of scientific knowledge but all assessments in science learning mainly focus on subject content knowledge. Since this aspect of scientific literacy is not assessed in schools, there is hardly any means through which to ascertain the extent to which the ideals of the national curriculum are being met. One way to ascertain students' understanding of the nature of scientific knowledge and knowing is to assess their beliefs.

Besides, motivation to learn science has been linked with beliefs about the nature of scientific knowledge and knowing and most of the conclusions drawn from such links support the notion that sophisticated beliefs may positively relate to motivation particularly self-efficacy. Whilst less sophisticated (absolutist) beliefs were associated with negative self-judgement. For these reasons, motivation was also view as a relevant component worthy of inclusion in this study. 
Afterall, advancing students' beliefs about the nature of scientific knowledge and knowing has featured prominently in recent research in science education (Chen, 2012; Chen, Metcalf, \& Tutwiler, 2014; Conley, Pintrich, Vekiri, \& Harrison, 2004; Tsai, Jessie Ho, Liang, \& Lin, 2011). This is also the case with studies that link motivation to learn science with scientific epistemic beliefs (Chen \& Pajares, 2010; Paulsen \& Feldman, 2007; Tuan, Chin, \& Shieh, 2005). A search for studies including online publications in repositories of local institutions in Namibia as well as on several international databases did not yield any reports of similar studies done in Namibia. Most of what is known about students' views about the nature of scientific knowledge or scientific epistemic beliefs and motivation to learn science comes from other countries, particularly the western world and the far east. None of such studies appear to have been conducted in Namibia.

Notwithstanding the above, there is no shortage of instruments for exploring students' views about the nature of scientific knowledge or epistemic beliefs (Conley et al., 2004; Lederman, Wade, \& Bell, 1998). However, many existing instruments have some limitations in terms of psychometric validity as they are based solely on qualitative validations. Qualitatively validated questionnaires such as the Views of Nature of Science (VNOS) developed by Lederman, Abd-El-Khalick, Bell, \& Schwartz (2002) has become a popular choice for researchers. This open-ended questionnaire has several versions A, $\mathrm{B}$, and $\mathrm{C}$. The versions are meant for use at different grade levels. Each version focuses on a particular dimension of the nature of science and were validated through response coding through interviews. Although the validation method used is sound, one version is not suitable for capturing multiple dimensions of a student's beliefs about the nature of science. The use of VNOS is also time-intensive in terms of essay response coding and follow-up interviews (Hillman, Zeeman, Tilburg, \& List, 2016) which may not be favourable for every researcher. The aims of this research were to develop, adapt and psychometrically validate instruments to address such limitations but also considering the cultural context of Namibia.

This study targeted senior grades of basic education in Namibia, the Grades 11 and 12. This age group was chosen considering caveats from previous studies that assumed that it was somewhat difficult to measure epistemological thinking among younger students (Conley et al., 2004). 


\subsection{Conceptual framework of the research}

This research used three theorisations, namely the nature of science (NOS); scientific epistemic beliefs (SEB) and motivation towards science learning (MTSL). It suggests that there is some kind of reciprocal relationship between understanding nature of science, epistemic beliefs and motivation as shown in Figure 1.

\section{Figure 1}

Relationship between NOS understanding, scientific epistemic beliefs and motivation towards science learning (Adapted from Peffer and Ramezani, 2019)

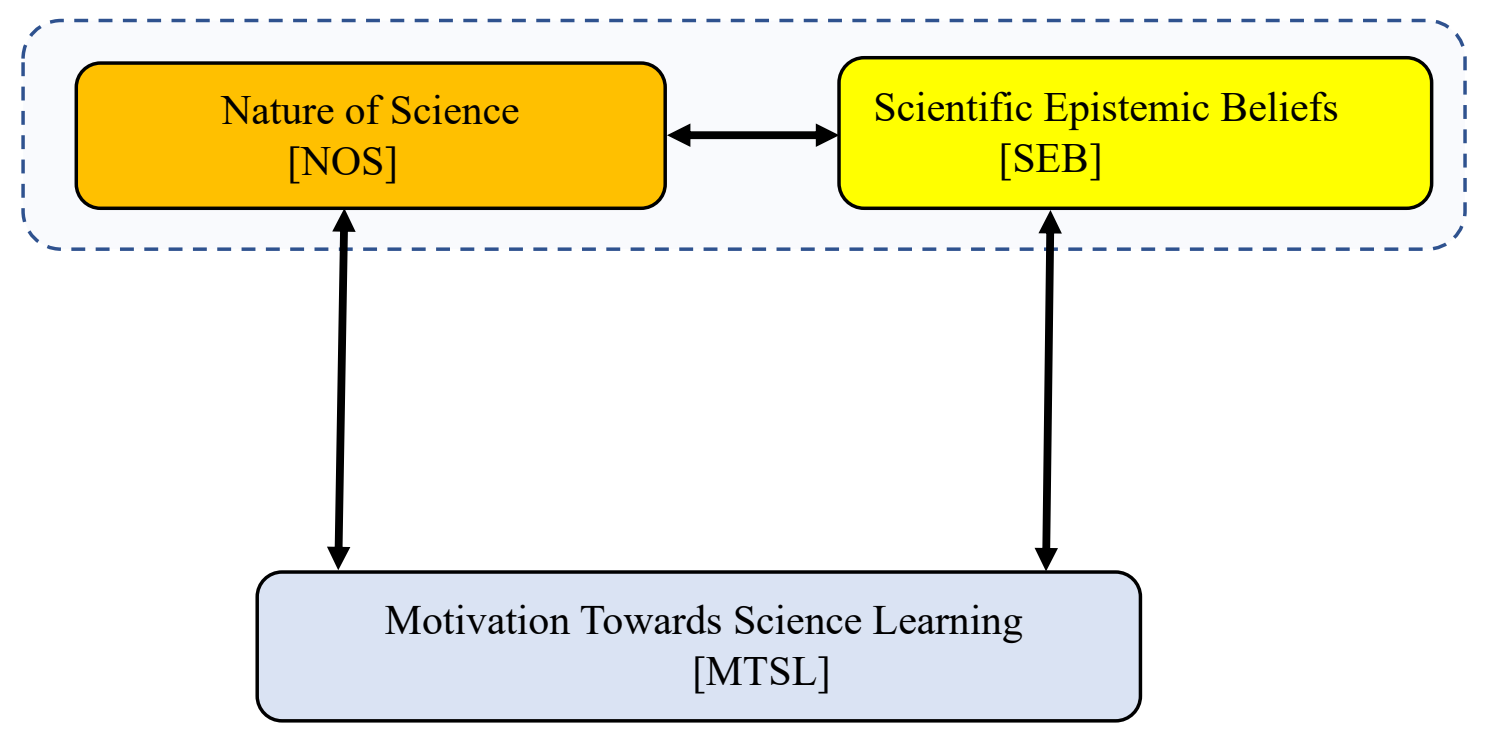

It has been established in the literature that motivation to learn science has been associated with NOS understanding and epistemic beliefs (Paulsen \& Feldman, 2007; Tsai et al., 2011). In the context of this research, the idea is that understanding of NOS and scientific epistemic beliefs overlap and both influence each other and motivation towards science learning (Peffer \& Ramezani, 2019).

For instance, one of the general aspects of NOS suggested is the tentativeness of scientific knowledge (Lederman et al., 2002) while one of the dimensions of beliefs is the certainty of scientific knowledge (Conley et al., 2004). When one understands that scientific knowledge can change due to factors such advancement in technology or reexamination of evidence, they are also likely to believe that scientific knowledge is not certain and vice-versa. This may influence their motivation to learn and such motivation can spark their NOS understanding and their epistemic beliefs about scientific 
knowledge. This research was designed to explore the possibilities of assessing the three concepts in the cultural context of Namibia and reported through a series of studies.

\subsection{Dissertation organisation}

There are six chapters in this dissertation. The first chapter introduces the study, the research problem, highlights the aims as well as describing the context of the study. This chapter also provide the overview of how the whole document is organised.

The second chapter provides a review of literature relevant to the research study. It discusses the three main aspects studied. These were two perspectives related to the nature of scientific knowledge i.e. nature of science (NOS) and scientific epistemic beliefs (SEBs) and the third one is the motivation to learn science. This chapter draws from research on science teachers' and students' beliefs about nature of science or scientific epistemic beliefs. The general findings point to overall less sophisticated beliefs about nature of science among science teachers and students. It also emphasises the need to shift from content and process skills to also include the epistemic aspect of scientific literacy needed for the development of $21^{\text {st }}$ century skills among students.

Studies on motivation to learn science were also discussed. A link has been established between motivation and scientific epistemic beliefs and most of the findings drawn from these studies support the notion that sophisticated beliefs may positively relate to motivation particularly self-efficacy. Whilst less sophisticated beliefs were associated with negative self-judgement.

The third chapter presents the aims and the overview of the research studies that formed the core of this dissertation. In this chapter, the research questions and hypotheses are also presented.

The fourth chapter describes the research methodologies used. These include the research design, site, sampling, data collection, analyses and validations.

The fifth chapter constitutes the four research studies. It serves to present the results of the four studies that formed the core of the whole research work. The first study was the piloting of the questionnaire that was developed to assess beliefs about nature of science and scientific inquiry in Namibia using science teachers for the purpose of content 
validation. The second study was a follow-up to the piloting. As part of the instrument validation, this study sought to explore the factorial validity of the beliefs about nature of science questionnaire, with a view to obtain psychometric validation. Scientific inquiry was dropped after analysis of the pilot data, as it was found to be a separate construct. The third study covered the concept of motivation to learn science. It was a cross-cultural validation of an adapted questionnaire for assessing motivation to learn science among Grade 12 students in Namibia. Motivation to learn science has been linked with beliefs about the nature of scientific knowledge and knowing and was found relevant for inclusion in this research. The fourth study was also a questionnaire adaptation, crosscultural validation and assessment of students' scientific epistemic beliefs of Grades 11 and 12 students in Namibia.

The sixth chapter is the last and concludes the study by drawing from the discussions of findings in the four studies. In this chapter, recommendations and suggestions for future research, and the limitations of the study are also presented. Last but not least, the references list, publications related to this research, and appendices of instruments, permission letters and data analysis clearance can be found at the end this last chapter. 


\section{CHAPTER 2: LITERATURE REVIEW}

\subsection{Introduction}

The most important goal of all reform efforts in science education around the world is to achieve a scientific literate citizenry (Khishfe \& Lederman, 2007). At the core of that goal is the strive to enhance students' understanding of nature of science. Recent reform efforts have given more attention to nature of science, particularly in developed countries (Fouad Abd-El-Khalick et al., 2017; Quigley, Pongsanon, \& Akerson, 2011; Smith \& Scharmann, 1999). An appropriate understanding the nature of science is severally attributed to developing scientific literacy (Akerson, Hanson, \& Cullen, 2007; Allchin, Andersen, \& Nielsen, 2014; Peters-Burton, 2016). Several reforms have taken place in the Namibian education system since independence in 1990, particularly in curriculum and assessment areas (lipinge \& Likando, 2012). However, none of the reforms provided explicit guidelines on how to teach the nature of science, particularly in science subjects' specific curricula.

Nature of science is viewed by some science educators as an affective learning outcome and not as a cognitive or instructional outcome of equal status with traditional subject matter outcomes (Lederman, 2006; Schwartz, Lederman, \& Crawford, 2004). Subsequently, it is not taught explicitly and reflectively in basic education science curricula, despite such curricula advocating that understanding of nature of science is a prerequisite for scientific literacy development.

It is assumed that students would acquire the understanding of nature of science just by doing science and inquiry activities (Khishfe, 2008). This approach was found to be ineffective (Fouad Abd-El-Khalick \& Lederman, 2000; Khishfe \& Abd-El-Khalick, 2002). For this reason, Khishfe and Abd-El-Khalick (2002) suggested that understanding of NOS should be considered as a cognitive learning outcome and should be taught explicitly rather than expected to being acquired through some kind of "osmotic process" while engaging in regular science activities (p. 554).

Research in many parts of the world reveals that students and teachers do not possess appropriate conception of nature of science (Randy L. Bell, Blair, Crawford, \& 
Lederman, 2003; Khishfe \& Abd-El-Khalick, 2002; Lederman, 1992; Meichtry, 1992; Moss, Abrams, \& Robb, 2001). There is no shortage of instruments for assessing students' views of nature of science (Lederman et al., 1998). However, no such instruments appear to exist in Namibia. Similarly, research on nature of science are hardly done in Namibia. The development of a valid instrument for assessing students' view of nature of science in Namibia is one of the goals of the present study. This chapter presents a review of literature on nature of science in science education coupled with a critical appraisal of nature of science representation in the Namibian basic education science curriculum. Before continuing with the literature review, it is deemed appropriate to highlight the structure of basic education in Namibia.

\subsection{The structure of basic education in Namibia}

Basic Education in Namibia is sub-divided into five phases: Pre-Primary, Lower Primary Grades 1-4, Upper Primary Grades 5-7, Junior Secondary Grades 8-10, and Senior Secondary Grades 11-12. Formal Basic Education is compulsory for all from PrePrimary to Grade 10, after which there are various opportunities: entry into formal Senior Secondary education, vocational education and training, direct entry to employment, or distance learning. Figure 2 gives a graphical representation of the structure.

\section{Figure 2}

Structure of Basic Education in Namibia (Ministry of Education, 2010)

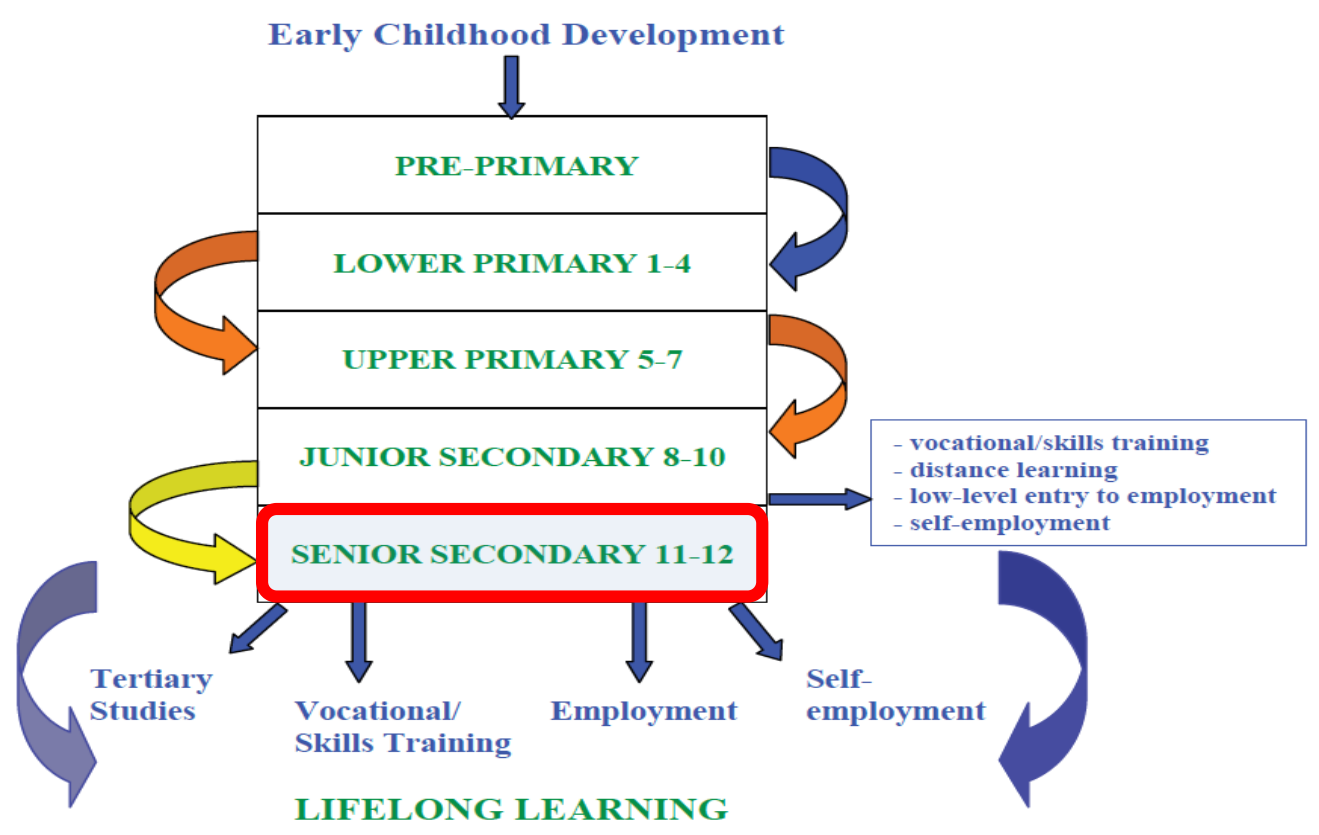


The Pre-Primary (5-6-year olds) and Lower Primary (7-10-year olds) phases lay the foundation for all further learning. In the Pre-Primary phase, students develop communication, motor and social skills, and concept formation, ready to start formal education. Teaching and learning are through the medium of the Mother Tongue or predominant local language, with a transition to English medium in Grade 4 (Ministry of Education, 2010a). The Natural Sciences learning area comprises Environmental Learning (Pre-Primary) and Environmental Studies (Grades 1-4). Science teaching time comprised of three lessons of forty minutes each per day for a five-day week.

In the Upper Primary phase (Grades 5-7, 11 - 13-year olds), students build on this foundation, develop irreversible literacy and numeracy, and develop learning skills and basic knowledge in Natural Sciences, Social Sciences, Technology, Arts, and Physical Education. Teaching is through the medium of English, and the Mother Tongue/predominant local language continues as a subject through to the end of formal basic education. The Natural Sciences learning area in this phase comprises Natural Science and Health Education and Elementary Agriculture (Namibia. Ministry of Education, 2010). Time allocation per subject is five lessons of forty minutes per day for a 5-day week.

The Junior Secondary phase (Grades 8-10, 14 - 16-year olds) continues with the same learning areas as Upper Primary, consolidates achievements and extends them to a level where the students are prepared for young adulthood and training, employment, or continued formal education. At the end of this phase, those who meet the entry requirements may continue to formal senior secondary education, which provides some specialisation and depth in one area. Those who do not meet the requirements have the option to continue their education through distance education, which will enable them to re-enter formal education. The Natural Sciences learning area comprises Life Science, (Agriculture) and Physical Science (Ministry of Education, 2010). Teaching time per subject is five lessons of forty-five minutes per day for a 5-day week.

In the Senior Secondary phase (Grades 11-12, 17 - 18-year olds), all students will continue to take English and Mathematics (compulsory), choose a field of study consisting of three mutually supportive subjects, and take supplementary subjects, for the Grade 12 examinations. At the end of Grade 12, students should be well prepared for 
further study or training, or to enter employment. The Natural Sciences learning area comprises Physical Science, (Agriculture) and Biology (Ministry of Education, 2010). Teaching time for the listed science subjects is seven lessons of forty-five minutes per day for six days (following a 7-day cycle). This research focused on the exit level of basic education in Namibia, the senior secondary level highlighted in red on Figure 2.

It should be noted that at the time of writing this dissertation, the basic education in Namibia has been undergoing revision. There would be significant changes to the grouping of the grades, thus affecting the current curricula. The implementation of the revision is undertaken in phases starting with the lowest grades in 2015 and the final implementation of the revision at the highest grades would be in 2021(Ministry of Education, 2014).

\subsection{The Nature of science (NOS)}

One of the important goals of science education is to foster students' scientific literacy (Nowak, Nehring, Tiemann, \& Upmeier Zu Belzen, 2013; Peters-Burton, 2016). Scientific literacy consists of different components, namely, content knowledge, scientific inquiry and nature of science (NOS from here on). The concept NOS has been commonly used to refer to "the epistemology of science, science as a way of knowing or the values and beliefs inherent to the development of scientific knowledge" (Lederman, 1992, p. 331; 2007). This definition of nature of science is rather general as to date there is still disagreement among philosophers of science, historians of science, scientists and science educators on the specific definition of the concept (Abd-El-Khalick, 1998). The lack of consensus on the specific definition of NOS is attributed to the complex, multifaceted and tentative nature of the scientific enterprise (Abd-El-Khalick, Waters, \& Le, 2008; Wenning, 2006). Similarly, NOS is said to be tentative and dynamic as the conceptions of NOS have changed throughout decades of scientific development (AbdEl-Khalick, 1998; Deng, Chen, Tsai, \& Chai, 2011).

However, the various disagreements about NOS are not important to science students in the basic education phase (Grades 1-12) due to the abstract nature of the NOS debates (Lederman et al., 2002). However, a general and simplistic view of some important aspects of NOS can be taken to be accessible and appropriate to basic education science students and it is at this level of simplification that little disagreement exists 
among historians, philosophers and science educators (Lederman \& Abd-El-Khalick, 1998; Lederman et al., 2002).

In recent decades, there has been a notable consensus among science educators pertaining the level of simplicity of the aspects of the nature of science that is suggestively accessible and appropriate to basic education science students. This concurrence is based upon the understanding that scientific knowledge is tentative (subject to change); empirically-based (based on and/or derived from observations of the natural world); myth of "The Scientific Method"; subjective (theory-laden); partially based on human inference, imagination and creativity; socially and culturally embedded; observation and inference are different; and theories and laws are distinct kinds of knowledge (Abd-ElKhalick et al., 2017; Abd-El-khalick \& Lederman, 2000; Lederman, 2007; McComas, 2008; Niaz, 2008; Osborne, Collins, Ratcliffe, Millar, \& Duschl, 2003). The eight aspects of NOS that frame this study are symbiotic of one another and are elaborated on in the following sub-sections.

\subsubsection{Tentative NOS}

Scientific knowledge is reliable and durable, but never absolute or certain (AbdEl-Khalick, et al., 2017; Lederman, 2007). All categories of knowledge including facts, theories and laws are subject to change. Scientific claims change as new evidence, made possible through advances in thinking and technological advances, is found. Similarly, existing evidence may be reinterpreted considering new or revised theoretical ideas or due to changes in the cultural and social spheres or shifts in the directions of established research programs (Lederman, Abd-El-Khalick, Bell, \& Schwartz, 2002; Abd-ElKhalick, Waters, \& Le, 2008). This aspect has roots in what Kuhn (1970) referred to as paradigm shift and scientific revolution. According to Kuhn, a scientific revolution occurs when scientific community encounter incongruities that cannot be explained by the universally accepted worldview (paradigm) within which scientific progress has been achieved. He argued that science changes when there is a consensus among the community of scientists about basic ontological arguments, in other words when they share a paradigm. 


\subsubsection{Empirical NOS}

Experiments are useful tools in science but are not the only means to generate scientific knowledge (McComas, 1996). Moreover, scientific knowledge is also derived from observations of the natural world (Lederman, 2007; Lederman, Lederman, \& Antink, 2013). However, scientists do not always have "direct" access to most natural phenomena, they rely on the use of human senses augmented by assumptions inherent to the workings of scientific instruments, to make conclusions about the natural world. (Abd-El-Khalick, et al., 2017, p. 89).

\subsubsection{Myth of "The Scientific Method"}

There is a commonly held misconception about science that there exists a single procedure which all scientists follow (Lederman, Abd-El-Khalick, Bell, \& Schwartz, 2002). "This myth is often manifested in the belief that there is a recipe-like stepwise procedure that epitomizes all scientific practice. This notion is erroneous: There is no single scientific method that would guarantee the development of infallible knowledge" (Abd-El-Khalick, Waters, \& Le, 2008, p. 838). Scientists do observe, compare, measure, test, speculate, hypothesize, debate, create ideas and conceptual tools, and construct theories and explanations. However, there is no single sequence of (practical, conceptual, or logical) activities that will indisputably lead them to valid claims, let alone "certain" knowledge (Abd-El-Khalick, et al., 2017, p. 89).

\subsection{Subjective/theory-laden nature of scientific knowledge}

Scientific knowledge is theory-laden (Lederman, Abd-El-Khalick, Bell, \& Schwartz, 2002). The work of scientists is influenced by their theoretical and disciplinary commitments, beliefs, prior knowledge, training, and expectations (Abd-El-Khalick, et al., 2017). These background factors affect scientists' choice of problems to investigate and methods of investigations, observations (both in terms of what is and is not observed), and interpretation of these observations. This self-identity is attributable to the role of theory in scientific knowledge production (Lederman, 2007; McComas, 2008; Niaz, 2008). Contrary to common belief, science never starts with neutral observations. Like investigations, observations are always motivated and guided by, and acquire meaning considering questions and problems derived from, certain theoretical perspectives (Abd- 
El-Khalick, Waters, \& Le, 2008). Further, the impact of individualism on scientific knowledge is mitigated through applying mechanisms such as peer review and data triangulation in order to enhance objectivity (Chen, 2006).

\subsubsection{Imaginative and creative nature of scientific knowledge}

The empirical nature of science requires the making of observations of the natural world (Lederman, Abd-El-Khalick, Bell, \& Schwartz, 2002). For this reason, science is not necessarily an orderly enterprise. Scientific knowledge production involves human creativity in terms of scientists inventing explanations and theoretical models and this requires a great deal of creativity by scientists (Abd-El-Khalick, Waters, \& Le, 2008). Creativity and imagination are vital at all stages of a scientific endeavour; from planning and designing through data collection to data interpretation, though with variable extent between stages (Wong, Hodson, Kwan, \& Yung, 2008). The creative NOS, coupled with its inferential nature, entail that scientific entities such as atoms, force fields, species, etc. are functional theoretical models rather than faithful copies of "reality" (Abd-El-Khalick, et al., 2017, p. 89). Chen (2006) claimed that "imagination is a source of innovation" (p. 806). She further asserted that scientists use imagination coupled with logic and prior knowledge to generate new scientific knowledge.

\subsubsection{Social and cultural embeddedness of science}

Science educators claim that science is a human invention that is entrenched and practiced in the context of a larger cultural setting. Different cultures have different perceptual experiences. For this reason, scientific knowledge affects and is affected by various cultural elements and spheres, including social fabric, trends, prestige, power structures, philosophy, religion, and political and economic factors (Abd-El-Khalick, et al., 2017; Lederman, Abd-El-Khalick, Bell, \& Schwartz, 2002; McComas, 2008). Such effects are manifested, among other things, through control of scientific research by economic interests e.g. research on carbon emission or on apparent dangers of cellular phone usage can be influenced by oil companies or cellular phone manufacturers respectively. As history would discern, many people believed in the geocentric model of the solar system because of religious authority (McComas, 2008). The space race, though it results in increases in science and technology development; it is more political than 
scientific between the so-called world super powers (Leden, Hansson, Redfors, \& Ideland, 2015; McComas, 2008).

\subsubsection{Difference between observations and inferences}

The scientific enterprise involves both observations and inferences (Schwartz et al., 2004). There is a crucial distinction between these two scientific processes skills. Observations are descriptions of the natural world that are accessible to the human senses whereby several observers could easily reach an agreement whilst inferences are interpretations or explanations of observations gathered (Lederman, Antink, \& Bartos, 2014; Schwartz et al., 2004). Alternatively, inferences are accounts of phenomena that are not directly accessible to the senses such as the notion of falling objects due to gravity or the structure of an atom as a central nucleus composed of positively charged particles (protons) and neutral particles (neutrons) with negatively charged particles (electrons) orbiting the nucleus (Abd-El Khalick, Bell, \& Lederman, 1998; Vesterinen, Aksela, \& Lavonen, 2013).

\subsubsection{Difference and relationship between theories and laws of science}

There are common misconceptions among students that there is a simplistic and hierarchical relationship between observations, hypotheses, theories and laws of science; and belief that laws have a higher status than theories within a scientific endeavour (Lederman et al., 2002). The notion that hypotheses are initially developed from observations and then become theories and theories become laws depending on the availability of supporting evidence is inappropriate (Lederman et al., 2002). Theories and laws are related but are distinct kinds of scientific knowledge and for this reason they serve different roles in the scientific enterprise and hence, theories do not in any way become laws, even with additional evidence (Niaz, 2008; McComas, 2008; Lederman, 2007).

Generally, laws describe relationships, observed or perceived, of the natural phenomena. Boyle's law, which relates the pressure of a gas to its volume at a constant temperature is one example of a scientific law. Theories are inferred explanations of the natural phenomena and mechanisms for relationships among natural phenomena (Schwartz et al., 2004). The kinetic molecular theory provides an explanation of what is observed and described by Boyle's law (Lederman et al., 2002). Hypotheses in science 
may lead to either theories or laws with the accumulation of substantial supporting evidence and acceptance in the scientific community. Hence, "theories are as legitimate a product of science as laws" (Abd-El-Khalick, et al., 2017, p. 90). The next section highlights some criticisms levelled against general NOS conceptualisation.

\subsection{Criticisms of the general aspects of NOS}

Ogunniyi (1982) asserted that "nature of science is a complex concept. It involves the processes, the products, the ethics, the regulative principles, and the logicomathematical systems-all defining and controlling the methodological inquiries of science" (p. 25). Because of such complexities, understanding NOS becomes a farfetched goal in basic education. In response to this challenge, science educators have reached a compromise about what NOS understanding for basic education students should entail (Tala \& Vesterinen, 2015). This resulted in a list of general characteristics of NOS that are deemed accessible to basic education students (Lederman \& Abd-ElKhalick, 1998; Lederman et al., 2002; McComas, Almazroa, \& Clough, 1998).

Subsequently, this general characterisation has drawn criticisms from some science educators, who felt that such characterisations are not comprehensive and hence cannot describe all kinds of science (Tala \& Vesterinen, 2015). Duschl and Grandy (2011) bemoaned this consensus view of NOS that it does not adequately cover all philosophical underpinnings that characterise the generation of scientific knowledge. Echoing the same sentiments was Allchin (2011) who called for whole science approach to NOS characterisation. He argued that the "selective lists of tenets" omitted numerous aspects that shape reliability in the scientific enterprise (p. 518). Moreover, Irzik and Nola (2011) castigated general aspect NOS framework, arguing that:

\footnotetext{
While we have no objection to this list, provided the items in it are properly understood, we believe that the consensus view has certain shortcomings and weaknesses. First of all, it portrays a too narrow image of science. ... Second, the consensus view portrays a too monolithic picture of science and is blind to the differences among scientific disciplines (p. 593).

They therefore suggested a family resemblance approach in which the differences between scientific disciplines are considered although there would be overlap of common characteristics among sciences.
}

The eight general aspects of NOS explicated above, though criticised by some science educators as being too general, over-simplified, prescriptive and narrow (Dagher 
\& Erduran, 2016; Grandy \& Duschl, 2008; Irzik \& Nola, 2011; Mathews, 2012) are considered as a guiding framework for this study as they serve as lenses through which to assess science students' and teachers' conceptions of NOS. The decision to adopt this framework is based on the clarification provided by its proponents, who in response to such criticisms stated that the list of the characteristics of NOS is by no means "a definitive or universal definition of the construct" (Lederman et al., 2014, p. 286). They further argued that they have never advocated an absolutist stance on those general statements about nature of science. Moreover, their focus is on understandings that they want basic education students to have given a plethora of hardly productive debates about the definitive description of NOS. It can also be said that other competing conceptualisations of NOS are much more complex to implement at school level.

In support, Kampourakis (2016, p. 674) expressed:

It should be noted that although the "general NOS aspects" conceptualization and the instruments developed by Lederman and his colleagues have been used widely, to the best of my knowledge, there is no empirical evidence that they lead to distorted views of science. In contrast, there is empirical evidence suggesting that this conceptualization is quite effective in teaching and learning about NOS.

He asserted that using the concept of general ideas about nature of science is an effective approach to introduce students to the nature of science, given available empirical data. "Once students start reflecting about general NOS aspects and teachers start addressing their preconceptions, it could be possible to move forward and study NOS in all its complexity" (Kampourakis, 2016, p. 676). The next section discusses the justification of NOS in science education.

\subsection{Rationales for teaching the NOS}

A variety of rationales for teaching nature of science has been suggested by science educators and researchers (Virginia Mathematics and Science Coalition, 2013). Bell (2008) argues that an accurate understanding of the nature of science helps students identify the strengths and limitations of the scientific knowledge, develop accurate views of how science can and cannot answer. Moreover, research suggests that teaching students the nature of science can facilitate the learning of science subject content and increase student achievement (Cleminson, 1990; Driver, Leach, Millar, \& Scott, 1996; Peters, 2012; Songer \& Linn, 1991). 
Mathews (1997) posited that an appropriate understanding of nature of science is essential to understanding the relationship between science and religion, the controversy over creation science and science as a distinctive intellectual enterprise with its special values and the essential differences between scientific and non-scientific disciplines. In addition, teaching the nature of science helps increase awareness of the influence of scientific knowledge on society (Driver et al., 1996; Lederman, 1999; Meyling, 1997).

Driver et al. (1996) argued that NOS influence society in terms of utilitarian (making sense of science and managing technological objects and processes in everyday life); democratic (informed decision-making on socio-scientific issues); cultural (appreciating the value of science as part of contemporary culture); moral (developing understanding of the norms of the scientific community that embody moral commitments that are of general value to society) and science learning (enhancing the learning of science subject matter). Ultimately, developing appropriate conceptions of NOS has been advocated as critical to acquiring scientific literacy by various science education reform documents worldwide, particularly in United States, United Kingdom, Australia, Canada and South Africa (Lederman, 2006). What follows is the analysis of NOS representation in the Namibian science curriculum.

\subsection{NOS in the Namibian Science curriculum: A critical appraisal}

Science education in Namibia's basic education phase predominantly focuses on teaching the subject-matter content in preparation for high stakes examinations. Other aspects of scientific literacy such as inquiry skills and the understanding of the nature of scientific knowledge ought to develop in students implicitly. Implicit approach assumes that "students' participation in authentic scientific investigations in itself would help students develop more accurate understandings of the nature of scientific inquiry and knowledge" (Bell, Matkins, \& Gansneder, 2011, p. 415). However, literature shows that this approach has not been effective in facilitating students' and teachers' understanding of NOS (Gess-Newsome, 2002; Lederman et al., 2013; McDonald, 2010).

The National Curriculum for Basic Education (NCBE) which is the broad curriculum, states that Natural Sciences are part of the main drivers of the transformation of society and the world. Hence the need to develop students into scientific literate citizens (Ministry of Education, 2010). According to the NCBE, scientific literacy which 
is "the understanding of scientific processes, the nature of scientific knowledge, and the ability to apply scientific thinking and skills, is indispensable today" (Ministry of Education, 2010, p. 12). Therefore, Natural Sciences area of learning should contribute to the foundation of a knowledge-based society by empowering students with the scientific knowledge, skills and attitudes to formulate hypotheses, to investigate, observe, make deductions and understand the physical world in a rational scientific and sustainable way (Ministry of Education, 2010).

The aims of the broad curriculum (NCBE) are manifested in the specific Natural Sciences curricula (syllabi). One of the syllabi states that providing basic scientific background for students with the hope of producing the much-needed scientists for the country is the main aim of science education in Namibia. It further states that the Namibian society needs to be scientifically literate if it is to cope with the challenges of appropriate global technology requirements (Ministry of Education, 2010a). At the heart of this study is an attempt to ascertain the extent to which science education is developing students' scientific literacy in terms of acquiring informed understanding of the nature of science, given that this aspect of scientific literacy is not taught explicitly in Namibian schools. The study also sought to gauge science teachers' views about NOS, as they play a vital role in students' learning of science.

Throughout primary and junior secondary phases of the Namibian education system, the specific science curricula state that scientific processes skills topic should not be taught in isolation as such skills form an integral part of the other topics (Namibia. Ministry of Education, 2010a, 2010b, 2016). This directive to the science teachers suggests that scientific inquiry skills and simultaneously the nature of scientific knowledge should not be taught as a "pull-out" content (Leden, Hansson, Redfors, \& Ideland, 2015, p. 1144) but should be integrated in the subject-matter content. What such instruction is not clearly spelling out is whether the integration should be implicit or explicit. This analysis is triggered by the claim that explicit teaching of NOS has been effective in enhancing students and teachers understanding of NOS (Lederman, 2007; Bell, Matkins, \& Gansneder, 2011; Leden, Hansson, Redfors, \& Ideland, 2015). Explicit approach entails using NOS and scientific inquiry (process skills as referred to in the Namibian science curriculum) as context for generation and learning of scientific knowledge (Gess-Newsome, 2002). This can be achieved by purposefully planning and 
integrating NOS in the science content. Lederman (2007) asserts that the best way to enhance students' conception of NOS is through "explicit, reflective instructions" ( $p$. 869). Moreover, explicit teaching should not be confused with direct instruction however, whether explicit instruction of NOS should be entrenched into the subject content or taught separately is still debatable (Leden, Hansson, Redfors, \& Ideland, 2015). Nevertheless, for students to become scientists in the near future as envisioned by the Namibian science curriculum, learning about NOS is a prerequisite (Tala \& Vesterinen, 2015).

In the context of this study, science refers to Natural Sciences. This study focuses on the exit phase of basic education in Namibia. At this exit point, which is the secondary phase (Grades 11 and 12) Natural Sciences comprise of Physical Science (a combination of Physics and Chemistry), and Biology. There is evident representation of some aspects of NOS within the aims of the Namibian science curriculum.

\section{Table 1}

A comparison of aggregated aims of the Namibian science curriculum with a consensus view of international science standards objectives

\section{Objectives of international science Aggregated aims of the Namibian science standards documents (McComas, et al., 1998, p. 513) \\ curriculum}

1. Scientific knowledge, while durable, has a tentative character.

2. Scientific knowledge relies heavily, but not entirely, on observation, experimental evidence, rational arguments, and scepticism.

3. There is no one way of to do science (i.e. there is no universal step-by-step specific method).

4. Science is an attempt to explain natural phenomena.

5. Laws and theories serve different roles in science; therefore, students should note that theories do not become laws even with additional evidence.

6. People from all cultures contribute to science.
A. Promote an awareness that scientific theories and methods have developed, and continue to do so, as result of the co-operative activities of groups and individuals.

None

B. Develop an understanding of the scientific method and its application (italics added).

None

None

C. Develop an awareness that the study

of science is subject to social, economic, ethnic and cultural influences and that its applications may be both beneficial and 
detrimental to the individual, the

community and the environment.

7. New knowledge must be reported clearly and openly.

8. Scientists require accurate record keeping, peer review and replicability.

9. Observations are theory-laden.

10. Scientists are creative.

D. Develop attitudes relevant to science such as concern for accuracy and precision; objectivity; integrity; enquiry and initiative.

11. The history of science reveals both an evolutionary and revolutionary character.

12. Science is part of social and cultural traditions

13. Science and technology impact each other.

None

E. Develop attitudes relevant to science such as concern inventiveness.

None

None

14. Scientific ideas are affected by their social and historical milieu.

F. Develop an awareness that the study of science is subject to technological influence.

None

Table 1 shows the comparison of aggregated aims of the Namibian science (Physical Science and Biology) curriculum with the unanimous view of nature of science objectives extracted from eight international science education standards documents (McComas, Almazroa, \& Clough, 1998).

It should be clarified here that this comparison is necessarily suggestive and not definitive given the aggregation of the aims of two science subjects' (Physical Science and Biology) curricula, although they overlap significantly.

The first column contains a unanimous view of nature of science compiled from eight international science standards documents as presented by McComas et al. (1998). The second column shows the aggregated aims of the Namibian science curriculum. The aggregated aims of the Namibian science curriculum are entered according to a suggestive overlap with the objectives of the eight international science education standards documents as emphasised in green colour. Where no overlap was seen, "None" has been entered adjacent to the applicable objectives in the table. This suggests that the aims of the Namibian curriculum to some extent conform to international science standards objectives and hence it is expected that Namibian teachers do teach such aspects of NOS to science students throughout basic education phase. 
However, attention is drawn to one of the aims of the Namibian science curriculum (indicated as B in the table). It says student should develop an understanding of the scientific method (italics added) and its application (Ministry of Education, 2010d, 2010c). This appears to suggest that there is one single scientific method that all scientists follow. Science educators and scholars argue that there is no single scientific method that would guarantee the development of infallible knowledge. Scientists do observe, compare, measure, test, speculate, hypothesize, debate, create ideas and conceptual tools, and construct theories and explanations. However, there is no single sequence of (practical, conceptual, or logical) activities that will indisputably lead them to valid claims, let alone absolute knowledge (Lederman, Abd-El-Khalick, Bell, \& Schwartz, 2002; Abd-El-Khalick, Waters, \& Le, 2008; Abd-El-Khalick, et al., 2017).

Lederman et al. (2014) argued that basic education students and even the public possess an inaccurate view of the scientific enterprise called the scientific method that has been acquired through schooling, from the media and from the way scientific reports are designed. They further posited that "there is no fixed single set or sequence of steps that all scientific investigations follow. The contemporary view of scientific inquiry is that the questions guide the approach and the approaches vary widely within and across scientific disciplines and fields" (p. 290). The next section presents a synthesis of research that has been done on the conception of NOS.

\subsection{Research on NOS conception}

Research on NOS can be traced to over half a century ago (Lederman, 2006). Lederman pointed out that studies on NOS focused on students' and teachers' conceptions; curriculum; attempts to improve teachers' conceptions and effectiveness of various instructional practices. Such studies were underpinned by the premise that scientific knowledge is tentative, empirically based, subjective, partially based on human inference, imagination and creativity, socially and culturally embedded, the myth about the scientific methods, the distinction between observation and inference and finally the relationship between scientific theories and laws (Liu \& Lederman, 2002). This review focuses on studies conducted in the most recent decades, focusing on students' and teachers' views of NOS. 


\subsection{Students' conceptions of NOS}

Students' views of NOS have been studied extensively by various researchers and science educators mostly in developed countries (Deng et al., 2011). Results consistently show that students throughout basic education (Grades 1-12) possess inadequate (naïve) and often inappropriate views of NOS (Lederman, 1992; Meichtry, 1992; Moss, Brams, \& Robb, 2001; Khishfe \& Abd-El-Khalick, 2002; Bell, Blair, Crawford, \& Lederman, 2003). The current study attempts to assess the state of NOS conceptions amongst Namibian science students and teachers in the highest phase of basic education (Grades 11 and 12). Students in this phase of basic education in Namibia have been studying science for almost twelve years.

Vhurumuku (2010) labelled views about the NOS as either naïve or sophisticated. Students can be designated as possessing naïve views when they reveal understandings such as: scientific knowledge is certain and fixed, proven true, exclusively empirically based (relies entirely, on observation, experimental evidence) and objective; theoretical models (atom structure) are copies of reality; there is one single method of science which all scientists follow; science can answer all questions in nature and scientific observations are free from human prejudices. From Schwartz, Lederman and Crawford (2004) such naïve understandings are such as observations and inferences are one and the same; and that theories become laws.

In extension to Vhurumuku's assertions, students possess sophisticated views of NOS when they exhibit understandings such as: scientific knowledge is dynamic, tentative, scientific claims are subject to change as new evidence is found or existent evidence is reinterpreted; there exist multiple truths and realities which are neither fixed nor absolute; there are several appropriate methods in science; scientific observations are theory-laden and dependent on the prior experience and preconceptions of the observer; while scientific knowledge is empirically based (based on evidence), imagination and creativity of scientists (atom structures) also play roles in knowledge creation; and that although scientists try to be open-minded and objective, there is always an element of subjectivity, which has to do with the fact that scientists are human beings. Furthermore, students should be able to distinguish between observation and inference and between scientific laws and theories. They should moreover, be able to explain that observations 
are products of the use of human senses and that inferences are the conclusions made after making such observations; and that laws are descriptive statements of what happens based on what is observed, whereas theories are explanations of what happens (the how and the why) (Lederman, et al., 2002; Lederman, 2007). Other science educators use other variations to describe students' views about NOS but still similar to naïve and sophisticated categorisation such as inconsistent vs consistent; adequate vs inadequate and naïve vs informed (Vhurumuku, 2010).

Moss et al. (2001) conducted a qualitative participant observation study to investigate five purposefully sampled high school (Grades 11-12) science students' understandings of the nature of science for a period of one year in the United States. They developed a model of NOS (for their study only) to examine students' conceptions of NOS through semi-structured, formal and one-to-one interviews. They captured the narrative of students' descriptions of NOS verbatim and interpreted them according to the NOS model developed for the study. The model consisted of eight characteristics pertaining both the nature of the scientific enterprise and the nature of scientific knowledge.

The study found that students held informed views that scientific knowledge is subject to change, however, they were not familiar with the idea that scientific knowledge was robust and is a product of many kinds of methods. Further, it was reported that students' preconceptions that scientific knowledge emanates from a specific method such as the scientific method, were largely not impacted by their participation in the year long project-based, hands-on science course.

Similarly, Bell et al. (2003) employed a pre-post training assessment of ten "highability" (p. 489) secondary (Grades 10-11) students' understandings of the nature of science and scientific inquiry. They used an open-ended questionnaire and semistructured interviews and their study used NOS framework as advocated by science education reform documents in the United states such as the National Science Education Standards. The study attempted to explain the effect of an 8-week science training (originally apprenticeship) programme on ten high-ability secondary students' understandings of the nature of science and scientific inquiry with a view to illustrate any variations in participating students' understandings of the nature of science and scientific 
inquiry; and to evaluate any direct or indirect effects of participating in the training programme on their understandings of the nature of science and scientific inquiry.

Findings from this study were not any different from the previous study reviewed above. It was found that students' views of nature of science and scientific inquiry were mostly not commensurate with the objectives of the current reforms. Students views were characterised by inconsistent or incomplete interpretations. Worth pointing out are for instance the view expressed by all students that data is the only prerequisite for change to scientific claims, missing the notion that theories might also change as a result of reinterpreting existing evidence (Lederman, Abd-El-Khalick, Bell, \& Schwartz, 2002). The belief that scientific laws represent absolute knowledge and failure to delineate the difference between theories and laws are all conforming to a plethora of research findings that basic education students barely possess views of NOS that are in line with science education reform objectives (Lederman, 1992; Meichtry, 1992; Deng, Chen, Tsai, \& Chai, 2011). The study noted despite apparent minimal gain in the students' knowledge about the processes of scientific inquiry, their preconceived views about key characteristics of NOS remained nearly the same (Bell, Blair, Crawford, \& Lederman, 2003).

The two studies above were all underpinned by an implicit approach to enhancing students' NOS views. Implicit approach assumes that students would acquire NOS understanding "automatically" just by doing science and engaging in hands-on-activities (Khishfe, 2008, p. 471). Using a different approach in comparison with the two studies above, Khishfe and Abd-El-Khalick (2002) conducted a quasi-experimental study following a "pre-test-post-test non-equivalent group design" (Cohen, Manion, \& Morrison, 2007, p. 282) to assess the influence of an explicit and reflective inquiryoriented instruction compared with implicit inquiry-oriented instructional approach on students' understanding of NOS.

The study involved sixty-two sixth graders allocated to two intact groups. The explicit (intervention) group was exposed to inquiry activities supplemented by reflective discussions of the target NOS aspects. The implicit (comparison) group was exposed to the same inquiry activities but no discussion of any NOS aspect was applied. Due to the abstract nature of NOS, even at the simplified level deemed appropriate for basic 
education students and with the age of participating students in hindsight, the study was limited to four aspects of NOS namely, tentativeness; empirical; creative and imaginative NOS as well as the difference between observation and inference.

The study found that at the beginning of the intervention, most students in both groups possessed incomplete views of the four target NOS characteristics. However, at the end of the study, most students in the explicit group exhibited a more informed view of one or more of the target NOS characteristics while there was no change in views of students in the implicit group. These results point to the same conclusion as other studies conducted on this component of scientific literacy (Moss, Brams, \& Robb, 2001; Bell, Blair, Crawford, \& Lederman, 2003). However, this study suggests that involving students in discussions related to NOS during inquiry activities effectively facilitates a shift in their conception of NOS (Khishfe \& Abd-El-Khalick, 2002).

Closer to home, (Ibrahim, Buffler and Lubben (2009) conducted a study involving 179 undergraduate students in a South African university. The study was aimed at capturing and describing physics students' views of the NOS using what they referred to as NOS "profiles" (p. 250). These profiles are conceived to be brief descriptions of different views of individual students which can be used to investigate their views of NOS and other associated observable aspects of the scientific endeavour. They found that only $44 \%$ of the sample exhibited desirable views of NOS. Such findings are not surprising as similar results are reported the world over.

Another African perspective on students views of NOS can be found in Vhurumuku, Holtman, Mikalsen and Kolsto (2006). They investigated Zimbabwean high school chemistry students' images of NOS during a laboratory session. They found that a substantial percentage of students view scientific knowledge produced by chemistry experiments and observations as "true" (p. 139). Moreover, those who viewed experimental results as not always true justified their reasoning with a blame on "failure to follow procedures, contamination of reagents, faulty apparatus, or unfavourable laboratory conditions" (p.139). These findings about students' images of NOS point to the prevalent inappropriate view about the validity of scientific knowledge (Vhurumuku, et al., (2006). McComas (1996) claimed that the availability of empirical evidence 
regardless how much such evidence is does not ensure the generation of valid scientific knowledge due to the problem of the method of induction. He explains that:

It is both impossible to make all observations pertaining to a given situation and illogical to secure all relevant facts for all time, past, present and future. However, only by making all relevant observations throughout all time, could one say that a final valid conclusion had been made (p. 12).

Despite that students and teachers views about NOS have been studied extensively in the last two decades, it has not been possible to locate such studies done in Namibia. Deng et al. (2011) conducted a thorough and critical review of research within the last two decades (from 1992 to 2010) and found 105 empirical studies that examined students' views of NOS. The search was conducted on some major online academic databases. They could locate such similar studies done in South Africa and Zimbabwe (these two countries being closest neighbours of Namibia) but none was found to have been done in Namibia.

A search on the University of Namibia's publications list and online repository came up with only one study that is closely related to NOS and scientific inquiry. It was conducted by Kandjeo-Marenga (2011). This study investigated the implication of two teaching approaches on the students' learning of process skills in Biology. The main focus of the study was "process skills" learning opportunities during practical work ( $p$. 44). Such skills are typical components of scientific inquiry (Lederman et al., 2014). However, the study fell short of tapping from "inquiry processes as a model of scientific practices" (for a better theoretical grounding) as well as recognizing the relationship between inquiry-based approaches to enhancing students understanding of NOS (Allchin et al., 2014, p. 467). Against the foregoing, the theoretical grounding of this study could be extended. Teachers' views of NOS are discussed in the following section.

\subsection{Science teachers' conceptions of NOS}

Current teaching and learning practices follow the learner-centred approach that is underpinned by the constructivist view (Ministry of Education, 2010). This principle advocates the provision of opportunities for students to construct new understandings for themselves at both individual and social levels (Brooks \& Brooks, 1993). However, the teacher has a significant role to play in this endeavor (Lederman, 1992). The role of the 
teacher is that of a "guide, provocateur, creator-of-opportunity, and co-developer of understanding with the students" (Windschitl, 1999, p. 191). Therefore, science teachers must possess an adequate understanding of NOS to effectively contribute to students' understanding of this concept (Lederman, 1992).

Nevertheless, it has been reported that teachers do not generally possess consistent or adequate conception about the NOS (Abd-El-Khalick \& Lederman, 2000; Dogan \& Abd-El-Khalick, 2008; Lederman, 1992). Subsequently, it can be assumed that teacher cannot effectively teach concepts that themselves do not understand (Bell, Matkins, \& Gansneder, 2011). However, Abd-El-Khalick et al. (1998) argued that even though teachers' understanding of the NOS can be assumed to be a necessary condition for effective teaching of NOS to students, it is not sufficient to make NOS visible in their science classroom. In corroboration of this argument, Bell et al. (2011) maintained that teachers with inadequate understandings of the NOS are likely to promote absolutists views while overemphasising vocabulary of the science content. Thus, suggested that enhancing teacher's conceptions of NOS is a vital preliminary attempt to improve NOS teaching to basic education students.

Aslan and Taşar (2013) investigated science teachers' NOS views with the intention of determining how their views influenced their instructional practices. They used items from the Views on Science-Technology-Society (VOSTS) questionnaire, semi-structured interviews and classroom observations, to assess teachers' NOS views. Their findings were consistent with earlier studies. They revealed that the participating science teachers held naïve views on many aspects of the NOS and further found that teachers' views about NOS did not directly influence their classroom practices. Other intervening factors such as the high stakes examinations, expectations of school administrators, students and parents, influenced teachers' instructional practices.

The common conclusion that can be deduced from the studies reviewed is that both in-service and pre-service teachers do not possess adequate understanding of the NOS. However, Mathews (2012) maintained that it is unrealistic to expect teachers to be experts in history, philosophy or sociology of science, hence emphasis should be on making multiple perspectives visible in the science lessons. 
This study recognises both congruent and opposing perspectives found in the studies reviewed. Studies of this nature are hardly done in Namibia and this has created a gap in the literature that the current study attempts to fill. Given the ground-breaking nature of the present study, one of the aims is to capture science teachers' views of NOS at least at the level of "a necessary condition" (Abd-El-Khalick, Bell, \& Lederman, 1998, p. 432).

\subsection{Assessment of NOS conceptions}

There is no shortage of instruments for assessing students and science teachers views about NOS. Lederman, Wade and Bell (1998), in their review of assessment instruments used to determine NOS conceptions, found that there are at least twenty-five instruments developed that have been formalised and used to assess certain aspects of the NOS in over three decades since NOS objectives in science education gained prominence. Notable from this review is their criticism of many of the instruments. They opined that most of these instruments were of the forced-choice nature (agree/disagree, Likert scale and multiple choice). They highlighted major difficulties with the validity of the instruments in two folds. Firstly, the instruments were based upon the assumption that the respondent would interpret the instrument items in the same manner as the researcher. Secondly, as they were forced-choice, which meant the instruments tended to reflect the biases of the developers on the respondents.

In response to this anomaly, researchers began to develop open-ended instruments, with emphasis on descriptive questions, together with interviews that allowed meaningful assessments of the individuals' NOS views (Thye \& Kwen, 2003). One of the widely-used instruments in recent years is the Views of the Nature of Science Questionnaire (VNOS). It comprised of ten-open ended questions and was developed by Lederman et al. (2002) focusing on the general aspects of the NOS such as its empirical nature; tentativeness of scientific knowledge; the theory-laden nature of scientific knowledge (subjectivity); the creative and imaginative nature of scientific knowledge; the social and cultural embeddedness of scientific knowledge; the myth of the scientific method; the relation between observation and inference; and the distinction between theories and laws. 
This questionnaire has been validated through versions $\mathrm{A}, \mathrm{B}$ and $\mathrm{C}$ by comparing views of experts, novice groups, undergraduate and graduate college students, pre-service elementary teachers, pre-service and in-service secondary teachers, augmented with follow-up interviews. By comparing and contrasting NOS profiles of participants produced from separate analyses of the questionnaire and interview transcripts, it was found that interpretations of participants NOS conceptions as obtained from the VNOS were congruent to those expressed by participants during individual interviews. The authors stress that the validity of such an instrument is not final and absolute, emphasising that the principal source of the instrument's validity evidence stems from the follow-up interviews, where it is possible to check respondents understanding of items. They also clarified that the questionnaire is developed with an interpretive stance in mind, with aims to illuminating students' views rather than for labelling their views as inadequate or adequate.

Notwithstanding the VNOS's popularity, it has had its fair share of criticism from other science educators. Chen (2006) argued that the items in the VNOS questionnaire often do not directly specify the target NOS aspects. Subsequently, it becomes too optimistic to assume that participants would be able to adequately articulate the details sought in the items within the 40 to 60 minutes time frame, thus becoming difficult for the researcher to obtain the intended information from every participant without followup interviews. Lederman et al. (2002) advised that a large proportion of students should be interviewed after taking the questionnaire to validate responses. This is indeed necessary however; it is not ideal for every researcher. Chen (2006) further asserted that out of her personal experience, it is difficult to get participants willing to commit so much time to respond to a questionnaire without any incentive.

In support of this argument, Osborne, Collins, Ratcliffe, Millar and Duschl (2003) argued that the use of open-ended questionnaire to gather views requires "a substantial commitment of time from each participant" (p. 716). Hence to succeed in this endeavour an incentive must be offered to the participant and the availability of such resource will determine the number of participants. Ultimately this renders open-ended questionnaires inappropriate for large scale empirical studies attributable to the cost involved. This argument forms the basis for the choice of instrument for this study. 
While the questionnaires such as VNOS and their accompanying interview protocols are good and relevant to the research on NOS, they have their limitations. In addressing such inadequacies, Chen (2006) developed the Views on Science and Education Questionnaire (VOSE). The VOSE is fifteen-question questionnaire with several empirically based sub-items under each question. The aim of the VOSE is to increase validity and minimise interpretations biases using students' perspectives on NOS and other relevant attitudes.

The VOSE was validated through expert panels, test-retest, interviews and data analysis. The VOSE is reported to have achieved a test-retest correlation coefficient of 0.82. The test-retest reliability is a measure of how consistent the results are over time (Chen, 2006). Furthermore, the VOSE uses the five-point ranking scale. This type of design enables the use of data in inferential statistics and thus can be used in large scale assessment of NOS. What differentiate the VOSE from other traditional questionnaires that are developed from an expert's point of view is that items where constructed from students' perspectives, which is believed to "reduce their ambiguity" (p. 816). It was also reported that participants felt less frustrated when taking the VOSE than when taking the VNOS, justifying that it requires more skills and a sharp mind to fully articulate views within the given time frame. The present study is of empirical nature and the choice of instrument is influence by Chen's ideas.

In the present study, no existing instrument has been used whether as whole or in an adapted or modified form. A separate questionnaire termed the "Beliefs About Nature of Science" (BANOS) questionnaire has been developed. However, ideas for possible items were obtained from existing scales. The items are declarative statements describing particular aspects of NOS. Respondents give their personal level of belief or agreement with the five-point Likert scale (Cohen et al., 2007) namely 1(strongly disagree), 2 (disagree), 3 (not sure), 4 (agree) 5 (strongly agree). The declarative statements are organised according to eight target general NOS aspects. The declarative statements are all informed views of respondents about NOS obtained from the literature (Chen, 2006; Dogan \& Abd-El-Khalick, 2008; Khishfe \& Abd-El-Khalick, 2002; Vhurumuku, 2010).

Much of the criticism of the existing instrument hovers around measurement validity. Validity entails providing evidence that the instrument does indeed measure 
what it purports to measure (Lederman, Abd-El-Khalick, Bell, \& Schwartz, 2002). Anderson and Bourke (2000) posit that for self-reporting affective assessments, one of the ways of establishing validity is evidence of construct validity. Both students and science teachers respond to the same instrument in the present study. Their responses are analysed and compared to ascertain construct validity. The reliability of the instrument is also computed using Cronbach's alpha coefficient.

\subsection{Scientific epistemic beliefs: terminology}

Epistemology is an aspect of philosophy that is concerned with the nature of human knowledge and reasoning (Muis, Bendixen, \& Haerle, 2006). Educational researchers study epistemology in terms of individual's perspective. They focus on beliefs individuals possess about how knowing occurs, how knowledge is justified and how these affect individuals' cognitive processes (Gu \& Belland, 2015). However, different terminologies referring to beliefs that people possess about nature of knowledge and knowing such as epistemic beliefs, epistemological beliefs, personal epistemology and epistemic cognition can be found in the literature. This suggests that there is no consensus regarding the terminology of this concept (Greene, Azevedo, \& Torney-Purta, 2008; Hofer, 2004).

According to Kitchener (2002), epistemic beliefs are beliefs about knowledge and knowing, including the source or justification of knowledge, whereas epistemological beliefs are beliefs about the field of epistemology or beliefs about the study of knowledge. Though personal epistemology or epistemological beliefs are used by most researchers in some measures of beliefs, it could be construed that such measures were aimed at the type of beliefs that Kitchener referred to as epistemic beliefs (Murphy, Edwards, Buehl, $\&$ Zeruth, 2007). For this reason, the term epistemic beliefs is adopted for this study to refer to students' beliefs about scientific knowledge and knowing.

Greene et al. (2008) suggest that epistemic beliefs develop continuously from a naïve orientation to a more sophisticated position though in an unorganised way. Such beliefs begin with absolutism through multiplism and evaluativism. Absolutism is concerned with beliefs that knowledge is absolute and certain. Multiplism entails beliefs 
that knowledge is subjective and the evaluativist views knowledge as evolving, actively constructed and justified with evidence (Kienhues, Bromme, \& Stahl, 2008).

\subsection{Students' scientific epistemic beliefs}

On the sidelines of the general characterisations epistemic beliefs is a suggestion that domain-specific epistemic beliefs are more pertinent and influential in academic learning (Muis et al., 2006). For this reason, this study is located in the science domain.

Conley et al. (2004) proposed that scientific epistemic beliefs have four dimensions. The four dimensions are source (science knowledge comes from authority or experts); certainty (science knowledge has only one answer); development (science knowledge is evolving and changing); and justification (science knowledge should be based on evidence from different experiments and observations). Epistemic beliefs have been associated with learning and academic achievement in science (Cano, 2005; Stathopoulou \& Vosniadou, 2007; Trautwein \& Lüdtke, 2007). These studies highlighted the importance of exploring student's views about the nature of scientific knowledge with a view to help them better understand science concepts. Studies that involved elementary students e.g. Conley et al., 2004; Elder, 2002) provided conflicting results. Elder's study revealed that students perceived science knowledge as changing (development) and derived from experiments (justification). The other one by Conley and other colleagues found no significant changes in beliefs regarding the changing nature (development) and justification of scientific knowledge, though they found that higher achievement in science was associated with more sophisticated beliefs. Morever, similar studies done with upper secondary students showed more consistent results (Liang \& Tsai, 2010; Stathopoulou \& Vosniadou, 2007; Trautwein \& Lüdtke, 2007).

This is perhaps not surprising because earlier work on epistemological thinking (Kuhn, 1988) asserted that it was not easy to identify epistemological thinking among younger students. However, this assertion was contradicted by Wellman's (1992) work on children's theory of mind, suggesting that epistemological thinking begins at an early age and hence it should continue developing (Chandler, Hallett, \& Sokol, 2002). Against the foregoing, this study chose senior secondary students (Grades 11 and 12) as the most appropriate sample to validate the adapted questionnaire in the Namibian context. 


\subsection{Motivation}

Generally, motivation is the force that causes an individual to take action and maintains such actions (Barrett \& Morgan, 2018). In the school context, these are actions that students take to gain knowledge through learning. Moreover, in this research, motivation is viewed in terms of domain-specific context, which is science learning.

Motivation has roots in the social cognitive theory of human learning (Bandura, 2009; Pintrich, 2003). This theory postulates that there are tripartite reciprocal interactions between personal characteristics, behaviour and environmental context (Bandura, 2009). In this theory, students' learning is construed as most effective when it is self-regulated, takes place when students understand, monitor, and control their motivation and behaviours which result in desirable academic achievement (Bandura, 2009; Glynn, Brickman, Armstrong, \& Taasoobshirazi, 2011).

Moreover, motivation is viewed as an internal process that arouses, directs and sustains goal-oriented activity (Glynn, Taasoobshirazi, \& Brickman, 2009). In particular, motivation to learn refers to individuals' inherent qualities of mind and character that enable them to view academic activities as relevant and worthwhile (Glynn et al., 2009).

Student motivation is a pivotal factor that influences their classroom engagement and learning performance, the reason students have for doing the task, which involves the students' goals, interests, and beliefs to the importance of the task. Research shows that students who have deep motive in learning are intrinsically motivated, mastery goaloriented, and actively seek the most meaning from their learning. In contrast, students who are surface motivated in learning tend to be motivated by external incentives and are performance goal-oriented, hence they only care about the essentials of the learning materials (Pintrich \& Schunk, 2002). Extensive evidence has supported that intrinsic and deep motivations usually result in the adoption of deep learning strategies and better academic performance (Ho \& Liang, 2015).

Another motivational component is task value beliefs, or students' beliefs about the utility and importance of a course. It is believed that having higher task value beliefs is favourable; typically, researchers have demonstrated positive relations of task value beliefs to deeper levels of cognitive processing and performance. Goal theorists 
commonly identify two primary achievement goals. These are mastery and performance goals. These are viewed to be important determinants of students' motivation and performance. Endorsement of a mastery goal, or the goal to develop competence and task mastery, has been found to be positively related to various learning and motivational indices (Zusho, Pintrich, \& Coppola, 2003). In contrast, adoption of a performance goal, or the goal to validate one's competence in relation to others, is generally thought to have a negative effect on students' achievement motivation and academic performance (Zusho et al., 2003).

\subsubsection{Science academic self-concept, self-efficacy and mastery motivation}

One of the prominent sources of individual expectation for success is students' perceptions of their ability (i.e. self-concept), which represents their broad perceptions of their current ability in a certain domain. Science academic self-concept is one such type of motivational belief in science learning (Wang \& Liou, 2017).

For students learning science, self-concept would be part of the motivational side of scientific literacy, that's to say a student's perception of his or her abilities in science (Rüschenpöhler \& Markic, 2019). There is every reason to be interested in students' selfconcept because it has been strongly related to achievement (Marsh \& Craven, 2006). Self-concept may be influenced by classroom environment. Students may compare their abilities with the perceived abilities of their classmates and this may negatively affect their self-concept development (Jansen, Scherer, \& Schroeders, 2015).

There exists several motivation and motivation-related components that have been linked to learning science: intrinsic motivation, which involves learning science for its own sake; extrinsic motivation, which is the learning of science as a means to an end, usually for some type of competition or reward personal relevance, the relevance of learning science to an individual's goals; self-determination, the control students felt over their learning of science; and self-efficacy, or students' confidence that they can achieve science (Chumbley, Haynes, \& Stofer, 2015). Among the motivational components that have been linked to learning science, five have been studied extensively, generally independently of each other, although they may be related. First, there is intrinsic motivation, which involves learning science for its own sake (Simpkins, Davis-Kean, \& Eccles, 2006). Second, there is extrinsic motivation, which involves learning science as 
a means to an end (Mazlo et al., 2002). Third, there is personal relevance, which is the relevance of learning science to students' goals (Cavallo, Rozman, Blinkenstaff, \& Walker, 2003). Fourth, there is self-determination, which refers to the control students believe they have over their learning of science (Black \& Deci, 2000). Fifth, there is selfefficacy, which refers to students' confidence that they can achieve well in science (Lawson, Banks, \& Logvin, 2007). Students hold beliefs about the nature of scientific knowledge and knowing which is essential their scientific epistemic beliefs.

Research has shown that these beliefs about knowledge and knowing are related to students' motivation, including their self-efficacy. Self-efficacy, is students' judgments of their capabilities to perform a task, as well as their beliefs about their agency in the tasks (Pintrich, 2003). There is good evidence to suggest that confident students will also be more cognitively engaged in learning and thinking than students who doubt their capabilities to do well (Pintrich, 2003). Generally, researchers have shown that it is more adaptive to have higher efficacy beliefs. Students who believe that they are capable of adequately completing a task and have more confidence in their ability to do so typically display the highest levels of academic achievement, and also engage in academic behaviours that promote learning (Chen et al., 2014). Self-efficacy has been shown to affect how productively individuals think, how well they motivate themselves, how long they persist in the face of failures, and ultimately what and how much they achieve (Chen, Metcalf \& Tutwiler, 2014).

Persistence in the face of challenges is described as mastery motivation. Barrett and Morgan (2018) described mastery motivation as the psychological urge that stimulates one to independently and persistently attempts solve a problem amidst existing challenges. Mastery motivation has been hailed as the most important predictor of school success (Józsa, Kis, \& Barrett, 2018). Like other forms of motivation, science mastery motivation has been found to decrease towards middle school (Józsa, Kis, \& Huang, 2017) and as such could have a negative effect on students' school achievement and overall life success. Such findings provide an opportunity for similar studies to be conducted in Namibia and this research attempted to instigate such endeavours. 


\subsubsection{Motivation towards science learning}

Motivation to learn science has been linked with beliefs about the nature of scientific knowledge and knowing (Chen \& Pajares, 2010; Paulsen \& Feldman, 2007; Tsai, Jessie Ho, Liang, \& Lin, 2011) and most of the conclusions drawn from these studies support the notion that sophisticated beliefs may positively relate to motivation particularly self-efficacy. Whilst less sophisticated (absolutist) beliefs were associated with negative self-judgement. For these reasons, motivation was viewed as a relevant component worthy of inclusion in this study.

In the current educational climate in which a high demand is put on students' performance on standardized tests, teachers have little time to allow their students to explore science concepts in interesting ways, thereby contributing to students' perception of science as uninteresting regurgitation of facts. This struggle to motivate students presents a significant challenge especially during the middle school and high school years, where it has been determined that there was a general decline in motivation (Chen et al., 2014; Józsa, Kis, \& Huang, 2017). This is likely to be the case in the Namibian context too however, given that no such similar studies were found to have been done in Namibia, it warrants a localised investigation. It should however, be noted that this research did not intend to focus on this aspect yet at this stage.

Students who believe they are able and that they can and will do well are much more likely to be motivated in terms of effort, persistence, and behaviour than students who believe they are less able and do not expect to succeed (Chen et al., 2014). Numerous studies have found that students' motivational beliefs in science learning are positively associated with their science achievement (Zusho et al., 2003).

In the context of motivation to learn science, the internal process arouses, directs and sustains science-learning behaviour (Glynn et al., 2011). Motivated students achieve academically by engaging in behaviour that enables them to actively participate in a learning task. Consequently, assessing motivation to learn science is concerned with establishing why students endeavour to learn science, how intensively they make such endeavours and the beliefs, feelings and emotions that characterise them in this process (Glynn et al., 2009). Students' self-efficacy, science learning value, learning strategies, learning goal and the learning environment stimulation are some of the important 
motivational factors attributable to science learning motivation (Tuan et al., 2005). Selfefficacy is the confidence that students possess in believing that they can achieve in science (Chumbley et al., 2015). It relates to the individual's ability to perform a specific task (Tuan et al., 2005). Higher self-efficacy means that the individual believes he/she is capable of accomplishing learning tasks, whether such tasks are easy or difficult.

Science learning values refers to whether or not students can see the value of the science they engage in (Tuan et al., 2005). Problem-solving, scientific inquiry and relevance of science in students' daily lives are some of the indicators of science value (American Association for the Advancement of Science, 1993).

Active learning strategies refers to taking an active role in using a variety of strategies to construct new knowledge based on previous understanding (Tuan et al., 2005). Achievement goal relates to the satisfaction experienced when competence and achievement increase during science learning (Elliot \& Murayama, 2008).

Learning environment stimulation is a form of extrinsic motivation, which relates to the interaction that students have with their surrounding which influences their motivation to learn such as the curriculum, teaching strategies and peer interactions (Tuan et al., 2005).

The sixth factor; performance goal refers to being motivated to learn just to compete with other students (good grades) and getting the attention from the teacher (van Sonderen, Sanderman, \& Coyne, 2013). This factor was not included in this research because all its items were viewed as best assessed if they were reverse-coded and such was not preferred for this study. Reverse coded items are intended to address response bias. Response bias refers to answering patterns on questionnaires that do not reflect the respondents' actual state or opinion (van Sonderen et al., 2013). Although reverse coding items can be used in instruments and can be reverse scored, it is often discouraged because it leads to confusion among respondents. Respondents, especially second language speakers, who are not careful may miss the reversing or the negative form and may incorrectly respond to the items (Weijters, Baumgartner, \& Schillewaert, 2013). The aforementioned factors excluding performance goal, were adapted for this research as the basis for assessing Namibian Grade 12 students' motivation to learn science. 


\subsection{Cross-cultural validation}

When adapting instruments for use in a culture different from what they have been developed for, it necessitates a cross-cultural validation. Cross-cultural validation entails ascertaining whether instruments that were originally developed in a particular culture are meaningfully applicable and thus equivalent for use in another culture (Huang \& Wong, 2014). It has often been applied in psychological studies in which self-reporting measures are adapted for use in languages other than the original language. Two instruments (Study 3 and Study 4) were adapted for use in the Namibian cultural context. However, the adapted versions remained in English as the original questionnaires. The cultural difference exists only in terms of geographical location; the original questionnaires were developed in Taiwan and USA respectively and adapted for use in Namibia.

\subsection{Conclusion}

The nature of science is a multifaceted and complex concept. To date there is no complete agreement among philosophers, historians, sociologists of science and science educators on how to define it. Notwithstanding this, there is less disagreement among philosophers of science and science educators about the general aspects of nature of science that are deemed less controversial and appropriate for inclusion in the basic education science curricula. Those aspects are manifested as unanimous view of nature of science objectives in eight international science education standards documents as presented by McComas et al. (1998).

The general characterisation of the nature of science has been criticised by some science educators, who felt that such characterisations are not comprehensive and hence cannot describe all kinds of science. Further bemoaning that the consensus view of NOS does not adequately cover all philosophical underpinnings that characterise the generation of scientific knowledge. There has since been calls to view nature of science as whole science or approaching it from a family resemblance perspective. However, the closing arguments that provided the way forward are that the disagreements among science educators are not necessarily relevant to basic education science students as such students do not study philosophy, history or sociology of science. The aim is to make NOS accessible to such students. Furthermore, the emphasis is that using the concept of 
general ideas about nature of science is an effective approach to introduce students to the nature of science.

NOS is an important component of scientific literacy. An accurate understanding of the nature of science is believed to help students identify the strengths and limitations of the scientific knowledge, develop accurate views of how science can and cannot answer. Moreover, research suggests that teaching students the nature of science can facilitate the learning of science subject content and increase student achievement. It is also essential to understanding the relationship between science, pseudo-science and religion and helps increase awareness of the influence of scientific knowledge on society. Developing appropriate conceptions of NOS has been advocated as critical to acquiring scientific literacy by various science education reform documents worldwide, particularly in United States, United Kingdom, Australia, Canada and South Africa.

Some aims of the science curriculum in Namibia were found to conform to some objectives of international science education standards documents. Namibia envisions developing future scientists through the teaching of natural sciences. This dream can be realised if students acquire appropriate understanding of the nature of scientific knowledge. However, the science curriculum adopts the implicit approach to teaching nature of science as is prevalent worldwide. However, research shows that this approach is not effective, hence the need to follow explicit-reflective instructional approach.

Research results of students and science teachers views of NOS consistently reveal that both students and teachers possess naïve (less sophisticated) views about NOS.

Due to the complexity of the nature of science concept, Conley et al. (2004) proposed that students' beliefs about the nature scientific knowledge and knowing from the epistemological perspective. Suggesting that students' scientific epistemic beliefs has four dimensions. These four dimensions are not very different from what other science educators proposed about nature of science. However, they were found interesting and could add value this study that is why that perspective was included.

What motivates students to learn science has been viewed as an important focus of research in science education. Motivation to learn science has been linked with beliefs about the nature of scientific knowledge and knowing and most of the conclusions drawn 
from these studies support the notion that sophisticated beliefs may positively relate to motivation particularly self-efficacy. Whilst less sophisticated (absolutist) beliefs were associated with negative self-judgement. For these reasons, motivation was also viewed as a relevant component worthy of inclusion in this study.

Studies related to beliefs about nature of science or from the perspective of scientific epistemic beliefs and their association with motivation were hardly found done in the Namibian cultural context, at the time this study was formulated. This constitutes a research gap that the present study attempted to fill. There is no paucity of instruments for assessing NOS, scientific epistemic beliefs and motivation to learn science. However, such instruments were never developed nor tried in the cultural context of Namibia. Developing, adapting and validating instruments for assessing the three focus areas using Namibian students were the aims of this research. 


\section{CHAPTER 3: AIMS OF THE RESEARCH AND EMPIRICAL STUDIES}

\subsection{Research aims and empirical studies}

This research had two overall aims; 1) to develop and validate an instrument for assessing students' (and teachers) beliefs about nature of science; 2 ) to adapt and validate instruments to assess their suitability for use in the cultural context of Namibia. The adapted instruments cover motivation towards science learning (MTSL) and scientific epistemic beliefs (SEB).

Namibia as a developing nation needs to keep abreast with the rest of the world in terms of educational reforms particularly in science education. Although the national curriculum recognises the importance of scientific literacy, the current assessment practices in Namibian secondary education phase do not include the epistemic aspect of scientific inquiry. Subsequently, there are no ways of ascertaining the realisation of the goals of the national curriculum, related to the understanding of the nature of scientific knowledge. Numerous instruments for exploring students' views about the nature of scientific knowledge or epistemic beliefs as well as motivation to learn science exist. However, many existing instruments have some limitations in terms of psychometric validity as they are based solely on qualitative validations and none of such instruments were developed in the cultural context of Namibia.

In this research, four empirical studies were carried out. Study 1 was a piloting of the new questionnaire developed to assess beliefs about nature of science and scientific inquiry, conducted subsequent to its development, with the aim of validating its content using secondary school science teachers in Namibia. As part of the continued validation of the new questionnaire, Study 2 aimed at exploring the factorial validity of the eightdimension theorisation of nature of science that underpinned the development of the new questionnaire termed 'Beliefs About the Nature of Science' (BANOS) and to assess senior secondary students' beliefs about the nature of scientific knowledge and knowing.

The review of literature revealed that motivation to learn science has been linked to beliefs about the nature of science and knowing. For this reason, Study 3 aimed to adapt and conduct a cross-cultural validation of the Students' Motivation Towards 
Science Learning (SMTSL) questionnaire in the cultural context of Namibia. Beside the eight general aspects conceptualisation, was the suggestion that scientific epistemic beliefs (SEB) had four dimensions. Study 4 was aimed at adapting and conducting a cross-cultural validation of the SEB questionnaire in the cultural context of Namibia using senior secondary science students.

In a nutshell, these four studies were aimed at developing, adapting and psychometrically validating questionnaires for assessing scientific epistemic beliefs and motivation to learn science among Namibian senior secondary science students.

\subsection{Research questions and hypotheses}

This research attempted to answer two main research questions, 1) What is the possibility of assessing multiple general aspects of nature of science using a single instrument? This question was answered in Studies 1 and 2 which entailed instrument development and validation. 2) What is the suitability of the adapted instruments in the Namibian context? This question was answered in Studies 3 and 4 which pertained the adaptation and validation of two instruments, one on motivation towards science learning and the other one scientific epistemic beliefs. This was achieved through several subresearch questions and hypotheses as presented corresponding to their respective studies, with S1, S2, S3 and S4 denoting studies 1 to 4 respectively. The sub-research questions to which hypotheses relate are shown in brackets at the end of each hypothesis.

\subsubsection{Research questions for Study 1}

The following questions were answered in the first study:

Q1/S1 - How do items function in the questionnaire?

Q2/S1 - What is the reliability of the questionnaire?

Q3/S1 - What are the science teachers' overall beliefs about nature of science and scientific inquiry?

Q4/S1 - Is there any difference in beliefs among teachers based on gender, teaching experience or type of science subject taught?

\subsubsection{Hypotheses for Study 1}

H1/S1 - We expect inter-item correlations to be within the preferable range (Q1/S1). 
H2/S1 - We expect the mean item-total correlation to be desirable (Q1/S1).

H3/S1 - We expect reliability estimates to be acceptable (Q2/S1).

H4/S1 - Based on literature, we expect teachers to possess less sophisticated beliefs about NOS (Q3/S1).

H5/S1 - No significant difference in beliefs in terms gender is anticipated (Q4/S1).

H6/S1- We hypothesize that teachers with more science teaching experience possess more sophisticated beliefs about NOS than less experienced teachers (Q4/S1).

H7/S1 - We expect no significant difference in beliefs based on the type of science subject taught (Q4/S1).

\subsubsection{Research questions for Study 2}

The following questions were answered in the second study:

Q1/S2 - What is the reliability of the BANOS questionnaire?

Q2/S2 - What is the construct validity of the BANOS questionnaire?

Q3/S2 - What is the factorial validity of the theorised eight-dimension nature of science?

\subsubsection{Hypotheses for Study 2}

H1/S2 - Reliability estimates are expected to be acceptable (Q1/S2).

H2/S2 - Composite reliability (CR) and Average variance extracted (AVE) are expected to be within recommended threshold in order to confirm convergent validity $(\mathrm{Q} 2 / \mathrm{S} 2)$.

H3/S2 - The square root of the AVE is expected to be higher than inter-latent factor correlations to confirm discriminant validity $(\mathrm{Q} 2 / \mathrm{S} 2)$.

H4/S2 - Convergent and discriminant validity together confirm construct validity $(\mathrm{Q} 2 / \mathrm{S} 2)$.

H5/S2 - We expect an interpretable factor structure from exploratory factor analysis (Q3/S2).

H6/S2 - We expect good measurement model fit from confirmatory factor analysis (Q3/S2).

\subsubsection{Research questions for Study 3}

The following questions were answered in the third study:

Q1/S3 - What is the reliability of the adapted SMTSL questionnaire?

Q2/S3 - What is the construct validity of the adapted SMTSL questionnaire? 
Q3/S3 - How is the factor structure of the adapted SMTSL questionnaire?

\subsubsection{Hypotheses for Study 3}

H1/S3 - We expect acceptable reliability estimates (Q1/S3).

H2/S3 - Composite reliability (CR) and Average variance extracted (AVE) are expected to be within recommended threshold in order to confirm convergent validity (Q2/S3).

$\mathrm{H} 3 / \mathrm{S} 3$ - The square root of the AVE is expected to be higher than inter-latent factor correlations to confirm discriminant validity (Q2/S3).

H4/S3 - Convergent and discriminant validity together confirm construct validity (Q2/S3).

H5/S3 - We expect an interpretable factor structure from exploratory factor analysis (Q3/S3).

H6/S3 - We expect good measurement model fit from confirmatory factor analysis (Q3/S3).

\subsubsection{Research questions for Study 4}

The following questions were answered in the fourth study:

Q1/S4 - How is the reliability of the adapted SEB questionnaire with the Namibian sample?

Q2/S4 - Does the data confirm the four-dimension hypothesised model?

Q3/S4 - Do students' scientific epistemic beliefs predict their achievement in science?

Q4/S4 - Is there a difference in mean levels of SEB in terms of gender, grade and socioeconomic status?

\subsubsection{Hypotheses for Study 4}

H1/S4 - We expect reliability estimates to be acceptable (Q1/S4).

$\mathrm{H} 2 / \mathrm{S} 4$ - Based on the literature, the four dimensions of beliefs should form distinct factors (Q2/S4).

H3/S4 - Composite reliability (CR) and Average variance extracted (AVE) are expected to be within recommended threshold in order to confirm convergent validity (Q2/S4).

H4/S4 - The square root of the AVE is expected to be higher than inter-latent factor correlations to confirm discriminant validity (Q2/S4). 
H5/S4 - Convergent and discriminant validity together confirm construct validity (Q2/S4).

H6/S4 - We expect good measurement model fit from confirmatory factor analysis $\mathrm{Q} 2 / \mathrm{S} 4)$.

H7/S4 - Based previous studies, the SEB should significantly predict achievement in science (Q3/S4).

H8/S4 - No significant difference in SEB in terms gender is anticipated (Q4/S4).

H9/S4 - We expect a significant difference in SEB in terms grade (Q4/S4).

H10/S4 - Based on the original study that developed the SEB, we should anticipate a significant difference in SEB in terms socioeconomic status (Q4/S4). 


\section{CHAPTER 4: METHODOLOGY}

\subsection{Research design}

This research was conducted as part of the requirements of a doctoral degree. This meant that there was limited time within which data should be collected and analysed. For this reason, the research followed a descriptive cross-sectional design. Descriptive research is concerned with describing and interpreting what exists such among others; beliefs, points of views, or attitudes that are held by respondents (Cohen et al., 2007). The research was cross-sectional in the sense that different respondents were used at different points in time. This design was deemed appropriate because the sample was based in Namibia and I was studying in Hungary. The respondents that participated in the research were those that were available at the time the data was collected, this was often when I had travelled to Namibia at the end of every semester of full-time studies.

\subsection{Samples}

Apart from the appropriateness of methodology and instrumentation, the quality of a piece of research is also dependent on the suitability of sampling strategies (Cohen et al., 2007). The issue of sampling emanates from what characterises the population on which the research focuses. Numerous "factors such as expense, time, accessibility frequently prevent researchers from gaining information from the whole population" (Cohen et al., 2007, p. 100). For this reason, a smaller but representative sample needs to be obtained.

This research targeted the population of senior secondary school students (Grades 11 and 12) in Namibia. This is the last phase of schooling in Namibia's basic education structure. To achieve representativeness, a national sample would have been ideal. However, due to limited time and lack of resources, this could not be realised. Furthermore, the issue of accessibility to state schools was also a limiting factor. As evident in Appendices 6 and 7, the state does not allow research to disrupt school academic activities. This meant that the researcher had to beg school management to see students only after school or during break time. But during these times, students are often either tired or busy preparing for some extra-curricular activities that schools had planned at the beginning of the academic year. Getting students to respond to research instruments 
while their minds are freshest is close to impossible in Namibia. This could affect the quality of responses from students and thereafter after jeopardises the outcome of research.

Nonetheless, a convenient sample could be obtained from few schools that were flexible enough with me to allow their students to respond to my instruments. This was made possible by the fact that I personally knew the school principals and some teachers in such schools. Thus, as shown in Figure 3, the samples were often drawn from few schools in Khomas region (12), particularly in Windhoek which is the capital city of Namibia. Others were drawn from Omusati (2), Ohangwena (4) and Oshana (3) regions. Schools in Omusati and Ohangwena regions are predominantly in rural areas whereas in Oshana are in urban areas. Although the samples obtained from these schools were not representative of the whole country or one particular region, the use of whole grades in the schools provided a sufficient sample appropriate for advanced statistical analyses such exploratory and confirmatory factor analyses as well as t-tests.

\section{Figure 3}

\section{Regions of Namibia}

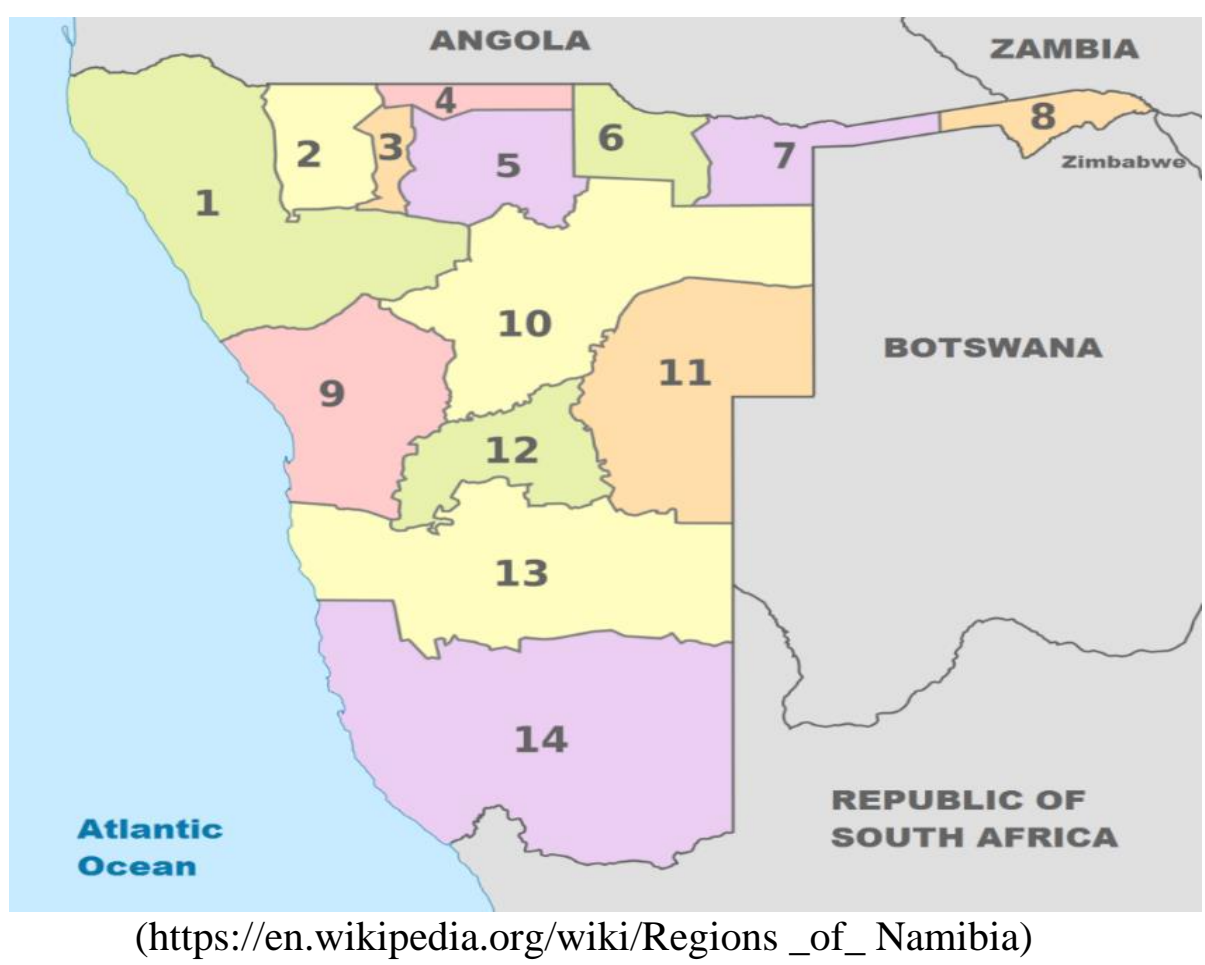


The questionnaire used in Study 1 was developed to assess students' beliefs about nature of science and scientific inquiry, however, it was nonetheless administered to a sample of 124 (39\% male and 61\% female) science teachers from most of the regions in Namibia as part of the preliminary stages of the validation process.

The criterion for inclusion was that teachers must have been teaching either of the two science subjects that make up the Natural Sciences in the Namibian curriculum. This means they should either be teaching Biology or Physical Science at senior secondary level. The respondents were grouped into ranges of years of experience in science teaching from 0-3 years to over 10 years and about $94 \%$ were within the desired categories of 3 or over 3 years of teaching experience. See Table 2.

Table 2

Demographic information of the science teachers

\begin{tabular}{llccccc}
\multirow{2}{*}{ Gender } & \multicolumn{5}{c}{ Teachers' experience teaching science } & \multicolumn{1}{c}{ Total } \\
\cline { 2 - 6 } Male & & $0-3$ years & $3-5$ years & $5-10$ years & 10+ years & $48(39 \%)$ \\
& $\%$ & 8 & 0 & 16 & 24 & 100 \\
\multirow{2}{*}{ Female } & $\%$ & 17 & 0 & 33 & 50 & $76(61 \%)$ \\
& $\mathrm{N}$ & 0 & 28 & 32 & 16 & 100 \\
\hline \multirow{2}{*}{ Total } & $\%$ & 0 & 37 & 42 & 21 & 124 \\
& $\mathrm{~N}$ & 8 & 28 & 48 & 40 & 100 \\
\hline
\end{tabular}

Samples of students used in Study 2 to 4 were all senior secondary students. Senior secondary students are those who were either in Grades 11 or 12 . These students should have passed certification examinations in Grade 10. All senior secondary schools use the same centrally developed curricula and study materials are prescribed through catalogues. This suggests that the samples are fairly homogenous. These students were in the exit phase of basic education in Namibia, their next step being progress to either universities or vocational training institutions. These students have been studying science for over ten years because science is compulsory from lower primary to Grade 10 and those who participated in this research were in the science field of study, meaning they continued to study science at senior secondary level.

For Study 2, the questionnaire was administered to a sample of 860 (male 52\% and female 48\%) secondary school students in Namibia, using the paper-and-pencil 
method. The mean age of students was $M=18.3$ and standard deviation $S D=1.32$. Sampling was inherently purposive because the study did not intend to generalize findings but rather to obtain sufficient sample suitable for advanced statistical analysis to examine psychometric properties of the questionnaire. All participating students were in senior secondary level (Grade 12). On average, students spent approximately 13 minutes to complete the questionnaire.

For Study 3, a total of 755 Grade 12 students (male 53\% and female 47\%) from four senior secondary schools in two regions (Omusati and Ohangwena) of Namibia participated in the study. The mean age of students was $M=18.3$ and standard deviation $D=1.32$. As in Study 2, sampling here was also convenient because the aim of the study was not to generalize findings but rather to obtain sufficient sample suitable for advanced statistical analysis to examine psychometric properties of the adapted questionnaire in the cultural context of Namibia.

In Study 4, a sample of 944 (45\% male; 55\% female) grade 11 and 12 students with the mean age $M=17.9, S D=1.4$ from three senior secondary schools in two regions (Omusati and Khomas) of Namibia participated in the study. Sampling was also convenient in this case for the same reasons as in Study 3.

In total, 124 science teachers and 2559 students constituted the samples of the research. The detailed composition of samples used in this research are shown in Table 3.

Table 3

Samples of all the studies

\begin{tabular}{cll}
\hline Studies & Samples & Instruments \\
\hline Study 1 & Science teachers N =124 & $\begin{array}{l}\text { Beliefs About Nature of Science } \\
\text { and Scientific Inquiry } \\
\text { (BANOS first Draft) }\end{array}$ \\
Study 2 & Grade 12 students N =755 & $\begin{array}{l}\text { Adapted SMTSL (Tuan et al., } \\
\text { 2005) }\end{array}$ \\
& Grade 12 students N =860 & $\begin{array}{l}\text { BANOS (Shaakumeni \& Csapó, } \\
\text { 2018) } \\
\text { Adapted SEBs (Conley et al., } \\
\text { 2004) }\end{array}$ \\
\hline
\end{tabular}




\subsection{Instruments}

One of the aims of this research was to develop a new questionnaire for assessing students' beliefs about the nature of science. The first version of the questionnaire developed for this purpose was used for Study 1 (see Appendix 1). The questionnaire included the scientific inquiry component as part of initial thoughts and ideas emanating from the review of literature. However, upon reviewing more latest relevant literature, it was found that scientific inquiry was a separate construct (Lederman et al., 2014) and warrant a separate investigation and for this reason it was removed from the questionnaire in subsequent validation stages.

After analysis of the first version of the above-mentioned questionnaire, some changes were made. As a result, a shorter questionnaire that we termed "Beliefs about Nature of Science" (BANOS) emerged and it was used for Study 2 (see Appendix 2).

The review of literature revealed motivation to learn science was linked to beliefs about nature of science and was hence adopted for inclusion in this research. This happened in a form adaptation of the already existing Students Motivation Towards Science Learning (SMTSL) developed by Tuan et al. (2005) and was used for Study 3 (see Appendix 3).

The fourth study covered the complimentary concept of scientific epistemic beliefs (SEBs). Proponents of this conceptualisation developed a questionnaire to assess four dimensions of beliefs in science (Conley et al., 2004). This questionnaire was adapted and used for Study 4 (see Appendix 4). All instruments were 5-point Likert scale questionnaires and administered using paper and pencil. The summary of instruments used are shown in Table 4. 
Table 4

Instruments used in the research

\begin{tabular}{|c|c|c|c|}
\hline Studies & Samples & Instruments & $\begin{array}{l}\text { No of } \\
\text { items }\end{array}$ \\
\hline Study 1 & $\begin{array}{l}\text { Science teachers } \\
\mathrm{N}=124\end{array}$ & $\begin{array}{l}\text { Beliefs About Nature of Science and } \\
\text { Scientific Inquiry (BANOS first Draft) }\end{array}$ & 40 \\
\hline Study 2 & $\begin{array}{l}\text { Grade } 12 \text { students } \\
\mathrm{N}=755\end{array}$ & Adapted SMTSL (Tuan et al., 2005) & 20 \\
\hline Study 3 & $\begin{array}{l}\text { Grade } 12 \text { students } \\
\mathrm{N}=860\end{array}$ & BANOS (Shaakumeni \& Csapó, 2018) & 28 \\
\hline Study 4 & $\begin{array}{l}\text { Grades } 11 \& 12 \text { students } \\
\mathrm{N}=944\end{array}$ & Adapted SEBs (Conley et al., 2004) & 22 \\
\hline
\end{tabular}

\subsection{Procedures}

\subsubsection{Data Collection}

As indicated earlier, the questionnaire for Study 1 was administered to a sample of science teachers from most of the regions in Namibia as part of content validation. These teachers were gathered at one place to mark national examinations for Biology and Physical science during December 2017. The selection of these teachers was done by the Directorate of National Examinations and Assessment in Namibia. Although effort was made by the directorate to source teachers from all fourteen regions of Namibia, they may not be representative of all science teachers in Namibia, hence representativeness could not be guaranteed here as well. Furthermore, I was not party to the selection process, I only requested in conjunction with relevant officials from the directorate, the teachers' permission to respond to my questionnaire.

Upon receiving the ethical approval from the supervising university's institutional review board (see Appendix 5) followed by permission from the gate keepers of the Ministry of Education, Arts and Culture in Namibia (Appendix $6 \&$ 7), informed consent forms (Appendix 8) were signed by participating students in conjunction with their parents or guardians. Data were collected at the beginning of the first Namibian schools' trimester in January 2018. This was deemed the best time to visit schools as they have just started their academic programme. Moreover, this was also in conformity with stringent conditions attached to the research permission; not to disturb academic 
activities. With help of the teachers at schools, the self-reporting BANOS questionnaire were administered using pencil-and-paper method for Study 2.

Study 3 was also administered subsequent to the same approvals and permissions. This study used the adapted Students Motivation Towards Science Learning questionnaire and with similar assistance from teachers as mentioned above, it was administered in February 2018.

Data collection for the Study 4 was handled slightly different. Although with some assistance from teachers at schools, students were assigned numbers corresponding to their position in their class list. This enabled me to accurately link their SEBs questionnaire responses to their mid-year science (Biology and Physical Science) marks obtained from school records. Science marks were used to relate students' SEBs to achievement in science. Provision was also made on the SEBs questionnaire to collect some background data such as age, gender, grade and socioeconomic status (SES) by means of mother's level of education. Table 5 shows the descriptive information for this study.

Table 5

Mother's level of education and gender of students

\begin{tabular}{llccc}
\hline \multirow{2}{*}{ Mother's level of education } & & \multicolumn{2}{c}{ Gender of student } & \\
\cline { 3 - 4 } & & Male & Female & Total \\
\cline { 3 - 4 } & Degree & 63 & 66 & 129 \\
& Diploma & 48 & 38 & 86 \\
& Matric & 63 & 84 & 147 \\
& Below matric & 69 & 74 & 143 \\
& I don't know & 178 & 261 & 439 \\
Total & & 421 & 523 & 944 \\
\hline
\end{tabular}

The SES was determined by grouping students into two. One group for those whose mothers had a degree or diploma considered as 'high SES' and the other group was for those whose mothers had matric or below matric considered as 'low SES'. Those who didn't know about the level of their mothers' education $(\mathrm{N}=439)$ were excluded from these analyses. The timeline for the planning and execution of the studies is presented in Table 6. 


\section{Table 6}

Timeline and research activities

\begin{tabular}{|c|c|c|c|}
\hline Timeline & Research activities & Instruments & Samples \\
\hline September 2016 & $\begin{array}{l}\text { - } \text { Contextualisation of the research focus, } \\
\text { preparation of research plan and presentation } \\
\text { - } \quad \text { Draft permission and ethical clearance letters } \\
\text { - } \quad \text { Literature search, selection and review } \\
\text { - } \quad \text { Development of questionnaire items }\end{array}$ & & \\
\hline June-August 2017 & - Piloting of the new questionnaire in Namibia & $\begin{array}{l}\text { - Beliefs About Nature of Science and } \\
\text { Scientific Inquiry (BANOS first } \\
\text { Draft) }\end{array}$ & $\begin{array}{l}\text { - } \quad \text { Science teachers } \\
\text { - } \quad \mathrm{N}=124\end{array}$ \\
\hline September 2017 & $\begin{array}{l}\text { - Analysis of item function in new } \\
\text { questionnaire (BANOS) and presentation of } \\
\text { results } \\
\text { - } \\
\text { - } \\
\text { Revision of new questionnaire (BANOS) }\end{array}$ & - $\quad$ SMTSL (Tuan et al., 2005) & \\
\hline January - February 2018 & $\begin{array}{l}\text { - Cross-cultural validation of the adapted } \\
\text { SMTSL } \\
\text { - Large scale administration of the BANOS } \\
\text { questionnaire }\end{array}$ & $\begin{array}{l}\text { - Adapted SMTSL (Tuan et al., 2005) } \\
\text { - } \begin{array}{l}\text { BANOS (Shaakumeni \& Csapó, } \\
\text { 2018) }\end{array}\end{array}$ & $\begin{array}{l}\text { - } \text { Grade } 12 \text { students } \\
\text { - } \mathrm{N}=755 \\
\text { - } \text { Grade } 12 \text { students } \\
\text { - } \mathrm{N}=860\end{array}$ \\
\hline March - August 2018 & $\begin{array}{l}\text { - Data analysis of SMTSL and BANOS } \\
\text { - Presentation of results in seminars and } \\
\text { conferences }\end{array}$ & & \\
\hline $\begin{array}{l}\text { September } 2018 \text { - January } \\
2019\end{array}$ & $\begin{array}{l}\text { Data analysis for BANOS continues and } \\
\text { presentation of results at seminar and } \\
\text { conferences } \\
\text { - Adaptation of SEBs questionnaire }\end{array}$ & - $\quad$ SEBs (Conley et al., 2004) & \\
\hline January - July 2019 & $\begin{array}{l}\text { - Cross-cultural validation of adapted SEBs } \\
\text { - } \quad \text { Data analysis of SEBs questionnaire } \\
\text { - Presentation of results in seminars and conferences }\end{array}$ & - $\quad$ Adapted SEBs (Conley et al., 2004) & $\begin{array}{l}\text { - Grades } 11 \& 12 \\
\text { students } \\
\text { - } \mathrm{N}=944\end{array}$ \\
\hline
\end{tabular}




\subsubsection{Data analysis}

This research was inherently quantitative. For this reason, several statistical analyses were performed on the data using Statistical Package for the Social Sciences (SPSS), AMOS, Mplus and Microsoft Excel (Gaskin, 2016). As a result of using Likert scale questionnaires, ordinal scales were analysed as if they were interval (Glynn et al., 2011). In this case items are assumed to be generally parallel indicators of the underlying latent variable (DeVellis, 2003).

For all four studies, Cronbach's alpha was used to estimate the reliability of responses. Reliability is a measure of how well the items in a scale measure the same construct (Streiner, 2003). This measure is commonly estimated using Cronbach's alpha reliability coefficient, which normally ranges between 0 and 1. The closer Cronbach's alpha coefficient is to 1 , the greater the internal consistency of the items in the scale (Gliem \& Gliem, 2003). Essentially, all the items on such measures should reflect the same underlying construct thus respondents' scores on those items should be correlated with each other (Wieland, Durach, Kembro, \& Treiblmaier, 2017).

It is suggested that Cronbach's alpha of $\alpha=.70$ or higher is ideal for research tools. This measure is commonly estimated using Cronbach's alpha reliability coefficient (George \& Mallery, 2003; Streiner, 2003). Both parametric and non-parametric statistics were used. To assess the assumption of normality for estimating the measurement model, the skewness and kurtosis values were used. The data is considered normally distributed if it does not deviate severely from normality. The skewness and kurtosis value should be below \pm 3 and \pm 10 respectively (Kline, 2011).

In particular, non-parametric tests such as Shapiro-Wilk, Mann-Whitney U and Kruskal-Wallis tests were used in Study 1 due to severely non-normal data distribution. The Shapiro-Wilk test was used to assess normality of the data (Field, 2009). The MannWhitney $U$ test was used to examine the difference in beliefs about nature of science and scientific inquiry based on the gender of teachers. Kruskal-Wallis test was used to examine the difference in beliefs based on ranges of years of science teaching experience.

Other analyses such as inter-item correlations were used to analyse the extent to which responses on one item are related to responses on all other items in a scale in the 
quest to produce a reliable scale of measurement (Cohen \& Swerdlik, 2005), whilst itemtotal correlations were used to assess whether there was an individual item whose score is not related to the summated scores of all other items in the scale so that such items are revised or discarded in order to purify the scale (Everitt, 2002; Field, 2005).

Study 2, 3 and 4 used relatively large samples. This warranted the use of parametric statistics involving exploratory factor analysis (EFA), confirmatory factor analysis (CFA), construct validity estimation, independent samples t-tests and linear regression analysis.

EFA using principal components extraction and varimax rotation (Henson \& Roberts, 2006) was used to assess the questionnaire factor structure particularly in Studies 2 and 3. Exploratory factor analysis is meant for cases where the relationships between the observed and latent variables are uncertain (Glynn et al., 2011). It was necessary to apply exploratory factor analysis to assess the factorability of the conceptualised eight general aspects of nature of science and for the five factors of motivation towards science learning in Study 2 and 3 respectively.

Confirmatory factor analysis in AMOS was used to assess the measurement model fit using the ratio of chi-square to degrees of freedom $\left(\chi^{2} / d f\right)$, root-mean-square error of approximation (RMSEA), standardized root mean square residual (SRMR), TuckerLewis index (TLI) and comparative fit index (CFI) as fit indices (Glynn et al., 2011; Teo, 2013) for both studies 2 and 3. The chi-square $\left(\chi^{2}\right)$ statistic assesses the extent to which the proposed model varies from the data (Glynn et al., 2011). Its p-values are acceptable when they are nonsignificant, indicating adequate model fit. However, this index is sample dependent, hence it is recommended that it should be divided by the degrees of freedom $\left(\chi^{2} / d f\right)$, (Garson, 2015) and the resultant values be in a recommended range of 1.0-3.0 (Glynn et al., 2011).

The root-mean-square error of approximation (RMSEA) and the standardized root mean square residual (SRMR) are independent of the sample size but are sensitive to model misspecification and adequate fit values should be 0.06 and 0.08 or less respectively (Teo, 2013). The Tucker-Lewis index (TLI) and the comparative fit index (CFI) are incremental indices with a recommended cut-off value of .95 , indicating 
goodness of fit, however, values above .90 are acceptable (Hooper, Coughlan, \& Mullen, 2008). Maximum likelihood (ML) estimation was used to estimate the model's parameters and fit indices.

For Study 4, EFA was not applied because based on previous studies that used the same questionnaire (e.g. Liang \& Tsai, 2010; Tsai, Jessie Ho, Liang \& Lin, 2011), an assumption was made that the factorial structure confirmed by such studies through exploratory factor analysis should be sufficient for the formulation an a priori hypothesis to test the adapted questionnaire's factorial structure suggesting that the four dimensions of beliefs proposed by Conley et al. (2004) should form distinct factors. Hence only confirmatory factor analyses in Mplus (Muthén \& Muthén, 2017) were used to assess measurement model fit using the ratio of chi-square to degrees of freedom $\left(\chi^{2} / d f\right)$, RMSEA, SRMR, TLI and CFI as fit indices (Glynn et al., 2011; Teo, 2013). Furthermore, linear regression analysis was conducted to relate SEBs to achievement in science. Independent sample t-test was also conducted to examine the difference in SEBs in terms of gender, grade and socioeconomic status. The reliability of the original SEB questionnaire ranged from $\alpha=.66$ to .82 . It also showed reasonable model fit for the data with the RMSEA of 0.038 , the CFI was .90 , the non-normed fit index (NNFI) was .89 , and the root mean square residual (RMR) of 0.062 (Conley et al., 2004).

Construct validity was assessed considering two criteria: convergent and discriminant validity (Cristobal, Flavián, \& Guinalíu, 2007). Convergent validity measures the level of correlation of multiple variables of the same construct that are in agreement (Ab Hamid, Sami, \& Sidek, 2017). To establish convergent validity, factor loadings of indicator variables, composite reliability $(\mathrm{CR})$ and the average variance extracted (AVE) were used (Ab Hamid et al., 2017). Convergent validity was evaluated using AVE and CR values computed using Microsoft Excel (Gaskin, 2016). The recommended thresholds for these measures are that the AVE should be above .50 and the CR should be .70 and above. However, when the AVE values are less than .40 and the composite reliability is higher than .60 , the convergent validity of the construct may still be adequate (Fornell \& Larcker, 1981).

Discriminant validity was assessed by comparing the square root of the AVE with the correlation of latent factors (dimensions) in the model (Hair et al., 2016). The extent 
to which latent factors (dimensions) differ from each other empirically defines discriminant validity (Hair, Hult, Ringle, \& Sarstedt, 2016). This means that a latent factor should explain the variance of its own indicators better than the variance of other latent factors (Ab Hamid et al., 2017). The square root of the AVE should be greater than .50 (Fornell \& Larcker, 1981) and greater than inter-latent factor correlations within the model (Hair, Black, Babin, \& Anderson, 2010). The maximum shared variance (MSV) was also compared to the AVE values in Study 2. The AVE values should be greater than the MSV values for each latent factor (Rebelo-Pinto, Pinto, Rebelo-Pinto, \& Paiva, 2014).

Independent samples t-tests and linear regression analyses were exclusively applied to Study 4. Linear regression analysis was used to assess whether SEBs were predictors of achievement in science whilst independent samples t-tests were used to ascertain whether there were statistically significant differences in mean levels of SEBs in terms of gender, grade and socioeconomic status (SES). Independent sample t-tests were conducted for each dimension, separately for each grouping (gender, grade and SES). The SES was determined by grouping students into two. One group for those whose mothers had a degree or diploma considered as 'high SES' and the other group was for those whose mothers had matric or below matric considered as 'low SES'. As indicated earlier, those who didn't know about the level of their mothers' education were excluded from these analyses.

\subsection{Summary}

This chapter provided a synopsis of the research methodology employed in this research. "The quality of a piece of research stands or falls not only by the appropriateness of methodology and instrumentation but also by the suitability of the sampling strategy that has been adopted" (Cohen et al., 2007, p. 100). On the basis of this caveat as well as on the aims of the research, a descriptive cross-sectional design using quantitative methods was considered to be appropriate for this research. The use of self-reporting questionnaires enables data for large-scales studies to be collected and analysed with limited resources. All these characteristics were explained in details in this chapter. The next chapter presents the results and discussions of the four studies that constitute the core of this dissertation. 


\section{CHAPTER 5: THE STUDIES}

\subsection{Study 1: Validation of an instrument to assess beliefs about nature of science and scientific inquiry in Namibia - a pilot study}

\subsubsection{Introduction}

The National Curriculum for Basic Education (NCBE) in Namibia which is the broad curriculum, demands that students develop into scientific literate citizens (Ministry of Education, 2010). According to the NCBE, one of the components of scientific literacy is the understanding of the nature of scientific knowledge. The nature of science entails what makes science different from other disciplines. In other words, it characterises scientific knowledge that is derived from how the knowledge is developed (Lederman, et al., 2014). However, the assessment of science knowledge in Namibian schools does not include these aspects of scientific literacy. All assessments mainly focus on one aspect of scientific literacy which is the subject content knowledge and hardly focus on assessing students' abilities to do inquiry and whether they acquire fundamental understanding of the characteristics of nature of science and scientific inquiry. Since these aspects of scientific literacy are not assessed in schools, there is hardly any means through which to ascertain the extent to which the ideals of the national curriculum are being met. One way to ascertain students' understanding of the nature of scientific knowledge and knowing is to assess their science epistemic beliefs. Advancing students' beliefs about the nature of scientific knowledge and knowing has featured prominently in recent research in science education (Conley, Pintrich, Vekiri, \& Harrison, 2004; Tsai, Ho, Liang, \& Lin, 2011; Chen, 2012; Chen, Metcalf, \& Tutwiler, 2014). However, none of such studies appear to have been conducted in Namibia.

\subsubsection{Methods}

\subsubsection{Instrument development}

The theoretical framework for the development of the instrument for assessing beliefs about the nature of science is based on general and symbiotic aspects of nature of science and scientific inquiry as proposed by Lederman and other scholars (Lederman, Abd-El-Khalick, Bell, \& Schwartz, 2002; Lederman \& Abd-El-Khalick, 1998; 
McComas, Almazroa, \& Clough, 1998, Lederman et al.,2014). These aspects of nature of science, though criticised by some science educators as being too general, oversimplified, prescriptive and narrow (Irzik \& Nola, 2011; Mathews, 2012; Dagher \& Erduran, 2016; Grandy \& Duschl, 2008), they are considered as a useful guiding framework for this study. They serve as the lens through which to assess students' beliefs about nature of science in Namibia. The decision to adopt this framework is based on the clarification provided by proponents of the general aspects of nature of science, who in response to criticisms stated that the suggested general aspects of nature of science are by no means "a definitive or universal definition of the construct" (Lederman, Antink, \& Bartos, 2014, p. 286). Furthermore, they do not advocate an absolutist stance on those general statements about nature of science. Moreover, their focus is on understandings that they deem necessary for basic education students, given a plethora of hardly productive debates about the specific definition of nature of science.

In the present study, no existing instrument has been used whether as whole or in an adapted or modified form. A separate questionnaire termed "Beliefs about Nature of Science" (BANOS) questionnaire has been developed. However, ideas for possible items were obtained from existing scales in the literature. The first version of the BANOS questionnaire comprised of thirty-five items. The items are declarative statements describing particular aspects of nature of scientific knowledge including scientific inquiry. Respondents give their personal level of belief or agreement with the five-point Likert scale (Cohen, Manion, \& Morrison, 2007) namely $1=$ strongly disagree, $2=$ disagree, $3=$ not sure, $4=$ agree and $5=$ strongly agree.

The declarative statements are organised according to the eight target general aspects of the nature of science including scientific inquiry. The statements are also in a form of sophisticated/informed views of respondents about nature of science and scientific inquiry obtained from the literature (Chen, 2006; Dogan \& Abd-El-Khalick, 2008; Khishfe \& Abd-El-Khalick, 2002; Summers \& Abd-El-Khalick, 2017; Vhurumuku, 2010). The statements were all positively worded so that a high score indicate more sophisticated beliefs about the nature of science and knowing and scientific inquiry. 


\subsubsection{Procedure}

An assessment of validity and reliability was conducted on the instrument. To ascertain face and content validity, a review of over seventy recent researches on nature of science and knowing was done. This served to ensure the accuracy of each declarative statement (item) that was included in the instrument. To check for comprehension and readability, the paper-and-pencil questionnaire was administered to a sample of 124 science teachers that were conveniently sampled from most regions in Namibia. These teachers gathered at one central venue to mark national end-of-year examinations. The involvement of teachers was to some extent expected to provide some validation as teachers' beliefs are expected to be different from that of students.

An English language expert was also engaged to read through the statements and modifications were made were applicable.

To assess differences between groups, raw scores were converted to standard scores because according to Osterlind (2006) standard scores provide more practical information for decision making than raw scores. The raw scores were converted into zscores in which the data had a mean of zero and standard deviation of one. Ordinal scales were analysed as if they were interval scales (Glynn, Brickman, Armstrong \& Taasoobshirazi, 2011). In this case items are assumed to be generally parallel indicators of the underlying latent variable (DeVellis, 2003).

\subsubsection{Results and discussions}

In order to produce a reliable scale of measurement, it is imperative to analyse the extent to which responses on one item are related to responses on all other items in a scale. For this reason, inter-item correlations are an essential element in the initial analysis of a set of items.

\subsubsection{Inter-item correlations}

This analysis provides information about the extent to which items on a scale are assessing the same construct (Cohen \& Swerdlik, 2005). The average inter-item correlation for a set of items should preferably be between $r=.20$ and $r=.40$ (Piedmont, 2014). This implies that although items should be reasonably similar in some way, it is 
pointless to have items on a scale that measure the construct in exactly the same way. When correlation values are below $r=.20$, it suggests that items do not relate to each other very well hence may not be suitable for measuring a single construct. Moreover, if the values are above $r=.40$ the items tend to be very similar to each other, almost to the point that they become redundant (Piedmont, 2014).

Table 7

Summary of item statistics

\begin{tabular}{cll}
\hline & Mean & No. of Items \\
\hline Item Means & 2.95 & 35 \\
Inter-Item Correlations & $\mathbf{. 4 0 3}$ & 35 \\
\hline
\end{tabular}

The average inter-item correlation for the items $(\mathrm{N}=35)$ in the first version of Beliefs about Nature of Science (BANOS) instrument was $r=.40$ (Table 7). As indicated above, correlations between $r=.20$ and $r=.40$ are preferable, this indicate that items relate to each other fairly well and therefore in the context of this study, they may be suitable for measuring beliefs about the nature of science and scientific inquiry in Namibia.

\subsubsection{Item-total correlations}

Items were further examined to ascertain whether there is an individual item whose score is not related to the summated score of all other items in the scale and such items are revised or discarded (Churchill, 1979). This is essentially performing item-total correlations. Item-total correlation values between $r=.20$ and $r=.40$ are desirable and a small correlation suggests that the item is not measuring the same construct measured by the other items in the scale (Field, 2005; Everitt, 2002). The mean item-total correlation $(\mathrm{N}=35)$ was $r=.63$. One item (number 8 ) had correlation values less than $r=.20$. This shows that the item was not measuring the same construct measured by the other items in the instrument. This item was examined to ascertain whether it can be improved or be discarded. Other items such 6, 7 and 10 had correlations less than $r=.40$ but greater than $r=.20$. These items displayed very weak correlations and were rewritten. Since this is a validation process, the intention was not to discard items yet but rather to modify them 
and pilot them for the second time. Subsequently, items were rewritten and none of the items were discarded.

\subsubsection{Internal consistency reliability}

The Cronbach's alpha computed on all the 35 items $(\mathrm{N}=124)$ was $\alpha=.96$. This shows that the instrument overall has very high reliability. Further assessment of reliability analysis reveals that there was no need to delete any item in order to improve the overall reliability value of the instrument.

The eight general aspects of nature of science plus scientific inquiry made up the nine subscales in the instrument. Participants' responses on the items for each subscale were computed to determine the median (Elliot \& Mcgregor, 2001). Despite that the overall reliability of the instrument as a whole was very high, two subscales namely the empirical nature of scientific knowledge and the scientific method did not show very good reliability. The reliability of the two subscales were $\alpha=.51$ and $\alpha=.67$ respectively (Table 8). Deleting one item from the empirical subscale improved the alpha coefficient value slightly to $\alpha=.54$. However, this was still very low. Moreover, by deleting one item from the scientific method subscale improved the alpha coefficient to $\alpha=.73$. This alpha coefficient value is now reasonable, however, the items in this subscale were reviewed and will be piloted for the second time before any permanent dropping of the items is implemented. 
Table 8

Reliability of the BANOS/SI subscales

\begin{tabular}{lcc}
\hline \multicolumn{1}{c}{ NOS aspects } & No. of items & Cronbach's alpha \\
\hline Tentative nature of science & 5 & .81 \\
Empirical nature of science & 4 & $.51(.54)^{*}$ \\
The scientific method & 3 & $.67(.73)^{*}$ \\
Subjective nature of science & 3 & .78 \\
Imaginative and Creativity & 4 & .75 \\
Socio-cultural influence & 3 & .88 \\
Observations and inferences & 3 & .90 \\
Theories \& laws & 5 & .83 \\
Scientific inquiry (SI) & 5 & .91 \\
Total items & 35 & .96 \\
\hline
\end{tabular}

Note. * shows the alpha value $(\alpha)$ if 1 item is deleted

The number of items in a scale partially influences the Cronbach's alpha values. These values could be increased by increasing the number of items in the scale or deleting individual items whose values are higher than the overall Cronbach's alpha value of the scale. The very high alpha values indicate that items were measuring the same construct very well. Notwithstanding the above, Gliem and Gliem (2003) cautioned that although a higher Cronbach's alpha indicates a good internal consistency of the items in the scale, it does not mean that the scale is unidimensional. Hence, factor analysis is still required to determine the dimensionality of the scale. However, for this first pilot study, factor analysis was not appropriate as the sample was inadequate to satisfy all the assumptions for factor analysis procedure. This was done during the follow-up study (Study 2).

\subsubsection{Subscale correlations}

The intertwined aspects of nature of science formed subscales that reflect the core constructs of nature of science including scientific inquiry subscale. When separate constructs are combined to form one scale, there is a need to justify that they are closely related (Summers \& Abd-El-Khalick, 2017). One way to show the relationship between constructs is by computing correlations. Without assuming causation (Carver \& Nash, 
2012), the analysis showed that there was an overall significant positive relationship between subscales at $\mathrm{p}<.001$ (Table 9) level. The weakest correlation was between tentativeness and empirical subscales $(r=.27)$. The empirical nature of science subscale showed poor reliability values ( $\alpha=.54$, Table 8$)$, this may explain this weak relationship. The strongest correlation was between observations and inferences and scientific inquiry $(r=.88)$. It should be noted that scientific inquiry though closely related, is not necessarily a component of nature of science because it entails the process of how scientists do their work and how the resultant knowledge is generated and accepted (Lederman, et al., 2014) however, beliefs about it was considered important for this study.

\section{Table 9}

\section{BANOS/SI subscales correlations}

\begin{tabular}{lccccccccc}
\hline \multicolumn{1}{c}{ Subscales } & 1 & 2 & 3 & 4 & 5 & 6 & 7 & 8 & 9 \\
\hline 1. Tentative nature of science & - & & & & & & & & \\
2. Empirical nature of science & $.27^{* *}$ & - & & & & & & \\
3. The scientific method & $.42^{* *}$ & $.51^{* *}$ & - & & & & & \\
4. Subjective nature of & $.59^{* *}$ & $.70^{* *}$ & $.50^{* *}$ & - & & & & \\
science & & & & & & & & \\
5. Imaginative and creativity & $.44^{* *}$ & $.77^{* *}$ & $.56^{* *}$ & $.78^{* *}$ & - & & & \\
6. Sociocultural & $.38^{* *}$ & $.44^{* *}$ & $.43^{* *}$ & $.43^{* *}$ & $.57^{* *}$ & - & & \\
7. Observations and & $.64^{* *}$ & $.54^{* *}$ & $.56^{* *}$ & $.69^{* *}$ & $.66^{* *}$ & $.66^{* *}$ & - & & \\
inferences & & & & & & & & & \\
8. Theories and laws & $.53^{* *}$ & $.64^{* *}$ & $.71^{* *}$ & $.59^{* *}$ & $.69^{* *}$ & $.65^{* *}$ & $.77^{* *}$ & - & \\
9. Scientific inquiry & $.74^{* *}$ & $.55^{* *}$ & $.69^{* *}$ & $.70^{* *}$ & $.68^{* *}$ & $.53^{* *}$ & $.88^{* *}$ & $.86^{* *}$ & - \\
\hline
\end{tabular}

Note. ${ }^{* *}$ Correlation is significant at $\mathrm{p}<.001$ level (2-tailed).

It should be noted however, that very high significant correlations between subscales point to strong similarity. As indicated in preceding section, the overall Chronbach's alpha value was very high $(\alpha=.96)$ and most likely indicate unnecessary redundancy of items (and subsequently the subscales) rather than a desirable level of internal consistency (Streiner, 2003).

\subsubsection{Teachers' response patterns on subscales}

Firstly, the median of responses was calculated for each subscale using the Statistical Package for Social Sciences (SPSS). The median as a measure of central tendency was deemed the most appropriate indicator of respondents' likeliest beliefs 
about each subscale. Secondly, the interquartile range (IQR) which is a measure of dispersion was also computed to indicate whether responses are clustered together or scattered across the range of possible responses. This is shown by the boxplot in Figure 4. With reference to the tentative nature of science, as shown in Figure 4, most respondents were more likely to choose option 4 (Agree) $(\mathrm{Mdn}=4, \mathrm{IQR}=3$ ). This aspect of nature of science is concerned with the idea that scientific knowledge is never absolute or certain but is subject to change (Abd-El-Khalick, et al., 2017; Lederman, 2007). However, the length of the boxplot indicates variability in opinion about this aspect of nature of science with more variability among the lower quartile.

\section{Figure 4}

Boxplot of responses to subscales showing the median scores

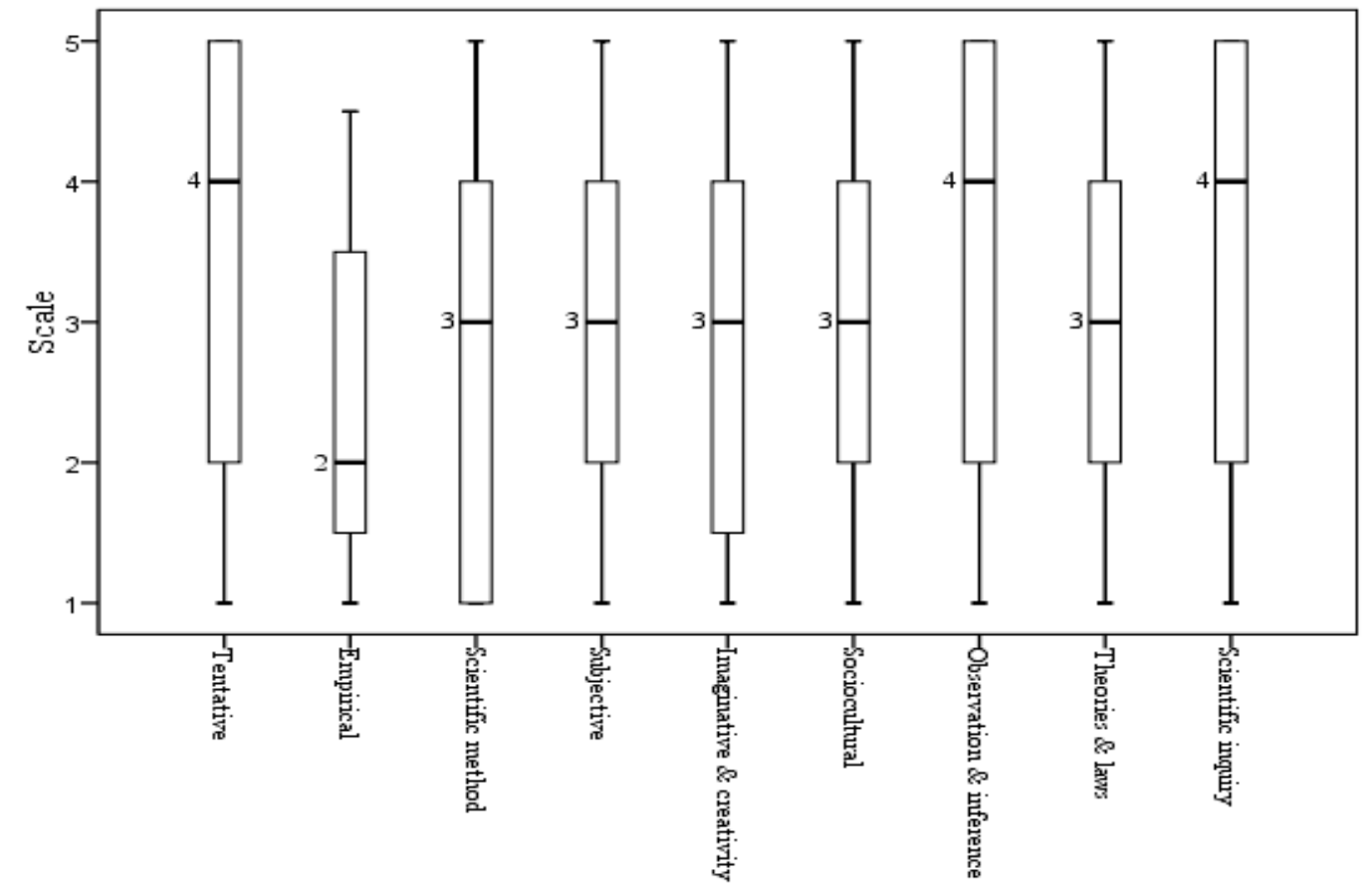

Four items that made up the empirical nature of science subscale were: science does not depend on experiments only to get evidence about the natural world; experiments cannot prove a scientific theory true; science cannot prove anything but is still valuable and; scientific evidence can be obtained from observations of the natural world. Respondents indicated disagreement with this notion $(\mathrm{Mdn}=2, \mathrm{IQR}=2)$. As shown in Figure 4, most respondents were likely to choose option 2 (disagree). This indicate that teachers' beliefs about this aspect of nature of science were not accurate or 
they may have interpreted the items in this scale differently than expected. Experiments are useful tools in science but are not the only means to generate scientific knowledge (McComas, 1996) and scientific knowledge is also derived from the observation of the natural world (Lederman, 2007; Lederman, et al., 2014).

With regards to the scientific method, respondents appear to be unsure about this aspect of the nature of science $(\mathrm{Mdn}=3, \mathrm{IQR}=3)$. Respondents were most likely to choose option 3 (Not sure) and the variability of responses spread more within the lower quartile. This indicates that those who did not choose option 3 mostly disagreed or strongly disagreed. There is a commonly held misconception about science that there exists a single procedure which all scientists follow (Lederman, Abd-El-Khalick, Bell, \& Schwartz, 2002). This was inaccurate as there is no single scientific method that all scientists follow but scientists use various methods in search of scientific knowledge (Abd-El-Khalick, Waters, \& Le, 2008; Abd-El-Khalick, et al., 2017).

The work of scientists is influenced by their theoretical and disciplinary commitments, beliefs, prior work knowledge, training and expectations (Abd-El-Khalick, et al., 2017). This suggests that scientific knowledge is subjective in nature as it is affected by scientists' backgrounds. Respondents' beliefs about this aspect of nature of science appear to be divided. About $48 \%$ of respondents disagreed but roughly equal proportion amounting to $45 \%$ of respondents indicated that they agreed $(\mathrm{Mdn}=3, \mathrm{IQR}=2)$. This is also evident in Figure 4; the upper and lower quartiles appear roughly equal.

Respondents' beliefs about the imaginative and creative nature of science appear to show more uncertainty as well with more variability in the lower quartile $(\mathrm{Mdn}=3$, IQR = 2.5). Scientific knowledge production involves human creativity in terms of scientists inventing explanations and theoretical models and this requires a great deal of creativity by scientists (Abd-El-Khalick, Waters, \& Le, 2008). Creativity and imagination are vital at all stages of a scientific endeavour; from planning and designing through data collection to data interpretation though with variable extent between stages (Wong \& Hodson, 2009).

Scientific knowledge affects and is affected by various cultural elements and spheres including social fabric, trends, prestige, power structures, religion, political and economic factors (McComas, 2008). Respondents' beliefs about this aspect of nature of 
science seem divided. About $32 \%$ of respondents agreed with this notion but a sizeable proportion amounting to $32 \%$ of respondents disagreed $(\mathrm{Mdn}=3, \mathrm{IQR}=2)$.

With reference to the difference between observations and inferences, most respondents were again more likely to choose option 4 (Agree) $(\mathrm{Mdn}=4, \mathrm{IQR}=3$ ). This aspect of nature of science deals with the fact that there is a crucial distinction between observations and inferences although both are scientific processes skills. Observations are descriptions of the natural world that are accessible to the human senses whereby several observers could easily reach an agreement whilst inferences are interpretations or explanations of observations gathered (Lederman, Antink, \& Bartos, 2014; Schwartz, Lederman, \& Crawford, 2004). The response pattern in this subscale is also showing variability in responses about this aspect of nature of science with more variability visible in the lower quartile as evident on Figure 4.

About $35 \%$ of respondents disagreed but sizeable proportion amounting to $48 \%$ of respondents indicated that they agree $(\mathrm{Mdn}=3, \mathrm{IQR}=2)$. This is also evident in Figure 4; the upper and lower quartiles appear roughly similar. There are common misconceptions among students that there is a simplistic and hierarchical relationship between observations, hypotheses, theories and laws of science; and belief that laws have a higher status than theories within a scientific endeavour (Lederman, Abd-El-Khalick, Bell, \& Schwartz, 2002). Theories and laws are related but are distinct kinds of scientific knowledge and for this reason they serve different roles in the scientific enterprise and hence, theories do not in any way become laws, even with additional evidence (Niaz, 2008; McComas, 2008; Lederman, 2007).

Scientific inquiry though closely related, is not necessarily a component of nature of science as it entails the process of how scientists do their work and how the resultant knowledge is generated. This subscale was made up of five items. Respondents were more likely to choose option 4 (Agree) $(\mathrm{Mdn}=4, \mathrm{IQR}=3)$. Similar to some of the subscales discussed, the length of the boxplot indicates variability in opinion about this component of scientific literacy with more variability among the lower quartile (Figure $4)$.

The response pattern revealed an interesting trend in the science teachers' beliefs about the nature of science and scientific inquiry. It shows that teachers' beliefs about the 
tentative nature of science; observations and inferences; and scientific inquiry is quite similar $(\mathrm{Mdn}=4)$. This means teachers' beliefs about these subscales are quite informed because option 4 in the scale represents 'agree'. However, the response pattern for five of the subscales namely, the scientific method; the subjective; imaginative and creative; socio-cultural nature of science and; scientific theories and laws, show substantive amount of uncertainty in the teachers' beliefs $(\mathrm{Mdn}=3)$. This suggests that they were not sure whether to agree or disagree with the statements. Furthermore, teachers' beliefs about the empirical nature of science was more confounding because they generally disagreed with this notion ( $\mathrm{Mdn}=2$ ). It was not possible to ascertain the reasons for this disagreement, whether or not it was a misinterpretation of the items or they simply had different views regarding the empirical nature of science. For this reason, it was imperative to conduct follow-up interview with participants to get clarity on their responses.

\subsubsection{Beliefs across gender, years of experience and science subject taught}

The assessment of normality of the data was conducted and the Shapiro-Wilk test was significant $(\mathrm{p}<.001)$. This suggests that the data was not normally distributed and non-parametric tests would be appropriate to examine the difference in beliefs (Field, 2009). The Mann-Whitney U test was used to examine the difference in beliefs about nature of science and scientific inquiry based on gender. The results showed that there was no significant difference ( $\mathrm{U}=1496, \mathrm{p}=.092$ ). It can be concluded that gender does not influence science teachers' beliefs about nature of science and scientific inquiry. Similarly, the Mann-Whitney U test showed no significant difference in beliefs based on the type of science subject (Biology or Physical Science) teachers taught $(\mathrm{U}=1896, \mathrm{p}=$ $.712)$.

Kruskal-Wallis test was used to examine the difference in beliefs based on ranges of years of science teaching experience. The results once again showed that there was no significant difference in beliefs between the different ranges of years of science teaching experience, $\chi^{2}(3)=6.717, p=.081$, with the mean rank belief score of 83.50 for $0-3$ years, 66.21 for 3-5 years, 53.33 for 5-10 years and 66.70 for $10+$ years of science teaching experience. This suggests that teaching experience did not influence teachers' beliefs about nature of science and scientific inquiry. 


\subsubsection{Conclusion}

This pilot study was carried out in Namibia as part of the initial stages of the validation process in the development an instrument for assessing beliefs about nature of science and scientific inquiry. The initial analyses of the instrument indicate that it has potential to be a reliable instrument for assessing beliefs about the nature of scientific knowledge and scientific inquiry in Namibia, owing to its preliminary very high reliability. This indicates that the items were pulling in one direction in terms of assessing the same construct. However, very high reliability values may indicate unnecessary redundancy of items in the scales. The correlations between subscales that constitute the instrument were generally significantly high. A phenomenon that may indicate that subscales were too similar and therefore the instrument may have poor discriminant validity. The study revealed that science teachers in Namibia have mixed beliefs about the nature of science and scientific inquiry. The study further established that at nonparametric level, gender, science teaching experience and the type of science subject taught did not influence teachers' beliefs about nature of science and scientific inquiry. Some methodological limitations may have influenced the findings of this study. First, respondents were not interviewed to ascertain accurate interpretation of the questionnaire items or to dig deeper and uncover possible explanations for the variability in the their responses (Lederman et al., 2002). It was assumed they interpreted the items as expected. Secondly, it was not possible at this juncture to apply more advanced statistical analyses such factor analysis to the data due to inadequate sample size.

\subsection{Study 2: Exploring the factorial validity of the beliefs about nature of science questionnaire (BANOS)}

\subsubsection{Introduction}

This study was a follow up to Study 1 which served as pilot study. The sample used in Study 1 was quite small and it constituted science teachers for face and content validity reasons. As mentioned in earlier in Study 1, the aim of this study was to develop and validate a new questionnaire 'Beliefs About the Nature of Science' (BANOS) for assessing Grade 12 students' scientific epistemic beliefs based on the eight-generalaspects conceptualisation of nature of science. This age group was chosen following previous studies that assumed that it was somewhat difficult to measure epistemological 
thinking among younger students (Conley et al., 2004). In the context of Namibia, students in Grade 12 are perceived to have developed good competencies in the English language which is the official language for the country and the language of learning and instructions. Such language competencies are presumed sufficient to help them understand the questionnaire's statements, considering that nature of science is not directly taught in Namibian schools.

Namibia as a developing nation needs to keep abreast with the rest of the world in terms of educational reforms particularly in science education. Studies related to beliefs about nature of science or what is also referred to as scientific epistemic beliefs, do not appear to be done in Namibia. This research is hence pioneering in this context. Scientific epistemic beliefs are individual domain-specific beliefs about scientific knowledge and the acquisition of such knowledge. These beliefs have an important role in several aspects of academic learning and achievement (Leal-Soto \& Ferrer-Urbina, 2017; Paechter et al., 2013). It attempts to instigate future research on students' science learning in Namibian basic education particularly using cross-sectional design.

\subsubsection{Methods}

\subsubsection{Instrument}

A new 28-item Likert scale questionnaire termed 'Beliefs About the Nature of Science' (BANOS) emanating from Study 1 (pilot) was used. After the analysis of items functioning in Study 1, some items were dropped, especially those related to scientific inquiry. Scientific inquiry though related to NOS, it is believed to be slightly different and hence warrants separate investigations. Worth noting at this point was that since the analysis of Study 1 was really at the basic level due to sample size and thus employed non-parametric analyses, most of the items were retained and used in this study. It should be highlighted here that this was a new questionnaire being developed and validated in the sense that although ideas for possible items were obtained from existing scales in the literature, no similar questionnaire existed in this format. The theoretical framework for the development of this instrument and the design was explained in Study 1. It should be emphasised here that English is the official language in Namibia and all items in the questionnaire were presented in English. 


\subsubsection{Procedure}

After obtaining ethical approval from the supervising university's institutional review board as well as permission from the gate keepers of the Ministry of Education in Namibia, informed consent forms were signed by participating students in conjunction with their parents or guardians. Data was collected at the beginning of the first school trimester in January. This was deemed the best time to visit schools as they have just started their academic programme. Moreover, this was also in conformity with stringent conditions attached to the research permission; not to disturb academic activities. Scientific epistemic beliefs (beliefs about the nature of science and knowing) were measured with self-report questionnaires using pencil-and-paper method.

The sample was randomly split into two, 503 students' scores were used for exploratory factor analysis (EFA) by means of principal components and 357 students were used confirmatory factor analysis (CFA). This was done because it is advisable to use different samples for EFA and CFA (Cabrera-Nguyen, 2010; Henson \& Roberts, 2006; Worthington \& Whittaker, 2006).

\subsubsection{Results and discussions}

\subsubsection{Reliability}

Based on the results from exploratory factor analysis (see section 5.2.3.3), items that were loading on multiple factors were systematically culled resulting in the final 16 items and five factors. The reliability of scores on the resultant 16-item questionnaire determined using Cronbach's alpha coefficient was $\alpha=.87$. Reliability of individual factors ranged from $\alpha=.72$ to .83 (Table 10). These results suggest that the questionnaire had good overall reliability for the sample used. 
Table 10

Reliabilities of the five factors retained in EFA

\begin{tabular}{lcccc}
\hline Factors & $M$ & $S D$ & No. of items & Cronbach's alpha \\
\hline Subjectivity & 3.25 & 1.05 & 5 & .72 \\
Empirical & 3.19 & 1.05 & 3 & .83 \\
Sociocultural & 2.93 & 1.01 & 3 & .76 \\
Scientific Methods & 3.49 & 0.97 & 3 & .72 \\
Tentativeness & 3.19 & 1.06 & 2 & .75 \\
BANOS & 3.21 & 0.75 & 16 & .87 \\
\hline
\end{tabular}

\subsubsection{Construct validity}

\subsection{Convergent validity}

As explained in section 4.4.2., convergent validity was evaluated using AVE and CR values computed using Microsoft Excel (Gaskin, 2016) and factor loadings from confirmatory factor analysis computed in AMOS. The AVE values for the five factors model ranged from .46 to .64. The CR values ranged from .75 to .81 (Table 11).

\section{Table 11}

Five-factor BANOS model CR, AVE, MSV and correlations

\begin{tabular}{lrrrrrrrr}
\hline Latent factors & CR & AVE & MSV & 1 & 2 & 3 & 4 & 5 \\
\hline Subjectivity & .77 & .52 & 0.55 & .72 & & & & \\
Empirical & .81 & .46 & 0.37 & .58 & .68 & & & \\
Socio-Cultural & .81 & .59 & 0.33 & .56 & .50 & .77 & & \\
Scientific Methods & .75 & .50 & 0.55 & .74 & .61 & .56 & .71 & \\
Tentativeness & .78 & .64 & 0.29 & .54 & .32 & .38 & .48 & .80 \\
\hline
\end{tabular}

Note. The diagonal numbers in italic are the square root of the AVE values

Although the AVE value for one factor was below the acceptable minimum cutoff point of .50 (empirical $=.46)$ convergent validity may still be adequate because all latent factors had CR values above .70 (Fornell \& Larcker, 1981). Malhotra and Dash (2011) also argued that the AVE is often too strict and validity can be established through CR alone. 


\subsection{Discriminant validity}

As evident in Table 11, not all latent factors met the requirements and their discriminant validity may not be adequate. For the five-factor model, although the square root of the AVE for all latent factors were greater than .50, it was not greater than interlatent factor correlations for all factors. The square root of AVE for subjectivity was less than its correlation to scientific methods (Table 11). The MSV values for the two factors (subjectivity and scientific methods) were greater that the AVE values which is contrary to recommendations. However, for the four-factor model (Table 12), all latent factors support the requirements and discriminant validity of all latent factors was adequate, thus construct validity was confirmed.

\section{Table 12}

Four-factor BANOS model CR, AVE, MSV and correlations

\begin{tabular}{lccccccc}
\hline Latent factors & CR & AVE & MSV & 1 & 2 & 3 & 4 \\
\hline Subjectivity & .82 & .43 & 0.42 & .66 & & & \\
Empirical & .82 & .48 & 0.32 & .56 & .69 & & \\
Socio-Cultural & .81 & .59 & 0.42 & .65 & .49 & .77 & \\
Tentativeness & .78 & .64 & 0.33 & .57 & .34 & .38 & .80 \\
\hline
\end{tabular}

Note. The diagonal numbers in italic are the square root of the AVE values

\subsubsection{Exploratory factor analysis}

The assessment of the correlation matrix for the 16 items was found to be appropriate for factor analysis by means of a Bartlett's test of sphericity, $\chi^{2}=3055.17$, $d f=120, \rho<.01$, and the Kaizer-Meyer-Olkin measure of sampling adequacy, KMO = .84. These tests of normality and sampling adequacy indicated that the correlation matrix was of acceptable quality (Glynn et al. 2011).

Exploratory factor analysis $(\mathrm{N}=503)$ using principal components extraction with varimax rotation produced a final interpretable five-factor structure consisting of 16 items after the culling of cross-loading items and the factor solution accounted for $67.73 \%$ of the total variance. The five factors retained based on eigenvalues greater than one and the percentage of variance were: empirical $(5.49,34.30 \%)$, sociocultural $(1.78,11.13 \%)$, subjectivity $(1.36,8.50 \%)$, scientific methods $(1.19,7.44 \%)$, and tentativeness $(1.02$, $6.37 \%)$. Table 13 shows the rotated factor loadings. 


\section{Table 13}

Rotated factor matrix showing the structure of the resultant BANOS questionnaire

\begin{tabular}{llllll}
\hline & \multicolumn{5}{c}{ Factor } \\
\cline { 2 - 6 } Factors & 1 & 2 & 3 & 4 & 5 \\
\hline
\end{tabular}

\section{Empirical}

$\begin{array}{llllll}\text { Scientists can use human senses to make } & .830 & -.054 & .164 & -.073 & .117\end{array}$

scientific claims (observations).

$\begin{array}{lllllll}\text { Experiments support rather than prove } & & .770 & .031 & .186 & .075 & .123\end{array}$

scientific claims.

$\begin{array}{llllll}\text { Scientific theories are conclusions about } & .737 & .155 & -.005 & .227 & .151\end{array}$

observable phenomena.

$\begin{array}{lllllll}\text { Experiments are not the only source of } & & .724 & .208 & .171 & .230 & -.070\end{array}$

scientific evidence.

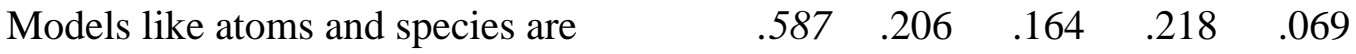

products of human imagination.

\section{Socio-cultural}

Science is influenced by cultures.

The values of the culture determine how

science is practiced.

$\begin{array}{llllll}\text { Science is influenced by economic factors } & .307 & .754 & -.043 & .203 & .086\end{array}$ such as research funding.

\section{Subjective}

Scientists can look at the same evidence

$\begin{array}{lllll}.179 & .079 & .793 & .154 & .103\end{array}$

or set of data and come up with different conclusions.

Scientists' backgrounds and beliefs

$\begin{array}{rrrrr}.049 & .820 & .186 & .061 & -.009 \\ .069 & .760 & .247 & .057 & .193\end{array}$

influence their work.

Scientists use their creativity to analyse data.

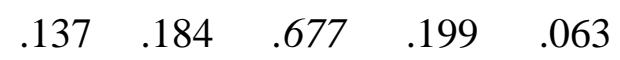

\section{Scientific methods}

There is no single step-by-step method

$\begin{array}{lllll}.192 & .095 & .148 & .817 & .032\end{array}$

that all scientists in the world follow.

Scientists use different procedures to

study the natural world.

Scientific laws are descriptions of the

relationship among observable

phenomena.

\section{Tentative}

$\begin{array}{lllll}.233 & .074 & .211 & .778 & .166\end{array}$

$\begin{array}{lllll}.030 & .375 & .362 & .534 & .220\end{array}$ 
$\begin{array}{llllll}\text { Some scientific ideas today were different } & .124 & .176 & .084 & .088 & .870\end{array}$ in the past.

$\begin{array}{lllllllll}\text { Scientific ideas can change due to } & & & & .138 & .039 & .203 & .146 & .830\end{array}$ advances in technology.

Note. Factor loadings of items in italic all exceeded the .40 criterion on their targeted factor.

However, using the eigenvalue greater than one criteria only may not be sufficient to decide on the number of factors to retain (Cabrera-Nguyen, 2010). Hence, parallel analysis was also employed. This procedure entails randomly ordering the respondents' item scores and conduct a factor analysis on both the original data set and the randomly ordered scores. The number of factors to retain is determined by comparing the eigenvalues determined in the original data set and in the randomly ordered data set. The factors are retained if the original eigenvalue is larger than the eigenvalue from the random data (Worthington \& Whittaker, 2006).

\section{Table 14}

Raw data eigenvalues, means and percentile random data eigenvalues

\begin{tabular}{cccc}
\hline Number of items & Raw Data & Means & Random data \\
\hline $\mathbf{1}$ & $5.488^{*}$ & 1.317 & $1.381^{*}$ \\
$\mathbf{2}$ & $1.780^{*}$ & 1.250 & $1.295^{*}$ \\
$\mathbf{3}$ & $1.359^{*}$ & 1.200 & $1.240^{*}$ \\
$\mathbf{4}$ & $1.191^{*}$ & 1.155 & $1.190^{*}$ \\
$\mathbf{5}$ & 1.018 & 1.114 & 1.144 \\
$\mathbf{6}$ & 0.830 & 1.077 & 1.105 \\
$\mathbf{7}$ & 0.684 & 1.042 & 1.072 \\
$\mathbf{8}$ & 0.558 & 1.008 & 1.037 \\
$\mathbf{9}$ & 0.520 & 0.975 & 1.001 \\
$\mathbf{1 0}$ & 0.461 & 0.942 & 0.970 \\
$\mathbf{1 1}$ & 0.428 & 0.909 & 0.937 \\
$\mathbf{1 2}$ & 0.421 & 0.876 & 0.903 \\
$\mathbf{1 3}$ & 0.349 & 0.842 & 0.871 \\
$\mathbf{1 4}$ & 0.343 & 0.807 & 0.838 \\
$\mathbf{1 5}$ & 0.322 & 0.767 & 0.802 \\
$\mathbf{1 6}$ & 0.249 & 0.720 & 0.760 \\
\hline
\end{tabular}

$* \rho=.05$

The analysis revealed that only four factors (Table 14) had eigenvalues that were statistically significant for retention at $\rho=.05$ (O'connor, 2000). The resultant scree plot 
also shows that only four factors can be seen at or above the intersections of the graphs thus supporting the retention of four factors (Figure 5).

\section{Figure 5}

Scree plot comparing raw and random data eigenvalues for factor retention

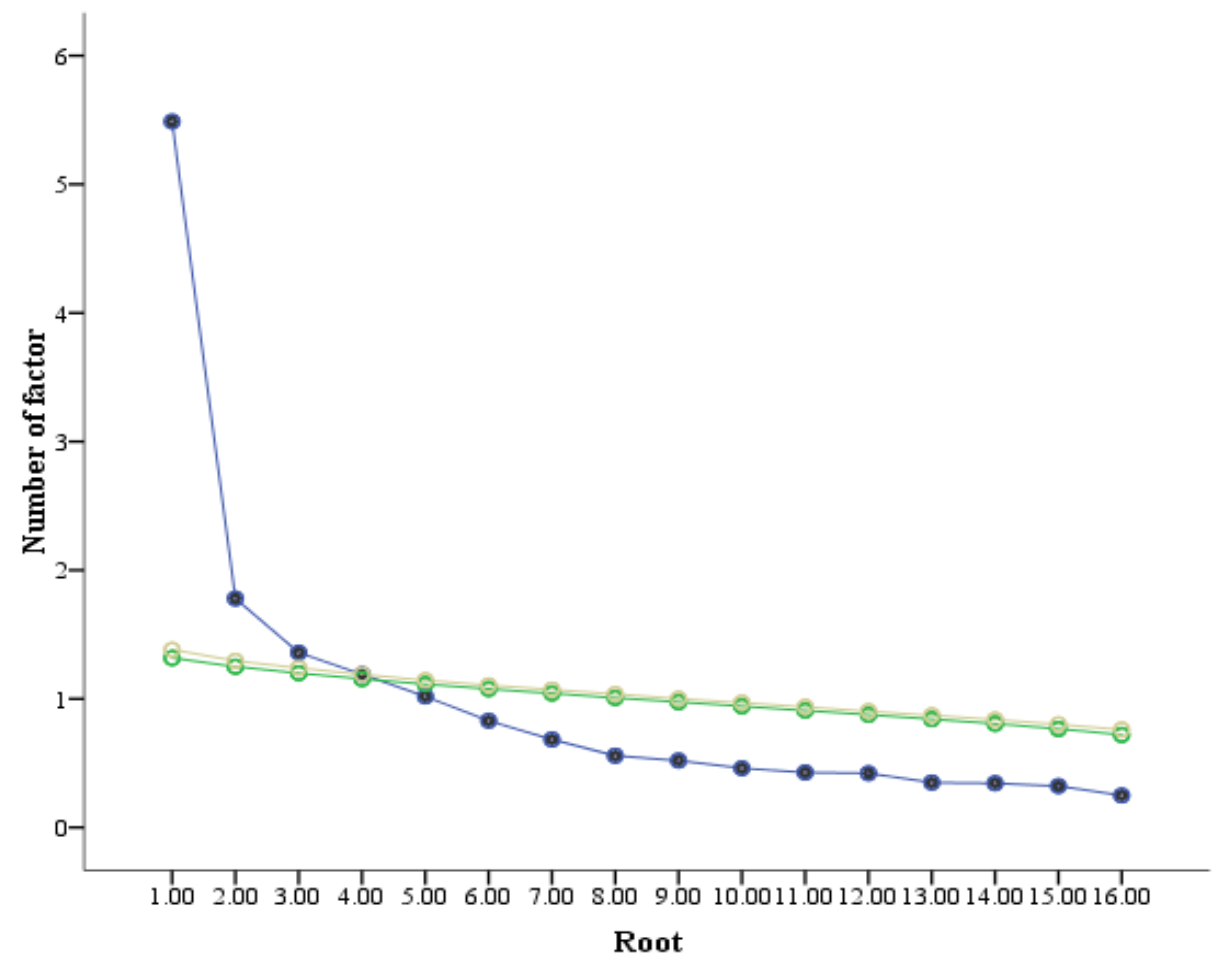

\subsubsection{Confirmatory factor analysis}

Using a separate sample of 357 students, confirmatory factor analysis was performed on the 16 items to validate the measurement model on which construct validity was assessed. In this study, the skewness and kurtosis value were found to be within the recommended range, suggesting that the data is coherent with normal distribution. The assessment of the model fit was done using the standardisation method where all covariances were set to 1.0 (Teo, 2013). The goodness of fit of the measurement models (hypothesized five and four-factor models) were assessed by three absolute ( $\chi^{2}$, RMSEA, \& SRMR) and two incremental (TLI \& CFI) fit indices.

Confirmatory factor analysis $(\mathrm{N}=357)$ results showed that the five-factor model had poor statistical fit for the data, with the following fit indices: $\chi^{2} / d f=0.5024$, TLI $=$ 
$.80, \mathrm{CFI}=.85, \mathrm{RMSEA}=0.11, \mathrm{SRMR}=0.07$. The standardised factor loadings and correlations of the factors from AMOS are shown in Figure 6.

\section{Figure 6}

The standardised factor loadings and correlations of the five-factor NOS aspects model

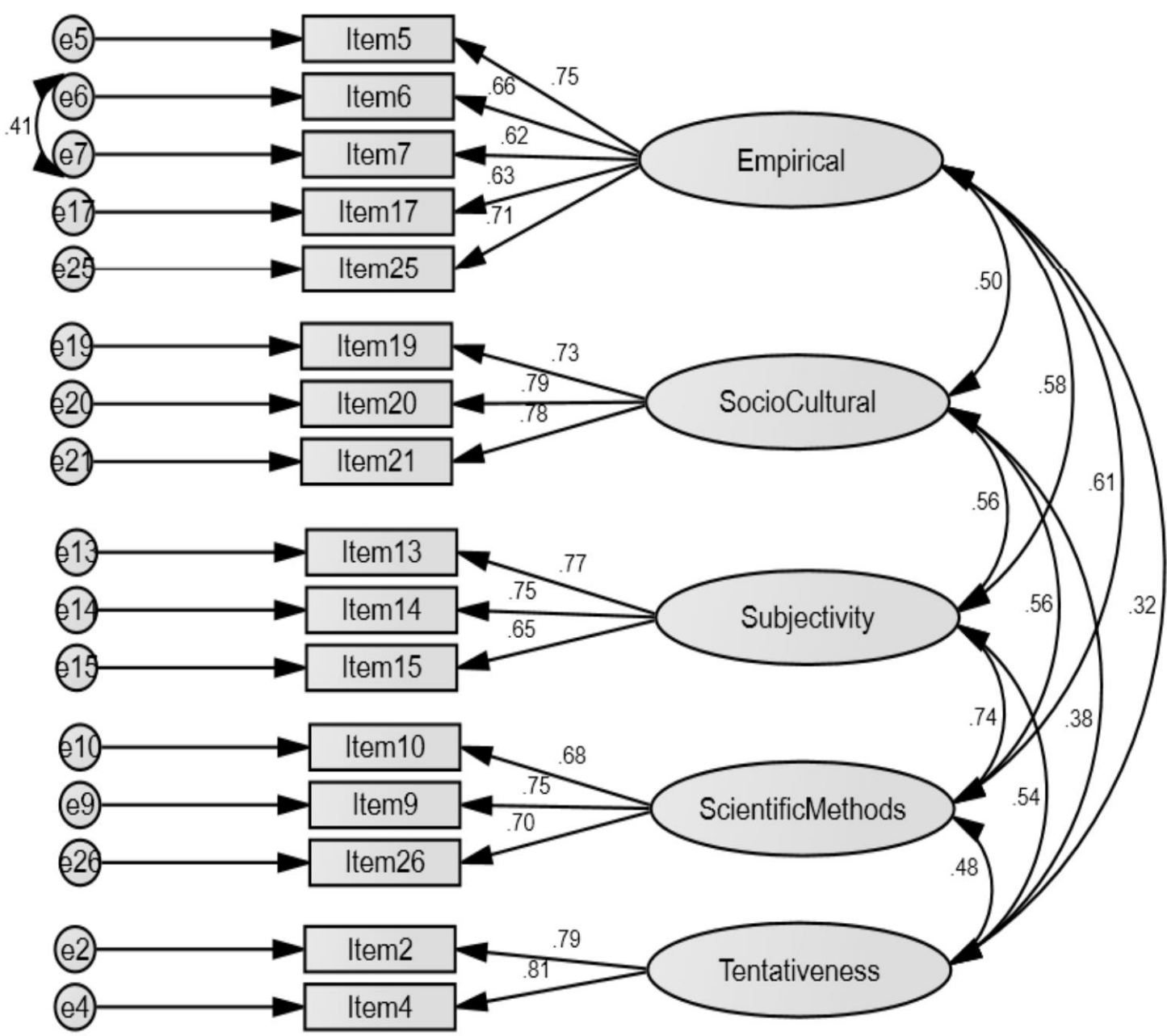

However, the four-factor model showed better statistical fit for the data, though still below recommended thresholds, with the following fit indices: $\chi^{2} / \mathrm{df}=4.163$, TLI $=$ $.85, \mathrm{CFI}=.88, \mathrm{RMSEA}=0.09, \mathrm{SRMR}=0.06($ Figure 7$)$. 


\section{Figure 7}

The standardised factor loadings and correlations of the four-factor NOS aspects model

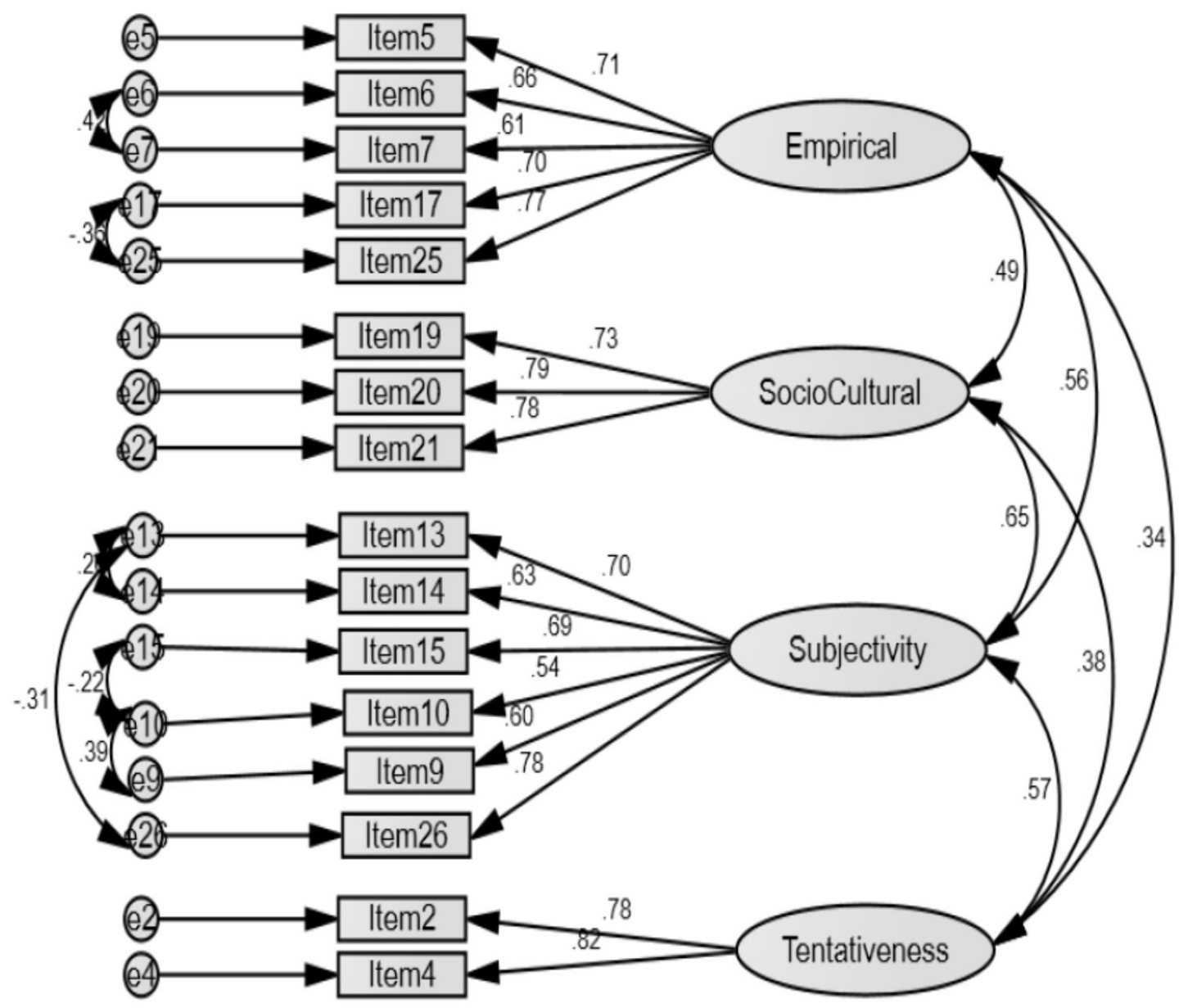

It is not surprising that a better measurement model had less factors than hypothesized. Conley et al., (2004) also found that students' scientific epistemic beliefs had four dimensions. Moreover, some of the dimensions were highly correlated. High correlations among epistemic belief scales points to redundancy in the measurement. In this sample, the highest correlation in the five-factor model was between subjectivity and scientific methods $(r=.74)$ and between sociocultural and subjectivity $(r=.65)$ in the four- factor model. However, proponents of the eight general aspects conceptualisation had also acknowledged that the general aspects of nature of science were intricately intertwined (Abd-El-Khalick et al., 2017) and as such was visible in this study. 


\subsubsection{Conclusion}

This study set out to assess the factorial validity of the hypothesised eight dimensions underlying nature of science. The findings indicate that the eight dimensions model that had been qualitatively suggested could not be supported at EFA level. This could be attributed to the inherent similarity among the dimensions of nature of science. However, the questionnaire had adequate construct validity and reliability though it had poor fit statistics values lower than the recommended thresholds, except for the $\chi^{2} / d f$ and SRMR (Hair et al., 2016). It can be concluded that the questionnaire showed potential to be psychometrically valid. However, it needs to be examined for possible flaws that affected measurement model fit.

\subsection{Study 3: A cross-cultural validation of adapted questionnaire for assessing motivation to learn science among Grade 12 students in Namibia}

\subsubsection{Introduction}

Science education reforms in recent years have been advancing the development of students' scientific literacy (National Academy of Sciences, 2010; National Research Council, 2007). The importance of scientifically literate citizens who can make sense of the scientific issues that confront them cannot be overemphasised (Glynn et al., 2009). However, research shows that motivation decreases towards middle school (Chen et al., 2014; Józsa et al., 2017). For this reason, the role of students' motivation to learn has increasingly been receiving attention (Chen, 2012; Wang \& Liou, 2017).

A search for studies including online publications in repositories of local institutions in Namibia as well as on several international databases did not yield any reports of similar studies done in Namibia. Most of what is known about students' motivation to learn science comes from other countries, particularly the developed world. Due to the considerable difference in the educational and cultural context in Namibia, the results from studies in developed world may or may not be transferable for Namibia. Thus, this study sought to instigate research on motivation towards science learning among Namibian students.

The aim of this study was therefore to validate an adapted form of the Students' Motivation Towards Science Learning (SMTSL) questionnaire that was put forward by 
Tuan, Chin, and Shieh (2005), using a sample of Namibian Grade 12 students. This questionnaire was chosen for adaptation because of its high reliability with the original Taiwanese sample. Secondly, the original SMTSL questionnaire was administered to junior high school students in English, a second language to the Taiwanese respondents. English is the official language in Namibia but not the home language for the Namibian respondents. All items in the adapted questionnaire were also presented in English.

The original instrument consisted of 35 items from six factors. It's reliability (Cronbach's alpha) was $\alpha=.89$ while subscale reliability ranged from $\alpha=.70$ to .89 . Among the six factors, five have been chosen for this study. These factors were: (1) selfefficacy, (2) science learning values, (3) active learning strategies, (4) achievement goal and (5) learning environment stimulation.

\subsubsection{Methods}

\subsubsection{Procedure}

The sample was randomly split into two, 403 students' scores were used for exploratory factor analysis (EFA) by means of principal components and 352 students were used for confirmatory factor analysis (CFA). This was done because it is advisable to use different samples for EFA and CFA (Cabrera-Nguyen, 2010; Henson \& Roberts, 2006; Worthington \& Whittaker, 2006).

All participating students were in senior secondary level (Grade 12). Students responded to the items using the paper-and-pencil method. Students in the two regions come from different socio-economic backgrounds. However, the general characteristics of students are similar because the two regions are predominantly rural areas. On average, students took approximately 10 minutes to complete the questionnaire.

\subsubsection{Instruments}

The 19-item questionnaire was adapted from the students' motivation towards science learning (SMTSL) questionnaire (Tuan et al., 2005). During the adaptation, an attempt was made to shorten the questionnaire in order to mitigate respondents' fatigue (Hochheimer et al., 2016; Reilly-Shah, 2017). Factors such as self-efficacy had seven items in the original version but five of them were in the negative (reverse) format, (i.e. 
I am not confident about understanding difficult science concepts; No matter how much effort I put in, I can't learn science etc) which was not desirable in this study. Such items were rewritten in the positive format and ended up with the final four items for this factor (see Table 15). Factors such as active learning strategies and learning environment stimulation had eight and six items respectively. In the quest to come up with a shorter questionnaire, such items were combined and/or rephrased. For the reminder of the factors, items were rephrased by mainly replacing the word 'course' with 'lesson'. The original version of the SMTSL questionnaire consisting of thirtyfive items can be found in the Tuan et al. (2005) article published in International Journal of Science Education.

Due to the adaptation of the questionnaire and the use of a sample different from the original sample, it is recommended to examine the psychometric properties of the adapted instrument in order to assess its measurement precision and validity (Schraw, Bendixen, \& Dunkle, 2002).

Students were asked to indicate the extent to which they were willing to learn science. Using recommendations from DeVellis (2003), the items were positively worded and unambiguously short, declarative statements without jargon. Each item was a fivepoint Likert scale of temporal frequency (Glynn et al., 2009), wherein $1=$ Never; $2=$ Rarely; 3 = Sometimes; 4 = Usually and $5=$ Always. Each item had to be answered by means of circling the number corresponding to the option that best described their beliefs. All items were worded in a positive direction so that a high score on a particular factor indicates a high level of motivation. The adapted questionnaire was given to two university lecturers of English and Linguistics who proof read and made suggestions to the final questionnaire.

Students' responses were captured manually and incomplete questionnaires were discarded, hence no missing data are found in the data set.

Some methodological limitations may have influenced the findings of this study. First, students were not interviewed to ascertain accuracy of interpretation of the questionnaire items. It was assumed that students interpreted the items as expected. Secondly, factor retention in EFA was based on eigenvalue greater than 1 criterion only which is suspect to underestimating the number of factors (Henson \& Roberts, 2006) and 
thirdly, the indices of model fit obtained from CFA might be biased due to departure from multivariate normality (Cabrera-Nguyen, 2010).

\subsubsection{Results and discussions}

\subsubsection{Reliability}

The overall reliability of the scores on the adapted questionnaire was $\alpha=.79$. The reliability of individual factors ranged from $\alpha=.66$ to .77 (Table 15). Suggesting that the questionnaire had reasonable overall reliability for the sample used although some individual factors showed reliability values below recommended thresholds (achievement goal $\alpha=.67$ and active learning strategies $\alpha=.66$ ).

\section{Table 15}

Reliability analyses of the scales and the questionnaire

\begin{tabular}{lcccc}
\hline Latent factors & $\begin{array}{c}\text { No. of } \\
\text { items }\end{array}$ & CR & AVE & $\begin{array}{c}\text { Cronbach's } \\
\text { Alpha }\end{array}$ \\
\hline Achievement goal & 4 & .65 & .32 & .67 \\
Learning environment & 4 & .78 & .47 & .77 \\
stimulation & & & & \\
Self-efficacy & 4 & .73 & .42 & .70 \\
Active learning strategies & 3 & .72 & .40 & .66 \\
Science learning value & 4 & .63 & .37 & .73 \\
Overall & 19 & & & .79 \\
\hline
\end{tabular}

However, this finding is not surprising because the reliability of the adapted questionnaire in the Namibian cultural context was quite similar to the reliability in previous studies (Dermitzaki, Stavroussi, Vavougios, \& Kotsis, 2013; Yilmaz \& Çava, 2007) that adapted the same questionnaire in different cultural settings of Turkey and Greece respectively.

\subsubsection{Construct validity}

\subsection{Convergent validity}

Convergent validity was evaluated using AVE and CR values computed using Microsoft Excel (Gaskin, 2016) and factor loadings from confirmatory factor analysis computed in AMOS. The AVE values for the five latent factors ranged from 32 to .47 . The CR values ranged from .63 to .78 (Table 16). 
Although the AVE values for all latent factors were below the preferred minimum cut-off point of .50 , convergent validity may still be adequate because most factors had AVE values above .40 (minimal acceptance level) except for two factors (achievement goal $=.32$ and science learning value $=.37)$ and all factors had $C R$ values above .60 (Fornell \& Larcker, 1981).

\subsubsection{Discriminant validity}

Discriminant validity was assessed by comparing the square root of the AVE with the correlation of latent factors (Hair et al., 2016). Table 16 shows the correlation matrix, the AVE values, the square root of the AVE values and the maximum shared variance (MSV) of each latent factor.

\section{Table 16}

Factor correlations and square root of the average variance extracted

\begin{tabular}{lccccccccc}
\hline Latent factors & $M$ & $S D$ & AVE & MSV & AG & LES & SE & ALS & SLV \\
\hline Achievement goal & 4.42 & 0.54 & .32 & .28 & .57 & & & & \\
Learning environment & 3.61 & 0.73 & .47 & .10 & .17 & .69 & & & \\
stimulation & & & & & & & & & \\
Self-efficacy & 3.82 & 0.64 & .42 & .16 & .34 & .32 & .65 & & \\
Active learning strategies & 4.16 & 0.57 & .40 & .15 & .38 & .13 & .29 & .63 & \\
Science learning value & 4.21 & 0.57 & .37 & .28 & .53 & .31 & .40 & .25 & .61 \\
\hline
\end{tabular}

Note. The diagonal numbers in italic are the square root of the AVE values

As evident in Table 16, the square root of the AVE (in italic) was greater than .50 and greater than inter-latent factor correlations within the model. All latent factors support these requirements and the discriminant validity of all latent factors is confirmed.

\subsubsection{Exploratory factor analysis}

Exploratory factor analysis is meant for cases where the relationships between the observed and latent variables are uncertain (Glynn et al., 2011). It was necessary to apply exploratory factor analysis to assess students' responses to the questionnaire because it was adapted from an existing questionnaire (STMSL) that was originally used with a different culture and items were rewritten to suit students' comprehension in the Namibian context. The assessment of the correlation matrix for the 19 items was found 
to be appropriate for factor analysis by means of a Bartlett's test of sphericity, $\chi^{2}=$ 1598.62, $d f=171, \mathrm{p}<.001$, and the Kaizer-Meyer-Olkin measure of sampling adequacy, $\mathrm{KMO}=.77$. These tests of normality and sampling adequacy indicated that the correlation matrix was of acceptable quality (Glynn et al., 2011).

Exploratory factor analysis was conducted on the 19 items $(\mathrm{N}=403)$ using principal components extraction with varimax rotation. Although direct oblimin rotation was also explored with similar results, varimax rotation produces a factor structure that is clearly interpretable (Henson \& Roberts, 2006). The analysis yielded five factors with eigenvalues greater than 1 and the factor solution accounted for $56.1 \%$ of the total variance. Table 18 shows the factor loadings.

\section{Table 17}

Rotated factor matrix of the five factors of motivation

\begin{tabular}{|c|c|c|c|c|c|}
\hline \multirow[b]{2}{*}{ Factors and items } & \multicolumn{5}{|c|}{ Factors } \\
\hline & LES & SE & ALS & $\mathrm{AG}$ & SLV \\
\hline \multicolumn{6}{|l|}{ Learning environment stimulation (LES) } \\
\hline $\begin{array}{l}\text { I am willing to participate in science lessons } \\
\text { because the teacher pays attention to me }\end{array}$ & .800 & .038 & .038 & .022 & .041 \\
\hline $\begin{array}{l}\text { I am willing to participate in science lessons } \\
\text { because learners are involved in discussions }\end{array}$ & .785 & .015 & .048 & .012 & .092 \\
\hline $\begin{array}{l}\text { I am willing to participate in science lessons } \\
\text { because the content is exciting }\end{array}$ & .721 & .217 & .007 & .073 & .117 \\
\hline $\begin{array}{l}\text { I am willing to participate in science lessons } \\
\text { because the teacher does not put a lot of pressure } \\
\text { on me }\end{array}$ & .713 & .077 & .074 & .020 & .065 \\
\hline \multicolumn{6}{|l|}{ Self-efficacy (SE) } \\
\hline $\begin{array}{l}\text { I am confident about understanding difficult } \\
\text { science concepts }\end{array}$ & .121 & .827 & .049 & .096 & .048 \\
\hline $\begin{array}{l}\text { I am sure that I can understand science content } \\
\text { even when it is difficult }\end{array}$ & .050 & .790 & .109 & .021 & .082 \\
\hline I always try to understand science concepts & .176 & .701 & .178 & .089 & .083 \\
\hline $\begin{array}{l}\text { I try to understand by myself rather than ask for } \\
\text { help with science tasks }\end{array}$ & .010 & .563 & -.079 & .143 & .062 \\
\hline \multicolumn{6}{|l|}{ Active learning strategies $(A L S)$} \\
\hline $\begin{array}{l}\text { When I do not understand a science concept, I } \\
\text { discuss with others to clarify my understanding }\end{array}$ & .005 & .085 & .778 & .142 & .046 \\
\hline $\begin{array}{l}\text { When I do not understand a science concept, I use } \\
\text { other sources of information }\end{array}$ & .087 & .048 & .739 & .042 & -.063 \\
\hline $\begin{array}{l}\text { When I meet science concepts that I do not } \\
\text { understand, I still try to learn them }\end{array}$ & -.025 & .049 & .671 & .107 & .105 \\
\hline
\end{tabular}


$\begin{array}{llllll}\text { When I learn new science concepts, I connect them } & .105 & .019 & .659 & .036 & .68\end{array}$ to my previous understanding

Achievement goal (AG)

$\begin{array}{llllll}\text { I feel good when my science teacher accepts my } & .051 & .050 & .015 & .764 & .176\end{array}$

ideas during science lessons

$\begin{array}{llllll}\text { I feel good when other learners accept my ideas } & .189 & .022 & .075 & .704 & -.090\end{array}$

during science lessons

I feel good when I am able to solve a difficult $\quad \begin{array}{llllll}-.013 & .149 & .115 & .632 & .233\end{array}$

science task

$\begin{array}{llllll}\text { I feel very good when I get good marks in science } & -.124 & .203 & .185 & .621 & .163\end{array}$

tests

Science learning value (SLV)

$\begin{array}{llllll}\text { I think learning science is important because it } & .085 & .151 & .051 & .084 & .769\end{array}$

stimulates my thinking

$\begin{array}{llllll}\text { I think it is important to learn science because it } & .094 & .041 & .105 & .160 & .762\end{array}$

provides an opportunity to satisfy my own

curiosity

$\begin{array}{llllll}\text { I think it is important to participate in science } & .109 & .060 & .077 & .122 & .678\end{array}$ activities during learning

Note. Factor loadings of items in italic all exceeded the 0.32 criterion on their targeted factor.

All items in Table 18 loaded above .50 (loading values in italic) on their respective factor; none of the cross-loadings exceeded .32 (Worthington \& Whittaker, 2006). The eigenvalues and the percent of variance explained by each factor were: learning environment stimulation $(4.0,21.09 \%)$, self-efficacy $(2.16,11.34 \%)$, active learning strategies $(1.71,9.02 \%)$, achievement goal $(1.59,8.35 \%)$, and science learning value $(1.19,6.27 \%)$.

\subsubsection{Confirmatory factor analysis}

Using a separate sample of 352 students, confirmatory factor analysis was performed on the 19 items to validate the measurement model in which construct and discriminant validity were assessed. To assess the assumption of normality for estimating the measurement model, the skewness and kurtosis values were used. The data is considered normally distributed if it does not deviate severely from normality. In this study, the skewness and kurtosis value were found to be within the recommended range, suggesting that the data is coherent with normal distribution. The assessment of the model fit was done using the standardisation method where all covariances were set to 1.0 (Teo, 2013). The goodness of fit of the measurement model (hypothesized five-factor model) 
was assessed by three absolute ( $\chi^{2}$, RMSEA, $\&$ SRMR) and two incremental (TLI \& CFI) fit indices, as specified below.

The analysis of the 19-item five-factor model yielded fit indices of $\chi^{2} / d f=1.54$, for the data, RMSEA $=0.039, \mathrm{SRMR}=0.047, \mathrm{TLI}=.94$ and $\mathrm{CFI}=.95$, indicating that the measurement model fit the data well. The standardised factor loadings and correlations among the factors from AMOS are shown in Figure 8. Factor loadings are estimated correlations which indicate how well a given item measures its corresponding factor (Glynn et al., 2011). 


\section{Figure 8}

Standardised loadings and correlations of the five factors of motivation

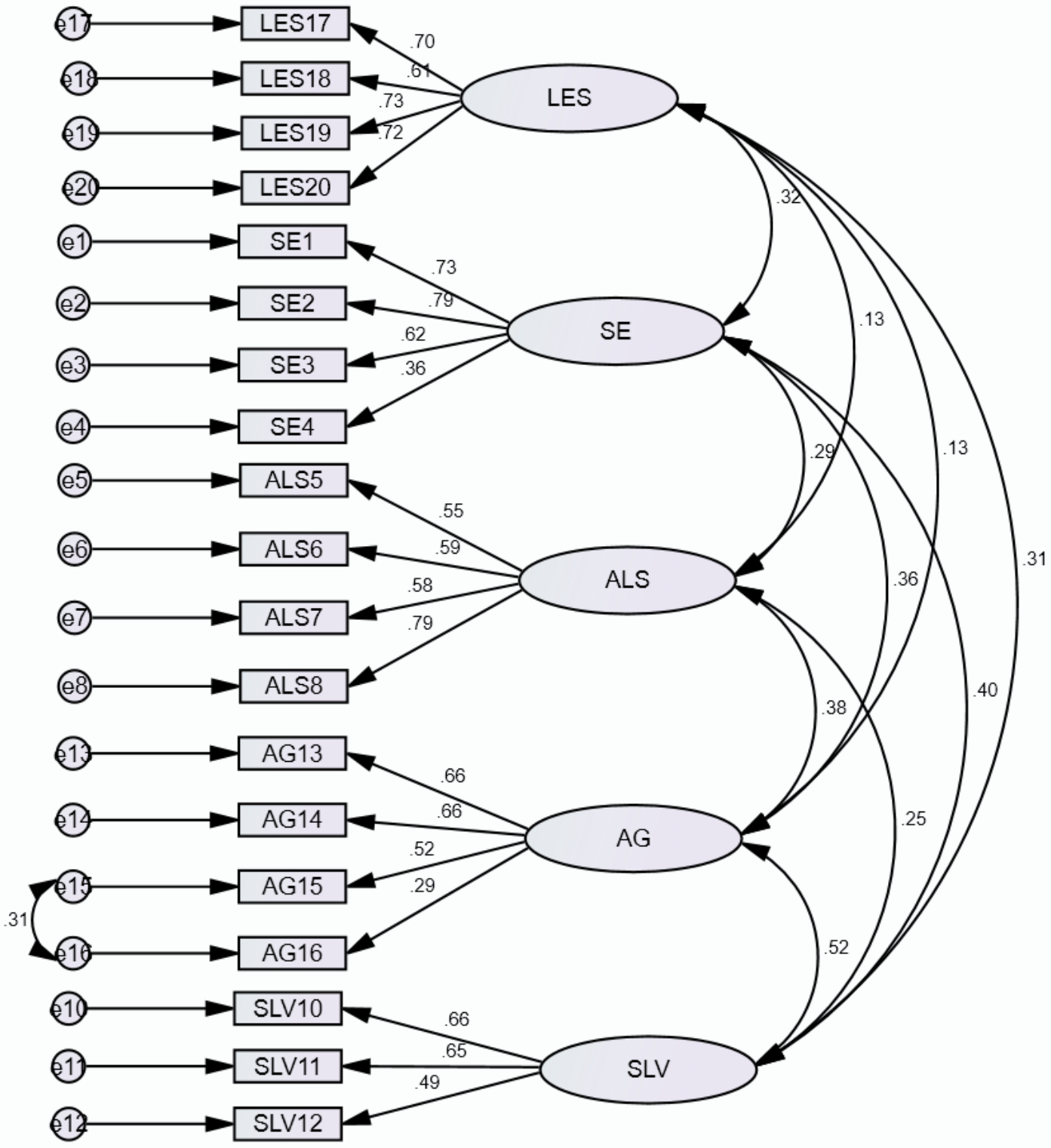

Note. LES = learning environment stimulation, SE = self-efficacy, ALS = active learning strategies, $\mathrm{AG}=$ achievement goal, $\mathrm{SLV}=$ science learning value; and e = error terms

In comparison with similar previous studies (Yilmaz \& Cava, 2007; Dermitzaki, Stavroussi, Vavougios \& Kotsis, 2013), the present study showed better model fit indices. The two previous studies adapted the SMTSL as a whole into Turkish and Greek 
respectively, while in this study, the adaptation maintained the language (English) of the instrument and used only five out the six factors in the original questionnaire.

\subsubsection{Conclusion}

This study examined the factorial validity of the five-factor model of the adapted students' motivation towards science learning (SMTSL) questionnaire on a sample of Grade 12 students in Namibia. These findings indicate that the adapted questionnaire may have adequate construct validity although convergent validity being one of the criteria for determining construct validity showed marginally acceptable properties in terms of latent factors having AVE values below the preferred minimum cut-off point of .50. In support, most of the factors had CR values above .70 with only two factors not meeting this criterion. Nonetheless, those two factors had CR values above .60 which is a moderately acceptable level of reliability. It is argued that the AVE is often too strict and on the basis of CR alone the researcher may conclude that the convergent validity of the construct may still be adequate, even though more than $50 \%$ of the variance is due to error (Malhotra \& Dash, 2011). Similarly, the reliability of responses in terms of both alpha coefficient and composite reliability estimates were reasonable although the estimates for some factors were below the preferred cut-off point of .70. The measurement model shows acceptable fit for the data with good fit statistics such as $\chi^{2} / d f$, RMSEA, SRMR, TLI and CFI. In comparison with similar previous studies, the present study showed better model fit indices.

The findings suggest that the adapted instrument is suitable for assessing Namibian Grade 12 science students' motivation to learn science particularly in large scale crosssectional studies. The questionnaire may also be combined with other scales for data collection in which comparisons of motivation to learn science with other variables such as demographic, achievement in science, and scientific epistemic beliefs. This study focused on the exit phase of the Namibian basic education phase. At the moment, there are no formal assessments for students' motivation to learn generally within the Namibian education system. However, knowing what motivates students to learn can help inform the development and improvement of current education policies. Given the paucity of similar instruments in the Namibian cultural context, this adaptation and validation may serve as a gateway for future similar studies particularly focusing on other, lower, stages 
of schooling. Copyrights for the original instrument is with the International Journal of Science Education. However, the authors were acknowledged accordingly in the present study and the adapted items for this study can be found in Table 18 under the subheading exploratory factor analysis.

\subsection{Study 4: Instrument adaptation, cross-cultural validation and assessment of students' scientific epistemic beliefs}

\subsubsection{Introduction}

The conceptualisation of scientific epistemic beliefs (SEB) overlaps with general aspects of nature of science (NOS) discuss in section 2.3 and in Study 2. Based on the similar research problem highlighted in Study 1 and 2, this study attempted to adapt and validate the SEB conceptualisation in the cultural context of Namibia. Epistemic beliefs refer to individual's beliefs about knowledge and knowing. This aspect of scientific literacy has been neglected yet the broad curriculum advocates for development of scientific understanding needed to help students develop $21^{\text {st }}$ century skills. Students need to develop sophisticated scientific epistemic beliefs in order to understand the nature of scientific knowledge and how such knowledge is constructed (Gu \& Belland, 2015). To access students' understanding of the nature of scientific knowledge and knowing an assessment of their scientific epistemic beliefs is necessary. To achieve this, reliable and valid measures are required. Numerous epistemic beliefs measures have been developed and adapted in recent years (Buehl, Alexander, \& Murphy, 2002; Conley et al., 2004; Murphy et al., 2007; Schraw et al., 2002; Tsai et al., 2011). However, a review of relevant literature suggests that these measures were either developed or adapted in the western world and Asia. None of such measures were tested in the cultural context of Namibia.

The aim of this study was therefore to adapt and validate the scientific epistemic beliefs (SEB) questionnaire developed by Conley, Pintrich, Vekiri and Harrison (2004), using the Namibian senior secondary school (Grades 11 and 12) students.

The original questionnaire was developed for a particular culture and in this study, it has been adapted for a different culture. This necessitates a cross-cultural validation similarly to Study 3. 
Huang and Wong (2014) asserted that it might be challenging to adapt an instrument in a culturally relevant and comprehensible form while maintaining the meaning of the original items.

In the context of this study, the adaptation entailed the removal of items that were deemed repetitive in an effort to shorten the questionnaire. Shortening the questionnaire was deemed beneficial as it could reduce redundancy suspected in the original questionnaire as well as mitigating respondents' fatigue (Hochheimer et al., 2016; ReillyShah, 2017). Wordy items were rephrased. Some words such as "stuff" were replaced with "things" for clarity. The development dimension showed lower reliability $(\alpha=.66)$ compare to other three dimensions in the original SEB questionnaire. For this reason, the item "Ideas in science sometimes change" was replaced with one that reads "Scientific ideas may change because technology may lead to new findings".

The original version of the SEB questionnaire consisting of 26 items can be found in the Conley et al. (2004) article published in the Contemporary Educational Psychology Journal. The final adapted questionnaire had 22 items in total (Table 18).

\section{Table 18}

Comparison of items composition of original and adapted SEB questionnaire

\begin{tabular}{lcc}
\hline Dimensions of beliefs & $\begin{array}{c}\text { Original SEB } \\
\text { (no. of items) }\end{array}$ & $\begin{array}{c}\text { Adapted SEB } \\
\text { (no. of items) }\end{array}$ \\
\hline Source & 5 & 4 \\
Certainty & 6 & 5 \\
Development & 6 & 6 \\
Justification & 9 & 7 \\
Total & 26 & 22 \\
\hline
\end{tabular}

Due to the adaptation of the questionnaire and the use of a sample different from the original one, it is recommended to examine the psychometric properties of the adapted instrument in order to assess its measurement precision and validity (Schraw et al., 2002).

Previous studies that used the same questionnaire (Liang \& Tsai, 2010; Tsai et al., 2011) confirmed its factorial structure suggesting that we could formulate an a priori hypothesis to test the questionnaire's factorial structure signifying that the four dimensions of beliefs proposed by Conley et al. (2004) should form distinct factors. 
Hence only confirmatory factor analyses were used to assess measurement model fit for the data in this study.

\subsubsection{Methods}

\subsubsection{Procedure}

All participating students were in senior secondary level (Grades 11 and 12). With the assistance of the teachers, students responded to the items using the paper-and-pencil method. Students in the senior secondary level were preferred considering their anticipated proficiency in the English language compare to younger students. On average, students spent approximately 10 minutes to complete the questionnaire. Students were assigned numbers corresponding to their position in their class list. This enabled the researcher to link their SEB questionnaire responses to their mid-year science (Biology and Physical Science) marks obtained from school records. Science marks were used to relate students' SEBs to achievement in science. Provision was also made on the SEB questionnaire to collect some background data such as age, gender, grade and socioeconomic status (SES) by means of mother's level of education.

\subsubsection{Instruments}

The 22-item questionnaire was adapted from the scientific epistemic beliefs' questionnaire (Conley et al., 2004). Students were asked to indicate their level of agreement with the statements on beliefs about scientific knowledge. Items were unambiguously short, declarative statements without jargon. Each item was a five-point Likert scale of temporal frequency (Glynn et al., 2009), wherein 1= strongly disagree; 2 $=$ disagree; $3=$ not sure $4=$ agree and $5=$ strongly agree. The questionnaire comprised of four dimensions of beliefs and example of items are given in brackets: source (Whatever the teacher says in science class is true); certainty (All questions in science have one right answer); development (Existing ideas in science may change as scientists come up with new ones); and justification (Good answers are based on evidence from many different experiments).

Each item had to be answered by means of circling the number corresponding to the option that best described their beliefs. All items were worded in both and negative directions however, items were negatively worded, all from the two naïve dimensions 
e.g. source and certainty were reverse scored so that a high score on a particular dimension indicates more sophisticated beliefs. The adapted questionnaire was given to one university lecturer of English and Linguistics who proof read and approved the language usage. Students' responses were captured manually and incomplete questionnaires were discarded, hence no missing data are found in the data set.

\subsubsection{Results and discussions}

The reliabilities of the scores from the five factors in the questionnaire for this study were assessed using Cronbach's alpha coefficient. The reliability of scores from individual dimensions ranged from $\alpha=.80$ to .83 (Table 19). The overall reliability of the scores on the adapted SEB questionnaire was $\alpha=.70$. This suggests that the questionnaire had good overall reliability for the sample used although as all dimensions showed reliability values well above the recommended minimum threshold of $\alpha=.70$ (Streiner, 2003).

\section{Table 19}

Reliability comparisons of original and adapted SEB questionnaires

\begin{tabular}{lcccc}
\hline Dimensions & \multicolumn{2}{c}{ No. of items } & \multicolumn{2}{c}{ Cronbach's alpha } \\
\hline & Original & Adapted & Original & Adapted \\
Source & 5 & 4 & .82 & .80 \\
Certainty & 6 & 5 & .79 & .81 \\
Development & 6 & 6 & .66 & .83 \\
Justification & 9 & 7 & .76 & .80 \\
Overall & 26 & 22 & - & .70 \\
\hline
\end{tabular}

The overall reliability of the original SEB questionnaire was not reported, however, based on what was reported dimensions wise, the adapted SEB showed better reliability. It should be noted that the original SEB questionnaire was administered to elementary school students while the adapted one in this study was administered to senior secondary students. The mode of administration was also different. In the original questionnaire, items were orally read out to students while in the present study, students responded by reading the questionnaires themselves.

Conley et al. (2004) reported that there was considerable redundancy in the original SEB questionnaire due to very high correlation between the source and certainty dimensions $(r=.92)$ which made it difficult to differentiate between the two concepts 
logically. However, our correlation analysis of the four dimensions (Table 20) showed that they were distinctly different from each other thus eliminated any possible redundancy of items.

Table 20

Correlation of adapted SEB dimensions

\begin{tabular}{lllllll}
\hline Dimensions & $M$ & $S D$ & 1 & 2 & 3 & 4 \\
\hline 1. Source & 3.4 & .10 & - & & & \\
2. Certainty & 3.9 & .79 & -.041 & - & & \\
3. Development & 4.1 & .62 & .025 & .014 & - & \\
4. Justification & 4.3 & .56 & .015 & -.014 & .007 & - \\
\hline
\end{tabular}

Note. $M=$ mean $\quad S D=$ Standard deviation

The overall level of beliefs was fairly low for the two naïve dimensions namely source $(M=3.4, S D=.10$ and certainty $(M=3.9, S D=.79)$ but were higher for the sophisticated dimensions namely development $(M=4.1, S D=.62)$ and justification $(M=$ $4.3, S D=.56)$.

Though these results are similar to the findings in the original questionnaire, it is difficult to interpret students' beliefs accurately due to the cross-sectional nature of the present study. Source and certainty were reverse scored so that high scores on them indicates sophisticated beliefs. Another assessment after an intervention could perhaps clarify this as one would be able to ascertain whether there were any changes in their beliefs. It should be noted that as such was not the aim of this study. It is rather an opportunity for future research.

\subsubsection{Confirmatory factor analysis of the SEBs dimensions}

Confirmatory factor analysis was performed to verify the construct validity of the SEBs hypothesized four-dimension model. The values of item loadings, composite reliability (CR) and average variance extracted (AVE) are advised to evaluate convergent validity of the constructs (Hair, Black, Babin, Anderson, \& Tatham, 2006). As shown in Table 21, almost all loading values of the items were significant and higher than .50 (except for one item under justification which had a loading value of .35), indicating that in most cases more than $50 \%$ of the variance is explained by the dimensions. The CR 
values all exceeded the recommended cutoff value of .70 (Fornell \& Larcker, 1981). The AVE values for three of the dimensions (source, certainty, and development) met the minimum cutoff point of .50 while the AVE value for the justification dimension was .40. The AVE values for the four dimensions ranged from .40 to .50 . The CR values ranged from .80 to .83 (Table 22). Although one dimension had the AVE value below the preferred minimum cut-off point of .50 , convergent validity may still be adequate because the other three dimensions had AVE values of .50 and all dimensions had CR values above .70 (Fornell \& Larcker, 1981).

\section{Table 21}

Factor loadings, composite reliability and average variance extracted values of the four dimensions SEB model

\begin{tabular}{cccc}
\hline Source $(\mathrm{S})$ & Factor loadings & CR & AVE \\
\hline S1 & $.675^{* *}$ & & \\
S2 & $.816^{* *}$ & .80 & .50 \\
S3 & $.625^{* *}$ & & \\
S4 & $.709^{* *}$ & & \\
Certainty (C) & & & \\
C5 & $.653^{* *}$ & .82 & .50 \\
C6 & $.820^{* *}$ & & \\
C7 & $.559^{* *}$ & & \\
C8 & $.772^{* *}$ & & .50 \\
C9 & $.606^{* *}$ & & \\
Development (D) & & & \\
D10 & $.744^{* *}$ & .83 & \\
D11 & $.506^{* *}$ & & \\
D12 & $.714^{* *}$ & & \\
D13 & $.583^{* *}$ & & \\
D14 & $.722^{* *}$ & & \\
D15 & $.733^{* *}$ & & \\
Justification (J) & & & \\
J16 & $.633^{* *}$ & .81 & \\
J17 & $.632^{* *}$ & & \\
J18 & $.718^{* *}$ & $.672^{* *}$ & \\
J19 & $.547^{* *}$ & $.753^{* *}$ & \\
J20 & $.354^{* *}$ & & \\
J21 & & & \\
J22 & & & \\
& & & \\
\hline
\end{tabular}

Note. ${ }^{* *}$ significant t-value, $p<.001$

To assess the assumption of normality for estimating the measurement model, the skewness and kurtosis values were used. In this study, the skewness and kurtosis value were found to be within the recommended range, suggesting that the data is coherent with 
normal distribution. Regarding goodness of fit of the measurement model, the ratio of chi-square to degrees of freedom $\left(\chi^{2} / d f\right)$ was 2.71, RMSEA $=0.043, \mathrm{CFI}=.95, \mathrm{TLI}=$ .94, SRMR $=0.032$, indicating that the measurement model fits the data very well (Garson, 2015). The standardised factor loadings and correlations of the four dimensions of beliefs are shown in Figure 9.

\section{Figure 9}

Standardised factor loading and correlations of the four dimensions of beliefs model

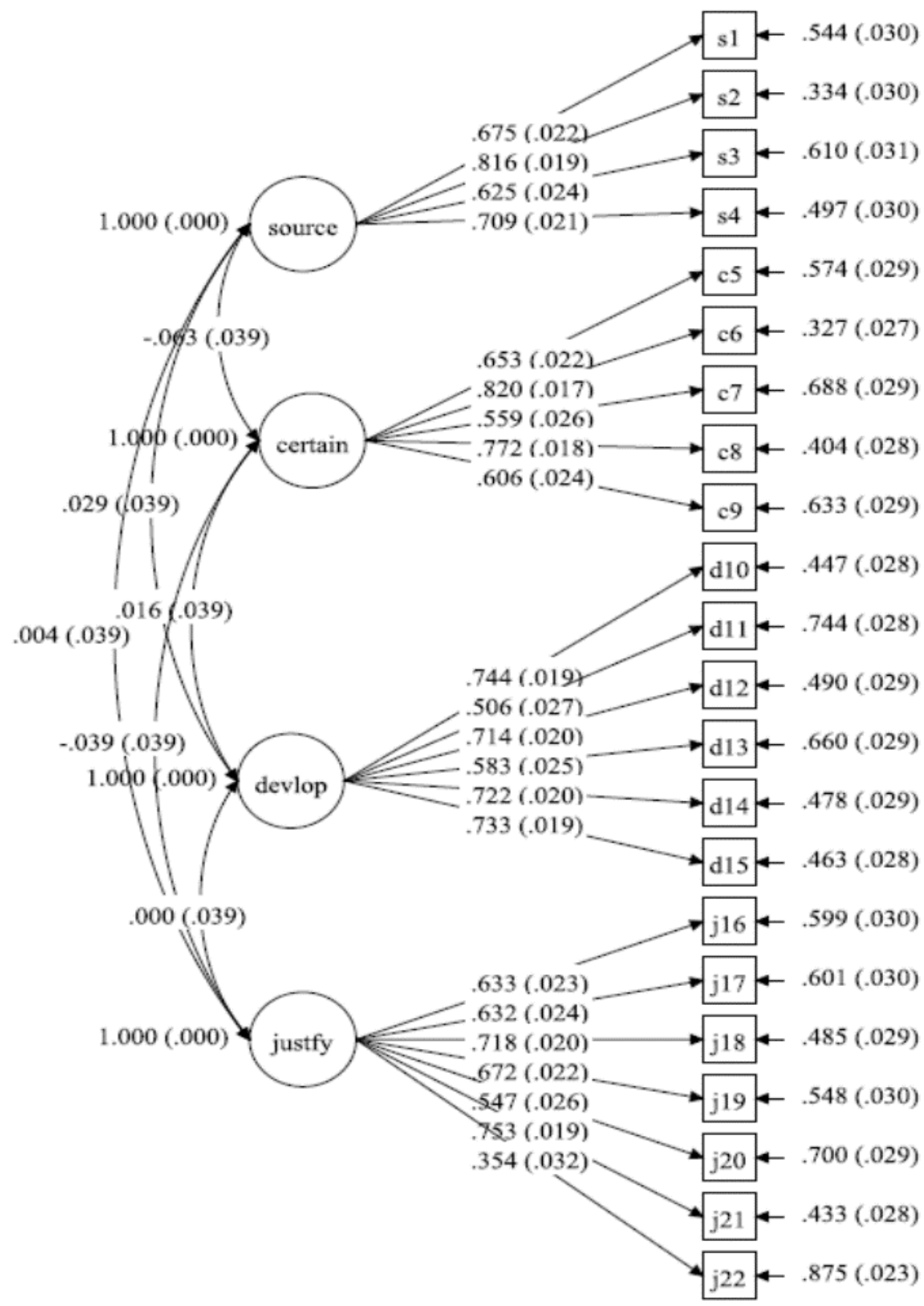


Note Certain $=$ certainty devlop $=$ development justfy $=$ justification

Discriminant validity was assessed by comparing the square root of the AVE with the correlation of latent factors (dimensions) in the model (Hair et al., 2016) and was tenable as shown in Table 22. All dimensions support the precedent requirements and together with convergent validity, construct validity is confirmed.

\section{Table 22}

Correlation matrix for adapted SEB dimensions

\begin{tabular}{lcccccc}
\hline Dimensions & $\mathrm{M}$ & $\mathrm{SD}$ & 1 & 2 & 3 & 4 \\
\hline 1. Development & 4.1 & .62 & 0.67 & & & \\
2. Source & 3.4 & .10 & 0.03 & 0.71 & & \\
3. Certainty & 3.9 & .79 & 0.02 & -0.06 & 0.69 & \\
4. Justification & 4.3 & .56 & 0.00 & 0.00 & -0.04 & 0.63 \\
\hline
\end{tabular}

Note. The diagonal numbers in italic are the square root of the AVE values

\subsubsection{Prediction of achievement in science}

Previous studies (Cano, 2005; Stathopoulou \& Vosniadou, 2007; Trautwein \& Lüdtke, 2007) have suggested that epistemic beliefs may have an influence on students' academic achievement. SEBs were used as predictors of achievement in science when regression analysis was conducted. Achievement in science was the outcome variable. Overall, the model fit proved to be good, $\chi^{2}(d f=4)=32.481$, TLI $=.95$, CFI $=.95$, RMSEA $=.012$, SRMR $=.024$. The resulting standardized beta coefficients are shown in Figure 10. The regression model was significant $F(4,939)=8.218, p<.001, R^{2}=.034$. However, only two dimensions namely certainty $(\beta=.154, \mathrm{p}<.001)$ and justification $(\beta=$ $.100, \mathrm{p}<.05)$ statistically significantly predicted achievement in science. Source $(\beta=-$ $.005, \mathrm{p}=.886)$ and development $(\beta=-.021, \mathrm{p}=.503)$ negatively predicted achievement in science but the regression weights were not statistically significant. 


\section{Figure 10}

Linear regression of SEBs and achievement in science

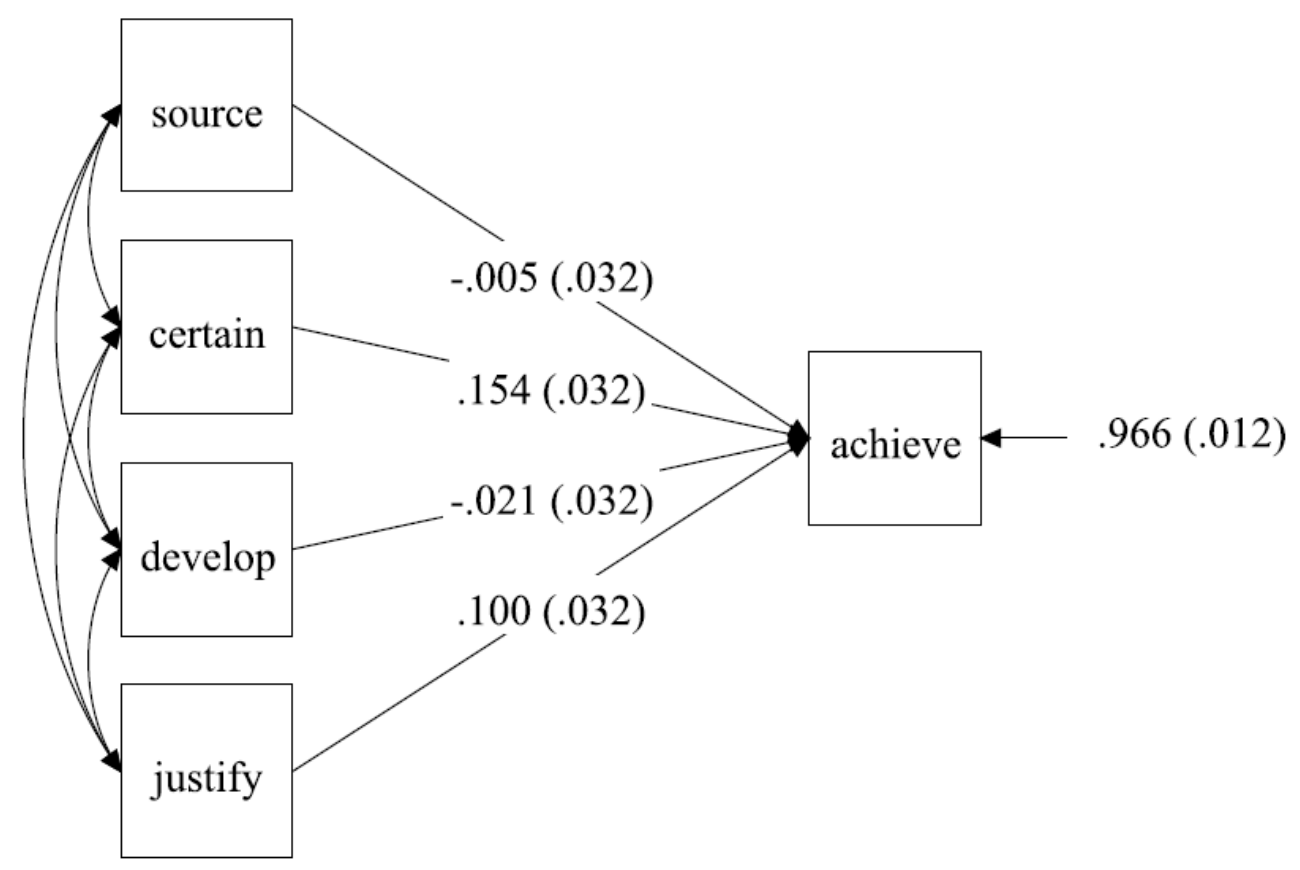

Note certain $=$ Certainty develop $=$ Development justify $=$ Justification

With regard to certainty dimension, the findings in this study are contrary to what Trautwein and Lüdtke (2007) reported in their study involving upper secondary students. They found that certainty beliefs were significantly negative predictor of achievement. However, their achievement factor was broader than the present study which focused on science only.

\subsubsection{Differences in SEBs in terms of gender, grade and socioeconomic status}

In response to the fourth research question which asked whether there were differences in mean levels of SEBs in terms of gender, grade and socioeconomic status (SES), independent sample t-test was conducted for each dimension, separately for each group. The SES was determined by grouping students into two. One group for those whose mothers had a degree or diploma considered as 'high SES' and the other group was for those whose mothers had matric or below matric considered as 'low SES'. Those who didn't know about the level of their mothers' education were excluded from these analyses. 
The study found that there was statistically significant difference in beliefs about source of scientific knowledge in terms of gender (Table 23). Female students $(M=3.44$, $S D=.892)$ showed slightly more sophisticated beliefs about source of scientific knowledge than male students $(M=3.26, S D=.890), \mathrm{t}(942)=-3.086, p<.05$, however, the effect size was very small, Cohen's $d=0.16$, probably owing to the large sample size. Nonetheless, this was a positive finding considering that this is a validation study. The results were congruent with Cano (2005), although using different instruments, it was found that girls' epistemological beliefs about knowledge and learning, at all school levels, were more realistic than for the boys. There was no statistically significant difference in beliefs about other three dimensions in terms of gender. This is in line with Pintrich (2002) who asserted that there were no important differences in epistemological thinking in terms of gender. The original study (Conley et al., 2004) also reported that boys and girls in the fifth grade appeared to have similar scientific epistemic thinking as they didn't find evidence suggesting the effects of gender nor any moderating effects of gender over time.

Table 23

Mean differences of beliefs in terms of gender

\begin{tabular}{|c|c|c|c|c|c|c|c|c|c|c|}
\hline \multirow[b]{2}{*}{ SEBs } & \multirow[b]{2}{*}{ Gender } & \multirow[b]{2}{*}{$\mathrm{M}$} & \multirow[b]{2}{*}{ SD } & \multirow[b]{2}{*}{$\mathrm{t}$} & \multirow[b]{2}{*}{ df } & \multirow{2}{*}{$\begin{array}{c}\text { Sig. } \\
(2- \\
\text { tailed) }\end{array}$} & \multirow{2}{*}{$\begin{array}{c}\text { Mean } \\
\text { Difference }\end{array}$} & \multirow{2}{*}{$\begin{array}{l}\text { Std. Error } \\
\text { Difference }\end{array}$} & \multicolumn{2}{|c|}{$\begin{array}{l}95 \% \text { CI of the } \\
\text { Difference }\end{array}$} \\
\hline & & & & & & & & & Lower & Upper \\
\hline \multirow[t]{2}{*}{ Source } & Male & 3.26 & .890 & \multirow{2}{*}{-3.086} & \multirow{2}{*}{942} & \multirow{2}{*}{.002} & \multirow{2}{*}{-.180} & \multirow{2}{*}{.058} & \multirow{2}{*}{-.295} & \multirow{2}{*}{-.066} \\
\hline & Female & 3.44 & .892 & & & & & & & \\
\hline \multirow[t]{2}{*}{ Certainty } & Male & 3.92 & .804 & \multirow{2}{*}{.301} & \multirow{2}{*}{942} & \multirow{2}{*}{.763} & \multirow{2}{*}{.016} & \multirow{2}{*}{.052} & \multirow{2}{*}{-.086} & \multirow{2}{*}{.117} \\
\hline & Female & 3.90 & .773 & & & & & & & \\
\hline \multirow[t]{2}{*}{ Development } & Male & 4.13 & .619 & \multirow{2}{*}{-.218} & \multirow{2}{*}{942} & \multirow{2}{*}{.827} & \multirow{2}{*}{-.009} & \multirow{2}{*}{.040} & \multirow{2}{*}{-.088} & \multirow{2}{*}{.070} \\
\hline & Female & 4.14 & 613 & & & & & & & \\
\hline \multirow[t]{2}{*}{ Justification } & Male & 4.24 & .571 & \multirow{2}{*}{-.851} & \multirow{2}{*}{942} & \multirow{2}{*}{.395} & \multirow{2}{*}{-.031} & 037 & -104 & 041 \\
\hline & Female & 4.27 & .555 & & & & & & & \\
\hline
\end{tabular}

Note. $\mathrm{N}_{\text {male }}=421 ; \mathrm{N}_{\text {female }}=523$

With regard to grades, there was a statistically significant difference in beliefs about source and certainty between grades (Table 24$)$. Grade 11 students $(M=3.43, S D$ $=.879)$ showed more sophisticated beliefs about source than Grade 12 students $(M=$ $3.29, S D=.908), \mathrm{t}(942)=2.389, p<.05$, with Cohen's $\mathrm{d}=0.22$, suggesting a small but significant difference. Alternately, Grade 12 students $(M=4.00, \mathrm{SD}=763)$ showed more 
sophisticated beliefs about certainty than Grade 11 students $(M=3.83, S D=.800)$, $\mathrm{t}(940.69)=-3.423, \mathrm{p}<.05$, which is also a small but significant difference (Cohen's $\mathrm{d}=$ $0.20)$.

These results are in conflict with the hypothesis that Grade 12 students would have more sophisticated beliefs than Grade 11 students, because they have been studying science longer. However, this can only be adequately tested with a pre-test post-test kind of assessment. As such was not possible for the present study. Although in the original study (Conley et al., 2004) students were assessed at two points in time, mimicking a pretest post-test scenario, it did not compare different grades as it used fifth graders only.

\section{Table 24}

Mean difference of beliefs in terms of grade

\begin{tabular}{|c|c|c|c|c|c|c|c|c|c|c|}
\hline \multirow[b]{2}{*}{ SEBs } & \multirow[b]{2}{*}{ Grade } & \multirow[b]{2}{*}{ M } & \multirow[b]{2}{*}{ SD } & \multirow[b]{2}{*}{$t$} & \multirow[b]{2}{*}{$\mathrm{df}$} & \multirow{2}{*}{$\begin{array}{l}\text { Sig. (2- } \\
\text { tailed) }\end{array}$} & \multirow{2}{*}{$\begin{array}{c}\text { Mean } \\
\text { Difference }\end{array}$} & \multirow{2}{*}{$\begin{array}{l}\text { Std. Error } \\
\text { Difference }\end{array}$} & \multicolumn{2}{|c|}{$\begin{array}{l}95 \% \text { CI of the } \\
\text { Difference }\end{array}$} \\
\hline & & & & & & & & & Lower & Upper \\
\hline \multirow[t]{2}{*}{ Source } & 11 & 3.43 & .879 & \multirow{2}{*}{2.389} & \multirow{2}{*}{942} & \multirow{2}{*}{.017} & \multirow{2}{*}{.139} & \multirow{2}{*}{.058} & \multirow{2}{*}{.025} & \multirow{2}{*}{.253} \\
\hline & 12 & 3.29 & .908 & & & & & & & \\
\hline \multirow[t]{2}{*}{ Certainty } & 11 & 3.83 & .800 & \multirow[t]{2}{*}{-3.423} & \multirow[t]{2}{*}{940.69} & \multirow[t]{2}{*}{.001} & \multirow[t]{2}{*}{-.174} & \multirow[t]{2}{*}{.051} & \multirow[t]{2}{*}{-.274} & \multirow[t]{2}{*}{-.074} \\
\hline & 12 & 4.00 & .763 & & & & & & & \\
\hline \multirow[t]{2}{*}{ Development } & 11 & 4.14 & .586 & \multirow{2}{*}{.075} & \multirow{2}{*}{942} & \multirow{2}{*}{.940} & \multirow{2}{*}{.003} & \multirow{2}{*}{.040} & \multirow{2}{*}{-.076} & \multirow{2}{*}{.082} \\
\hline & 12 & 4.14 & .647 & & & & & & & \\
\hline \multirow[t]{2}{*}{ Justification } & 11 & 4.25 & .554 & \multirow{2}{*}{-.696} & \multirow{2}{*}{942} & \multirow{2}{*}{.487} & \multirow{2}{*}{-.025} & .037 & -.097 & .046 \\
\hline & 12 & 4.27 & .571 & & & & & & & \\
\hline
\end{tabular}

Note. $\mathrm{N}_{\text {Grade11 }}=492 ; \mathrm{N}_{\text {Grade } 12}=452$

The results showed that there was no statistically significant difference in the means of high and low SES across all four dimensions of beliefs. Both groups showed overall lower scores on source and certainty and higher scores on development and justification (Table 25). The results suggest that regardless of the SES, students possessed less sophisticated beliefs about source (high SES: $M=3.30, S D=.904$; low SES: $M=$ $3.41, S D=.824$ ) and certainty (high SES: $M=3.90, S D=.827$; low SES: $M=3.92, S D$ $=.771$ ) but possessed more sophisticated beliefs about development (high SES: $M=4.16$, $S D=.561$; low SES: $M=4.06, S D=.693$ ) and justification (high SES: $M=4.24, S D=$ .653 ; low SES: $M=4.30, S D=.513$ ). 
Table 25

Mean difference of beliefs in terms of socioeconomic status

\begin{tabular}{|c|c|c|c|c|c|c|c|c|c|c|}
\hline \multirow[b]{2}{*}{ SEBs } & \multirow[b]{2}{*}{ SES } & \multirow[b]{2}{*}{ M } & \multirow[b]{2}{*}{$\mathrm{SD}$} & \multirow[b]{2}{*}{$\mathrm{t}$} & \multirow[b]{2}{*}{ df } & \multirow{2}{*}{$\begin{array}{c}\text { Sig. } \\
(2- \\
\text { tailed) }\end{array}$} & \multirow{2}{*}{$\begin{array}{c}\text { Mean } \\
\text { Difference }\end{array}$} & \multirow{2}{*}{$\begin{array}{l}\text { Std. Error } \\
\text { Difference }\end{array}$} & \multicolumn{2}{|c|}{$\begin{array}{l}95 \% \text { CI of the } \\
\text { Difference }\end{array}$} \\
\hline & & & & & & & & & Lower & Upper \\
\hline \multirow[t]{2}{*}{ Source } & High SES & 3.30 & .904 & -1.427 & 503 & .154 & -.110 & .077 & -.262 & .042 \\
\hline & Low SES & 3.41 & .824 & & & & & & & \\
\hline \multirow[t]{2}{*}{ Certainty } & High SES & 3.90 & .827 & -.237 & 503 & .813 & -.017 & .072 & -.158 & .124 \\
\hline & Low SES & 3.92 & .771 & & & & & & & \\
\hline \multirow[t]{2}{*}{ Development } & High SES & 4.16 & .561 & 1.787 & 503 & .075 & .103 & .058 & -.010 & .216 \\
\hline & Low SES & 4.06 & .693 & & & & & & & \\
\hline \multirow[t]{2}{*}{ Justification } & High SES & 4.24 & .653 & -1.228 & 393.544 & .220 & -.066 & .054 & -.172 & . 040 \\
\hline & Low SES & 4.30 & .513 & & & & & & & \\
\hline
\end{tabular}

Note. $\mathrm{N}_{\text {HighSES }}=215 ; \mathrm{N}_{\text {LowSES }}=290$

This implies that students' mothers' level of education did not have an influence on their beliefs about scientific knowledge and knowing. These findings are contrary to what was reported about SES in the original study (Conley et al., 2004). It was reported that low SES students scored lower in all four dimensions of beliefs than average SES students. Suggesting that low SES students appeared to possess less sophisticated epistemic beliefs. It should be noted that the criteria for classifying students into low and high SES were different. In the original study, the SES was determined in terms of eligibility for free lunch at school while in the present study it was based on mothers' level of education.

\subsubsection{Conclusion}

This study set out to adapt and validate the scientific epistemic beliefs questionnaire using the Namibian sample of Grades 11 and 12 students. The overall level of beliefs was fairly low for the two naïve dimensions namely source and certainty but was higher for the sophisticated dimensions namely development and justification. These results were similar to the findings of the original questionnaire but it is difficult to interpret students' beliefs accurately due to the cross-sectional nature of the present study. Source and certainty were reverse scored because their items were reverse-coded, so that high scores on them indicate more sophisticated beliefs. Although reverse-coded items may help mitigate response bias, it can also lead to confusion among respondents. Respondents, especially second language speakers, who are not careful may miss the 
reversing or the negative form and may incorrectly respond to the reverse-coded items (Weijters, Baumgartner, \& Schillewaert, 2013).

Another assessment after an intervention could perhaps clarify the current state of students' beliefs as one would be able to ascertain whether there were any changes in beliefs. It should be noted that as such was not the aim of the present study. It is rather an opportunity for future research.

The results indicate that the adapted questionnaire had adequate construct validity owing to good convergent and discriminant validity estimates. Similarly, the reliability of responses in terms of both alpha coefficient and composite reliability estimates were good as the estimates for all four dimensions of beliefs were above the preferred cut-off point of .70. The measurement model shows good fit for the data with good fit statistics such as $\chi^{2} / d f$, RMSEA, SRMR, TLI and CFI. In comparison with the original questionnaire, the present study showed better model fit indices. This study also found that two dimensions of beliefs namely certainty and justification statistically significantly predicted achievement in science in this sample.

Further analyses revealed that there was a statistically significant difference in beliefs about source in terms of gender and grade as well as about certainty in terms of grade. No difference was found in other two dimensions of beliefs (development and justification) in terms of gender, grade and socioeconomic status. The results showed that the adapted questionnaire works well with the Namibian sample used given the good model fit for the data and reliability. This study focused on the exit phase of the Namibian basic education (Grades 11 and 12). At the moment, there are no formal assessments for students' scientific epistemic beliefs within the Namibian education system. Elsewhere especially in the developed world, there has been a shift of learning goals in recent years, from content knowledge to emphasising the epistemic aspect of scientific inquiry needed to help students develop $21^{\text {st }}$ century skills (Gu \& Belland, 2015).

As such, Namibia as a developing nation needs to keep abreast with the developments in science education in order to achieve the aims of its science curriculum. The main aim of the science curriculum is to provide students with the basic scientific background and develop them into scientifically literate citizens who are capable of 
dealing with $21^{\text {st }}$ century challenges (Ministry of Education, 2010). Thus, developing sophisticated scientific epistemic beliefs is a prerequisite for developing $21^{\text {st }}$ century skills. However, the fact that epistemic beliefs are not explicitly emphasised during science instructions and subsequently not assessed, also given the dearth of instruments for assessing scientific epistemic beliefs in the Namibian cultural context, this study intended to provide a valid instrument for use by researchers of science education. Copyrights for the original questionnaire is with the Contemporary Educational Psychology Journal.

\subsection{Summary of findings from the Studies 1 to 4}

- Study 1 - The average inter-item correlation was reasonable, the mean item-total correlations were also acceptable and the reliability was very high. Science teachers' response pattern showed several variations indicating mixed beliefs about the nature of science and scientific inquiry. At non-parametric level, it was established that gender, science teaching and the type of science subject taught did not influence teachers' beliefs about nature of science and scientific inquiry (Shaakumeni, 2019).

- Study 2 - The reliability of the BANOS was good. EFA revealed a final interpretable five-factor structure and the factor solution accounted for $67.73 \%$ of the total variance. However, parallel analysis revealed that only four factors had eigenvalues that were statistically significant and the resultant scree plot also supported the retention of four factors. CFA results showed that the measurement model had poor statistical fit for the data. These findings indicate that the eight general aspects NOS framework could not be confirmed at EFA level (Shaakumeni \& Csapó, 2019).

- Study 3 - The overall reliability of the scores on the 19-item questionnaire was acceptable. Exploratory factor analysis revealed an interpretable factor structure and the factor solution accounted for $56.1 \%$ of the total variance. Confirmatory factor analysis the results showed that the model had adequate statistical fit for the data. Construct validity was confirmed through the assessment of convergent and discriminant validity and both were found tenable (Shaakumeni \& Csapó, 2018). 
- Study 4 - The adapted questionnaire had good reliability. Model fit analysis yielded good statistical fit for the data. The overall regression model was significant and two dimensions, namely, certainty and justification statistically significantly predicted achievement in science. There was statistically significant difference in beliefs about source in terms of gender and grade and about certainty in terms of grade (Shaakumeni, 2019). 


\section{CHAPTER 6: CONCLUSIONS AND RECOMMENDATIONS}

\subsection{Introduction}

This research endeavoured to develop, adapt and validate instruments for assessing Namibian secondary school students' epistemic beliefs about the nature of scientific knowledge and associated components such as motivation to learn science. It was focused on the sample of the population that is in the exit phase of the Namibian basic education phase, the senior secondary phase (Grades 11 and 12). Through the review of literature, it was found that there was lack of research in Namibia regarding students' epistemic beliefs about the nature of science. Although numerous instruments for assessing students' beliefs about nature of science exist, their psychometric validity has been uncertain because many such instruments were validated through qualitative methods only and as such limited the confidence in their use. Similarly, there were no psychometrically validated instruments for assessing students' epistemic beliefs about nature of science neither motivation to learn science in the Namibian context. The research was made up of four studies. This chapter presents the conclusions and recommendations in terms of suggestions for further research.

\subsection{Development and validation of the beliefs about nature of science questionnaires (BANOS)}

These aspects of the research were dealt with in Study 1 and 2 in the quest to answer the first main research question, sought whether it was possible of assess multiple general aspects of nature of science using a single instrument. Study 1 formed part of the initial stages of the validation process at item level after the development of the new questionnaire for assessing beliefs about nature of science and scientific inquiry as well as assessing science teachers' beliefs as part of content validation. The new questionnaire was developed using the general and symbiotic aspects of nature of science and scientific inquiry proposed by Lederman and other scholars (Lederman, Abd-El-Khalick, Bell, \& Schwartz, 2002; Lederman \& Abd-El-Khalick, 1998; McComas, Almazroa, \& Clough, 1998, Lederman et al.,2014) as a theoretical framework. It is important to reiterate that although we claim to have developed a new questionnaire termed "Beliefs about Nature 
of Science" (BANOS) in this study, ideas for possible items were obtained from existing scales in the literature.

The initial analyses of this questionnaire indicated that it had potential to be a reliable instrument for assessing beliefs about the nature of scientific knowledge and scientific inquiry in Namibia, with respect to its preliminary very high reliability. This indicates that the items were pulling in one direction in terms of assessing the same construct. However, very high reliability values may indicate unnecessary redundancy of items in the scales. The correlations between subscales that constituted the questionnaire were generally significantly high. Together these findings confirm hypotheses H1/S1 to H3/S1. However, the fact that very high correlations were found, may indicate that subscales were too similar and therefore the questionnaire may suffer from poor discriminant validity. Moreover, due to the very correlations and with further review of literature, scientific inquiry was dropped from the questionnaire as it was found to be a separate construct. Lederman, et al. (2014) asserted that scientific inquiry though closely related, is not necessarily a component of nature of science because it entails the process of how scientists do their work and how the resultant knowledge is generated and accepted. This study further revealed that science teachers in Namibia have mixed beliefs about the nature of science and scientific inquiry.

The beliefs of teachers on most of the subscales (aspects of NOS) were uncertain. This was in conformity with the literature that teachers often possess inconsistent or less sophisticated beliefs about NOS (Lederman, 1992; Abd-El-Khalick \& Lederman, 2000; Dogan \& Abd-El-Khalick, 2008), thus confirming hypothesis H4/S1. The study further established that at non-parametric level, gender, science teaching experience, and the type of science subject taught did not influence teachers' beliefs about nature of science and scientific inquiry. In this case hypotheses H5/S1 and H7/S1 were confirmed, however, H6/S1 could not be confirmed as there was no difference in beliefs in terms of teachers' years of science teaching experience.

The findings in Study 1 particularly its limitations, necessitated a large-scale validation effort which led to the Study 2 . This study attempted to assess the psychometric properties in terms of the factorial validity of the hypothesised eight-aspect categorisation that underpinned the beliefs about nature of science questionnaire using factor analysis. 
The findings indicate that although the questionnaire had reasonable construct validity and good reliability as confirmed by hypotheses H1/S2 to H4/S2, the eight-aspect model that had been qualitatively suggested could not be supported at EFA level, thus H5/S2 could not be confirmed. The eight aspects of the nature of science did not form distinct factors. The most interpretable structure consisted of only five factors. Notwithstanding this finding, parallel analysis revealed that only four factors were significant in the model. This suggests that fewer factors may produce a better model for this eight-aspect categorisation.

Moreover, this could be attributed to the inherent similarity among the aspects of nature of science. The results further showed that the measurement model had poor fit statistics values as they were lower than the recommended thresholds, except for the ratio of the chi-square to degrees of freedom $\left(\chi^{2} / d f\right)$ and the SRMR (Hair et al., 2016), thus H6/S2 could not be confirmed. It can be seen that the questionnaire continues to show potential to be psychometrically valid. It is believed that developing an instrument cannot be accomplished in one shot. This suggests further examination for possible flaws that affected the measurement model fit.

\subsection{Cross-cultural validation of adapted questionnaires}

Two complimentary studies were conducted at the side-lines of the BANOS questionnaire's development. These were Studies 3 and 4 were intended to answer the second main research question which sought to ascertain the suitability of adapted instruments for assessing motivation towards science learning and scientific epistemic beliefs, in the Namibian cultural context. The two studies were conducted under similar methodologies. The questionnaires used for both studies were adapted from existing instruments with the aim to conduct a cross-cultural validation in the Namibian cultural context. This was necessitated by the fact that the original instruments were developed for a particular culture and in this research, they were adapted for a different culture (Namibian). As Huang and Wong (2014) asserted, it important to ascertain whether instruments that were originally developed in a particular culture are meaningfully applicable and thus equivalent for use in another culture. Although both the original instruments and the present research were in English, the cultural difference exists in terms of geographical location: the original questionnaires were developed in Taiwan 
(Asia) and the USA respectively while the adapted version was used in Namibia (Africa).

Motivation to learn science has been linked with beliefs about the nature of scientific knowledge and knowing (Chen \& Pajares, 2010; Paulsen \& Feldman, 2007; Tsai, Jessie Ho, Liang, \& Lin, 2011) and most of the conclusions drawn from these studies support the notion that sophisticated beliefs may positively relate to motivation particularly self-efficacy. Whilst less sophisticated (absolutist) beliefs were associated with negative self-judgement. For these reasons, motivation was viewed as a relevant component worthy of inclusion in this study.

Against the aforementioned reason, Study 3 was aimed at examining the psychometric properties of a questionnaire adapted from the students' motivation towards science learning (SMTSL) questionnaire (Tuan et al., 2005). Findings from this study indicated that the adapted questionnaire may have adequate construct validity although convergent validity being one of the criteria for determining construct validity showed marginally acceptable properties in terms of latent factors having AVE values below the preferred minimum cut-off point of .50. In support, most of the factors had CR values above .70 with only two factors not meeting this criterion.

Nonetheless, those two factors had CR values above .60 which is a moderately acceptable level of reliability. Similarly, the reliability of responses in terms of both alpha coefficient and composite reliability estimates were reasonable although the estimates for some factors were below the preferred cut-off point of .70. Looking at the aforementioned findings hypotheses H1/S3 to H4/S3 were confirmed. The results also showed that the five-factor model could be supported at EFA level as the five factors of motivation to learn science formed distinct factors and subsequently an interpretable structure of the questionnaire; thus, confirmed H5/S3. The measurement model showed acceptable fit for the data with good fit statistics such as $\chi^{2} / d f$, RMSEA, SRMR, TLI and CFI, confirming hypothesis H6/S3. In comparison with similar previous studies, the present study showed better model fit indices.

The findings suggest that the adapted instrument is suitable for assessing Namibian Grade 12 science students' motivation to learn science particularly in large 
scale cross-sectional studies. The questionnaire may also be combined with other scales for data collection in which comparisons of motivation to learn science with other variables such as demographic, achievement in science, and scientific epistemic beliefs. At the moment, there are no formal assessments for students' motivation to learn generally within the Namibian education system. However, knowing what motivates students to learn can help inform the development and improvement of current education policies. Given the paucity of similar instruments in the Namibian cultural context, this adaptation and validation may serve as a gateway for future similar studies particularly focusing on other, lower, stages of schooling.

The fourth and the last study was based on a slightly different conceptualisation of beliefs about nature of scientific knowledge and knowing, termed the scientific epistemic beliefs (SEB). Scientific epistemic beliefs are individual domain-specific beliefs about scientific knowledge and the acquisition of such knowledge. This theorisation hypothesised only four dimensions of beliefs about scientific beliefs and knowing contrary to eight aspects studied in Studies 1 and 2. Hence aims of this study were to adapt and validate a questionnaire for assessing Namibian senior secondary (Grades 11 and 12) students' scientific epistemic beliefs and explore their relation to achievement in science, gender, grade and socioeconomic status.

The findings revealed that the overall level of beliefs of students was fairly low for the two naïve dimensions namely source and certainty but was higher for the sophisticated dimensions namely development and justification. These results were similar to the findings of the original questionnaire however it is difficult to interpret students' beliefs accurately due to the cross-sectional nature of this study. Source and certainty dimensions were reverse scored because their items were reverse-coded, so that high scores on them indicate more sophisticated beliefs. Although reverse-coded items may help mitigate response bias, it could also lead to confusion among respondents. Respondents, especially second language speakers, who are not careful may miss the reversing or the negative form and may incorrectly respond to the reverse-coded items (Weijters, Baumgartner, \& Schillewaert, 2013). 
Another assessment after an intervention could have clarified the current state of students' beliefs as one would be able to ascertain whether there were any changes in their beliefs. It should be noted that as such was not the aim of this study.

The results indicated that the adapted questionnaire had adequate construct validity owing to good convergent and discriminant validity estimates. Similarly, the reliability of responses in terms of both alpha coefficient and composite reliability estimates were good as the estimates for all four dimensions of beliefs were above the preferred cut-off point of .70. Together these results confirm hypotheses H1/S4, H3/S4, $\mathrm{H} 4 / \mathrm{S} 4$, and H5/S4.

No exploratory factor analysis was conducted for this study to assess the factor structure of the questionnaire. Previous studies that used the same questionnaire (Liang \& Tsai, 2010; Tsai, Jessie Ho, Liang \& Lin, 2011) confirmed its factorial structure suggesting that we could formulate an a priori hypothesis to test the questionnaire's factorial structure signifying that the four dimensions of beliefs proposed by Conley et al. (2004) should form distinct factors. Indeed, the four dimensions of beliefs formed distinct factors when confirmatory factor analysis was applied to the data. Thus, hypothesis $\mathrm{H} 2 / \mathrm{S} 4$ was confirmed.

The measurement model showed very good fit for the data with fit statistics such as $\chi^{2} / d f$, RMSEA, SRMR, TLI and CFI and this confirmed hypothesis H6/S4. In comparison with the original questionnaire, this study showed better model fit indices. This study also found that two dimensions of beliefs namely certainty and justification statistically significantly predicted achievement in science in this sample. Since not all dimensions significantly predicted achievement in science, H7/S4 could not be supported.

Further analyses revealed that there was a statistically significant difference in beliefs about source in terms of gender and grade as well as about certainty in terms of grade. No difference was found in other two dimensions of beliefs (development and justification) in terms of gender, grade and socioeconomic status. Due to such inconsistencies in the results H8/S4 to H10/S4 could not be supported. 
In the nutshell, the results showed that the adapted questionnaire works well with the Namibian sample used given the good model fit for the data and reliability. As mentioned earlier, this research focused on the exit phase of the Namibian basic education (Grades 11 and 12) and further that at the moment, there are no formal assessments for students' scientific epistemic beliefs within the Namibian education system. Elsewhere especially in the developed world, there has been a shift of learning goals in recent years, from content knowledge to emphasising the epistemic aspect of scientific inquiry needed to help students develop $21^{\text {st }}$ century skills (Gu \& Belland, 2015).

As such, Namibia as a developing nation needs to keep abreast with the developments in science education in order to achieve the aims of its science curriculum. The main aim of the science curriculum is to provide students with the basic scientific background and develop them into scientifically literate citizens who are capable of dealing with $21^{\text {st }}$ century challenges (Ministry of Education, 2010). Thus, developing sophisticated scientific epistemic beliefs is a prerequisite for developing $21^{\text {st }}$ century skills. However, the fact that epistemic beliefs are not explicitly emphasised during science instructions and subsequently not assessed, also given the dearth of instruments for assessing scientific epistemic beliefs in the Namibian cultural context, this research intended to provide valid instruments for use by researchers of science education in Namibia in particular and the rest of the world in general.

\subsection{Recommendations}

Due to the pioneering nature of this this research and considering its limitations, recommendations are made in terms of suggestions for further research among Namibian students and science teachers.

\subsubsection{Development of the beliefs about nature of science questionnaire (BANOS)}

Considering the findings from Study 2, shortcomings regarding model fit were detected. The confirmatory model did not fit the data well despite very good reliability estimates. This suggests that the dimensions in the model, which in this research are the aspects of nature of science, may be too similar (Stanley \& Edwards, 2016), because when a model with fewer dimensions was assessed, it showed improved goodness of fit though still outside the recommended threshold. Although this was expected considering 
the literature, there is a need to conduct qualitative validations to ascertain whether respondents understand and interpret items in the questionnaire accurately. Additionally, after qualitative validations, a different discriminant validity test could be conducted on the data (Hooper et al., 2008).

\subsubsection{Cross-cultural validation studies}

Pertaining Studies 3 and 4, they both had good reliability, reasonable construct and acceptable measurement model fit indices. However, for Study 4, the use of reversecoded items needs to avoided in future, because the scores on such items were not favourable compared to positively worded items. There is plenty of literature supporting the use of positively worded items only to mitigate the possibility of respondents missing the reversing and thus giving unintended responses to the items. There is also a need to conduct qualitative validations for both adapted questionnaires to ascertain whether respondents understand and interpret items in the questionnaire accurately.

\subsubsection{General suggestions}

As mentioned before, given the ground-breaking nature of the present study as no similar study appear to have been done in Namibia at the time of formulating this study, gives a preponderance of areas of future research such as:

- Students and teachers' views about scientific inquiry.

- The influence of curriculum design on students' acquisition of appropriate NOS beliefs.

- Improving science teachers' views of the NOS.

- The influence of teachers' beliefs about NOS on their teaching practice (necessary and sufficient conditions).

- The effective methods of teaching NOS to students in basic education (embedded or "pull out" topic).

- Science student teachers' beliefs about NOS and scientific inquiry (at University).

- Teachers' attitudes towards NOS inclusion in the teaching of science content.

- Exploration of the effects of scientific epistemic beliefs and motivation to learn science among Namibian students in all grades. 
- Intervention studies to assess changes in students' scientific epistemic beliefs and relation to academic achievement in science across basic education.

Future research should also capture the demographic variables such as location (urban or rural) and ascertain whether there is a significant difference between beliefs of students in urban and rural areas of Namibia.

Last but not least, the Ministry of Education in Namibia should support educational research endeavours of individual researchers by allowing them better access to state schools. The current conditions that are often attached to research permissions granted to researchers by the said ministry are not favourable.

\subsection{Limitations}

As mentioned earlier, this research was conducted as part of the requirements of a doctoral degree. This meant that there was limited time within which data should be collected and analysed. For these reasons, the research followed the cross-sectional design as opposed to the more appealing longitudinal design. Longitudinal research is preferred because of "its ability to establish causality and to make inferences" (Cohen et al., 2007, p. 212). Furthermore, the cross-sectional design limited the results from being able to be generalised to the general population of senior secondary students in Namibia.

For research involving instruments development, it may be necessary for the sake of reliability and validity to combine quantitative and qualitative methodologies for data collection (Cohen et al., 2007). According to Creswell and Plano Clark (2017), the combination of quantitative and qualitative approaches provides a better understanding of research problems than either approach alone. Combining qualitative and quantitative approaches is a powerful tool in obtaining a clear picture of the data and of the research participants (Creswell \& Plano Clark, 2017).

Furthermore, combining qualitative and quantitative research approaches allow triangulation of data, which is essential in achieving validity in research. The survey approach was used in this research to gain an overall picture of the students' current beliefs about the nature of science; however, a better validation could have been achieved through individual and/or focus group interviews to ascertain students' interpretation of 
the questionnaire items. In this research it was only assumed that students interpreted the items as expected.

Students in the senior secondary phase can be seen as the top crop of academically-able because in Namibia for students to proceed to Grades 11 and 12, they should pass a certification examination in Grade 10. Hence, the results of using a sample in grades lower than Grade 11 could be different.

As seen in Appendices 6 and 7, access to state schools was limited by the condition attached to the research permission granted by the Ministry of Education in Namibia. It stated that academic activities at schools are not to be disrupted by the research. This condition has negative implications to the quality of responses the researcher can get. Firstly, most schools in urban areas such Windhoek do not have boarding facilities for students. This means the researcher is unlikely to get a chance to meet students after school as they must go home and many are always collected by their parents immediately. Secondly, when a research uses self-reporting instruments or tests, the most ideal time to administer them to respondents is in the morning when their minds are freshest. However, the condition set in the permission render this untenable.

Last but not least, the researcher is left at the mercy of the school administrators whom sometime do not at all allow the researcher to access the students, especially when such a researcher is unknown to them. For these reasons, I was left with no other option but to employ convenient sampling using only schools whose administrators are my acquaintances. I was able to get some students at mostly rural boarding schools. But nonetheless, this was often after normal school hours. This was not the best time since students were already generally tired. Hence their responses to the questionnaires may not be of good quality. Overall, some methodological limitations may have influenced the findings of this research. First, students were not interviewed to ascertain accuracy of interpretation of the questionnaire items. It was assumed that students interpreted the items as expected. Secondly, the indices of model fit obtained from CFA might be biased due to departure from multivariate normality (Cabrera-Nguyen, 2010) particularly in Studies 2 and 3. Thirdly and finally, the results of the data analysis did not always fit perfectly with recommended requirements in the literature, thus such is considered a limitation for this research. 


\subsection{Summary}

This chapter draws together the conclusions and recommendations as well as the limitations of the research. The main aims of the research were to develop, adapt and validate instruments for assessing Namibian secondary school students' epistemic beliefs about the nature of scientific knowledge and associated components such as motivation towards science learning. It sought to instigate research in the area of scientific epistemic beliefs and nature of science particularly that currently there are hardly any such research done in Namibia. These beliefs have been seen to influence students' academic achievement and motivation to learn science especially the aspect of self-efficacy. Namibia as a developing nation need to keep abreast with the rest of the world in terms research in science education, in order for Namibian students to develop into scientific literate citizens who are able to deal with 21 st-century challenges. For these reasons, several recommendations for future research have been suggested.

\section{ACKNOWLEDGEMENTS}

It was not an easy decision to resign from work and leave my family behind in Namibia to come to Hungary to pursue this dream. However, the opportunity availed to me by the Hungarian government through the Stipendium Hungaricum scholarship was irresistible. I looked at the bigger picture and the journey began.

It is therefore my greatest pleasure to acknowledge those who supported me throughout my $\mathrm{PhD}$ journey. I am heavily indebted to you all for your support and encouragement. To the Hungarian government through the Tempus Public Foundation, many thanks for your generosity. Without being a beneficiary of the Stipendium Hungaricum scholarship, this dream would not have been realised.

I would also like to thank my supervisor, Professor, Dr. Csapó Benő "The walking library". I was privileged to have been under your wing for guidance during my studies. Your supervision and intelligent advices made my student life comfortable. I aspire to be as knowledgeable as you are.

A special gratitude goes to my selfless brother from another mother, Dr. Linus Kambeyo for sharing information with me about the Hungarian scholarship and the city of Szeged. Comrade, you have paved the way for me by sharing information and insights. I can't thank you enough. 
To my colleagues, Class of 2016-2020, both Hungarian and international, thank you for being helpful friends for the past three years. To the lecturers and the entire staff of the Institute of Education, thank you for your patience and support.

To my wife Tulimuwo, thank you for the love and support. I was never worried during the time I have been away because I believed in your personal strength. Thank you for keeping the family together, particularly by taking care of our little bundles of joy without me. I am very proud of you. To my daughter Nena, you have always asked where I was and when I will be coming back home. Let me promise you that I will be home after completing my studies and never leave again. Thank you for your patience. To my son Tunelao "TJ", you were born at the time when I was away from home pursuing this dream. You have grown into an adorable little man. I missed out on some of your journey of growth but this achievement is for you. Thank you for being the good boy that you are. In the same vein, I would like to thank my long-time friend Mrs. Tuwilika Endjala for always having had my back especially around the deliveries of my two children. "Thank you, daddy number two".

Last but not least, I would like to thank the students, teachers and principals of schools that participated in this study. Your support and cooperation despite hectic schedules are highly appreciated. 


\section{REFERENCES}

Ab Hamid, M. R., Sami, W., \& Sidek, M. H. (2017). Discriminant Validity Assessment : Use of Fornell \& Larcker criterion versus HTMT Criterion. Journal of Physics: Conference Series, 890(12163). https://doi.org/https://doi.org/10.10 88/1742-6596/890/1/012163

Abd-El-Khalick, F., Bell, R. L., \& Lederman, N. G. (1998). The nature of science and instructional practice: Making the unnatural nature. Science Education, 82(4), 417437.

Abd-El-Khalick, F. S. (1998). The influence of history of science courses on students conceptions of the nature of science. Unpublished Doctoral Dissertation. Oregon: Oregon State University.

Abd-El-Khalick, Fouad, \& Lederman, N. G. (2000). Improving science teachers' conceptions of nature of science: A critical review of the literature. International Journal of Science Education, 22(7), 665-701. h ttps://doi.org/10.1080/0950069 0050044044

Abd-El-Khalick, Fouad, Myers, J. Y., Summers, R., Brunner, J., Waight, N., Wahbeh, N., ... Belarmino, J. (2017). A longitudinal analysis of the extent and manner of representations of nature of science in U.S. high school biology and physics textbooks. Journal of Research in Science Teaching, 54(1), 82-120. https://do i.org/10.1002/tea.21339

Abd-El-Khalick, Fouad, Waters, M., \& Le, A. P. (2008). Representations of nature of science in high School chemistry textbooks over the past four decades. Journal of Research in Science Teaching, 45(7), 835-855. https://doi.org/10.1002/tea.20226

Akerson, V. L., Hanson, D. L., \& Cullen, T. A. (2007). The influence of guided inquiry and explicit instruction on K-6 teachers' views of nature of science. Journal of Science Teacher Education, 18(5), 751-772. https://doi.org/10.1007/s10972-0079065-4

Allchin, D. (2011). Evaluating knowledge of the nature of (whole) science. Science Education, 95(3), 518-542. https://doi.org/10.1002/sce.20432

Allchin, D., Andersen, H. M., \& Nielsen, K. (2014). Complementary Approaches to Teaching Nature of Science: Integrating Student Inquiry, Historical Cases, and Contemporary Cases in Classroom Practice. Science Education, 98(3), 461-486. https://doi.org/10.1002/sce.21111

American Association for the Advancement of Science. (1993). Benchmarks for Science Literacy. New York: Oxford University Press.

Anderson, L. W., \& Bourke, S. F. (2000). Assessing affective charactersitics in the school. Mahwah, NJ,: Lawrence Erlbaum Associates.

Aslan, O., \& Taşar, M. F. (2013). How do Science Teachers View and Teach the Nature of Science? A Classroom Investigation Fen Öğretmenlerinin Bilimin Doğası 
Görüşleri ve Öğretimleri Nasıldır? Bir Sınıf İçi Araştırması. Eğitim ve Bilim, 38(167), 65-80.

Bandura, A. (2001). Social Cognitive Theory of Mass Communication. Mediapsychology, 265-299. https://doi.org/10.1207/S1532785XMEP0303

Barrett, K. C., \& Morgan, G. A. (2018). Mastery Motivation: Retrospect, Present, and Future Directions. Advances in Motivation Science (1st ed., Vol. 5). Elsevier Inc. https://doi.org/10.1016/bs.adms.2018.01.002

Bell, R. L. (2008). Teaching the nature of science through process skills: Activities for Grades 3-8. New York: Allyn \& Bacon/Longman.

Bell, Randy L., Blair, L. M., Crawford, B. A., \& Lederman, N. G. (2003). Just do it? Impact of a science apprenticeship program on high school students' understandings of the nature of science and scientific inquiry. Journal of Research in Science Teaching, 40(5), 487-509. https://doi.org/10.1002/tea.10086

Bell, Randy L., Matkins, J. J., \& Gansneder, B. M. (2011). Impacts of contextual and explicit instruction on preservice elementary teachers' understandings of the nature of science. Journal of Research in Science Teaching, 48(4), 414-436. https://doi.org/10.1002/tea.20402

Black, D. E., \& Deci, E. L. (2000). The effects of instructors' autonomy support and students' autonomous motivation on learning organic chemistry: a selfdetermination theory perspective. Sci Educ, 84, 740-756. https://doi.org/3.0.CO;23

Brooks, J. G., \& Brooks, M. G. (1993). In search of understanding: The case for constructivist classrooms. Alexandria VA: ASCD.

Buehl, M. M., Alexander, P. A., \& Murphy, P. K. (2002). Beliefs about schooled knowledge: Domain specific or domain general? Contemporary Educational Psychology, 27(3), 415-449. https://doi.org/10.1006/ceps.2001.1103

Bybee, R., McCrae, B., \& Laurie, R. (2009). PISA 2006: An assessment of scientific literacy. Journal of Research in Science Teaching, 46(8), 865-883. https://doi.org/10.1002/tea.20333

Cabrera-Nguyen, P. (2010). Author Guidelines for Reporting Scale Development and Validation Results in the Journal of the Society for Social Work and Research. Journal of the Society for Social Work and Research, 1(2), 99-103. https://doi.o $\mathrm{rg} / 10.5243 /$ jsswr.2010.8

Cano, F. (2005). Epistemological beliefs and approaches to learning: Their change through secondary school and their influence on academic performance. British Journal of Educational Psychology, 75(2), 203-221. https: //doi.org/1 $0.1348 / 000709904 X 22683$

Carver, R. H., \& Nash, J. G. (2012). Doing Data Analysis with SPSS® Version 18. Boston: Cengage Learning. 
Cavallo, A. M., Rozman, M., Blinkenstaff, J., \& Walker, N. (2003). Students' learning approaches, reasoning abilities, motivational goals and epistemological beliefs in differing college science courses. Journal of College Science Teaching, 33, 18-23.

Chandler, M. J., Hallett, D., \& Sokol, B. W. (2002). Competing claims about competing knowledge claims. In P. R Pintrich (Ed.), Personal epistemology: The psychology of beliefs about knowledge and knowing (pp. 145-168). Mahwah, NJ, USA: Lawrence Erlbaum Associates Publishers.

Chen, J. A. (2012). Implicit theories, epistemic beliefs, and science motivation: A personcentered approach. Learning and Individual Differences, 22(6), 724-735. https://doi.org/10.1016/j.lindif.2012.07.013

Chen, J. A., Metcalf, S. J., \& Tutwiler, M. S. (2014). Motivation and beliefs about the nature of scientific knowledge within an immersive virtual ecosystems environment. Contemporary Educational Psychology, 39(2), 112-123. htt ps://doi.org/10.1016/j.cedpsych.2014.02.004

Chen, J. A., \& Pajares, F. (2010). Implicit theories of ability of Grade 6 science students: Relation to epistemological beliefs and academic motivation and achievement in science. Contemporary Educational Psychology, 35(1), 75-87. http s://doi.org/10.1016/j.cedpsych.2009.10.003

Chen, S. (2006). Development of an instrument to assess views on nature of science and attitudes toward teaching science. Science Education, 90(5), 803-819. https://doi.org/10.1002/sce.20147

Chumbley, S. B., Haynes, J. C., \& Stofer, K. A. (2015). A Measure of Students' Motivation to Learn Science through Agricultural STEM Emphasis. Journal of Agricultural Education, 56(4), 107-122. https://doi.org/10.5032/jae.2015.04107

Churchill, G. A. (1979). A Paradigm for Developing Better Measures of Marketing Constructs. Journal of Marketing Research, 16(1), 64. http s://doi.org/10.2307/3150876

Cleminson, A. (1990). Establishing an epistemological base for science teaching in the light of contemporary notions of the nature of science and of how children learn science. Journal of Research in Science Teaching, 27(5), 429-445.

Cohen, L., Manion, L., \& Morrison, K. (2007). Research methods in education (Sixth). New York: Routledge.

Cohen, R. J., \& Swerdlik, M. E. (2005). Psychological Testing and Assessment (6th ed.). New York: McGraw Hill.

Conley, A. M. M., Pintrich, P. R., Vekiri, I., \& Harrison, D. (2004). Changes in epistemological beliefs in elementary science students. Contemporary Educational Psychology, 29(2), 186-204. https://doi.org/10.1016/j.cedpsych.2004.01.004

Creswell, J. W., \& Plano Clark, V. L. (2017). Designing and conducting mixed methods research (3rd ed.). Thousand Oaks, CA: Sage. 
Cristobal, E., Flavián, C., \& Guinalíu, M. (2007). Perceived e - service quality (PeSQ). Managing Service Quality: An International Journal, 17(3), 317-340. https://doi.org/10.1108/09604520710744326

Dagher, Z. R., \& Erduran, S. (2016). Reconceptualizing the Nature of Science for Science Education. Science \& Education, 25(1-2), 147-164. htt ps://doi.org/10.1007/s11191-015-9800-8

Decoster, J., \& Hall, G. P. (2005). Scale Construction Notes. Construction, 9(2), 177204. https://doi.org/10.1300/J027v09n02_12

Deng, F., Chen, D.-T., Tsai, C.-C., \& Chai, C. S. (2011). Students' views of the nature of science: A critical review of research. Science Education, 95(6), 961-999. https://doi.org/10.1002/sce.20460

Dermitzaki, I., Stavroussi, P., Vavougios, D., \& Kotsis, K. T. (2013). Adaptation of the Students' Motivation Towards Science Learning (SMTSL) questionnaire in the Greek language. European Journal of Psychology of Education, 28(3), 747-766. https://doi.org/10.1007/s10212-012-0138-1

DeVellis, R. F. (2003). Scale development: Theory and applications (2nd ed.). Thousand Oaks, CA: Sage.

Dogan, N., \& Abd-El-Khalick, F. (2008). Turkish grade 10 students' and science teachers' conceptions of nature of science: A national study. Journal of Research in Science Teaching, 45(10), 1083-1112. https://doi.org/10.1002/tea.20243

Driver, R., Leach, J., Millar, R., \& Scott, P. (1996). Young people's images of science . Philadelphia: Open University Press.

Duschl, R., \& Grandy, R. (2011). Demarcation in science education: Towards an enhanced view of scientific method. In R. Taylor \& M. Ferrari (Eds.), Epistemology and science education: Understanding the evolution vs. intelligent design controversy (pp. 3-19). New York: Routledge.

Eita, J., Appolus, M., \& Ndimbira, J. (2004). Namibia Vision 2030. Office. Windhoek: NAMPRINT. Retrieved from http://wwwisis.unam.na/hivdocs/UNICEF/Vision 2030/NPC_Vision 2030_8_External environment - 68 p.pdf

Elder, A. D. (2002). Characterising first grade students' epistemological beliefs in science. In B. K. Hofer \& P. R. Pintrich (Eds.), Personal epistemology: The psychology of beliefs about knowledge and knowing. Mahwah, NJ, USA: Erlbaum.

Elliot, A. J., \& Mcgregor, H. A. (2001). A 2 X 2 Achievement Goal Framework, 80(3), 501-519. https://doi.org/10.1037//0022-3514.80.3.501

Elliot, A. J., \& Murayama, K. (2008). On the Measurement of Achievement Goals : Critique , Illustration , and Application, 100(3), 613-628. https://doi.org/10.1037/0022-0663.100.3.613

Everitt, B. S. (2002). The Cambridge Dictionary of statistics. Cambridge, UK: 
Cambridge University Press.

Field, A. (2005). Discovering Statistics Using SPSS (2nd ed.). London: Sage.

Field, A. (2009). Dicscovering Statistics Using SPSS. London: Sage Publications Ltd.

Fornell, C., \& Larcker, D. F. (1981). Evaluating Structural Equation Models with Unobservable Variables and Measurement Error. Journal of Marketing Research, 18(1), 39. https://doi.org/10.2307/3151312

Garson, G. D. (2015). Structural equation modelling. Asheboro, NC: Statistical Associates Publishers.

Gaskin, J. (2016). Validity master: Stats Tools Package. Retrieved from http://statwiki.kolobkreations.com

George, D., \& Mallery, P. (2003). SPSS for Windows step by step: A simple guide and reference. 11.0 update (4th ed.). Boston: Allyn \& Bacon.

Gess-Newsome, J. (2002). The use and impact of explicit instruction about the nature of science and science inquiry in an elementary science methods course. Science and Education, 11(1), 55-67. https://doi.org/10.1023/A:1013054823482

Gliem, J. A., \& Gliem, R. R. (2003). Calculating, Interpreting, and Reporting Cronbach's Alpha Reliability Coefficient for Likert-Type Scales, (1992), 82-88. https://doi.org/10.1109/PROC.1975.9792

Glynn, S. M., Brickman, P., Armstrong, N., \& Taasoobshirazi, G. (2011). Science motivation questionnaire II: Validation with science majors and nonscience majors. Journal of Research in Science Teaching, 48(10), 1159-1176. https://doi.org/10.1002/tea.20442

Glynn, S. M., Taasoobshirazi, G., \& Brickman, P. (2009). Science motivation questionnaire: Construct validation with nonscience majors. Journal of Research in Science Teaching, 46(2), 127-146. https://doi.org/10.1002/tea.20267

Grandy, R., \& Duschl, R. (2008). Consensus: Expanding the scientific method and school science. In R. Duschl \& R. Grandy (Eds.), Teaching scientific inquiry: Recommendations for research and implementation (pp. 304-325). Rotterdam, The Netherlands: Sense.

Greene, J. A., Azevedo, R., \& Torney-Purta, J. (2008). Modeling epistemic and ontological cognition: Philosophical perspectives and methodological directions. Educational Psychologist, $43(3), \quad 142-160$. https://doi.org/10.1080/00461520802178458

Gu, J., \& Belland, B. R. (2015). Emerging Technologies for STEAM Education. Emerging Technologies for STEAM Education, 39-60. https://doi.org/10.1007/9783-319-02573-5

Hair, J., Black, W., Babin, B., \& Anderson, R. (2010). Multivariate data analysis (7th 
ed.). Upper Saddle River, NJ, USA: Prentice-Hall, Inc.

Hair, J., Black, W., Babin, B., Anderson, R., \& Tatham, R. (2006). Multivariate Data Analysis (6th ed.). Upper Saddle River, NJ, USA: Pearson Prentice Hall.

Hair Jr, J. F., Hult, G. T. M., Ringle, C., \& Sarstedt, M. (2016). A primer on partial least squares structural equation modeling (PLS-SEM). Sage Publications.

Henson, R. K., \& Roberts, J. K. (2006). Use of exploratory factor analysis in published research: Common errors and some comment on improved practice. Educational and Psychological Measurement, 66(3), 393-416. $\mathrm{h}$ ttps://doi.or $\mathrm{g} / 10.1177 / 0013164405282485$

Hillman, S. J., Zeeman, S. I., Tilburg, C. E., \& List, H. E. (2016). My Attitudes Toward Science (MATS): the development of a multidimensional instrument measuring students' science attitudes. Learning Environments Research, 19(2), 203-219. https://doi.org/10.1007/s10984-016-9205-x

Ho, H.-N. J., \& Liang, J.-C. (2015). The Relationships Among Scientific Epistemic Beliefs, Conceptions of Learning Science, and Motivation of Learning Science: A study of Taiwan high school students. International Journal of Science Education, 0693(July 2016), 1-20. https://doi.org/10.1080/09500693.2015.1100346

Hochheimer, C. J., Sabo, R. T., Krist, A. H., Day, T., Cyrus, J., Woolf, S. H., ... Street, E. M. (2016). Methods for Evaluating Respondent Attrition in Web-Based Surveys Corresponding Author :, 18, 1-11. https://doi.org/10.2196/jmir.6342

Hofer, Barbara K. (2004). Epistemological Understanding as a Metacognitive Process: Thinking Aloud During Online Searching. Educational Psychologist, 39(1), 43-55. https://doi.org/10.1207/s15326985ep3901

Hooper, D., Coughlan, J., \& Mullen, M. R. (2008). Structural Equation Modelling: Guidelines for Determining Model Fit. The Electronic Journal of Business Research Methods, 6(1), 53-60.

Huang, W. Y., \& Wong, S. H. (2014). Cross-cultural validation. In A. C. Michalos (Ed.), Encyclopedia of Quality of Life and Well-Being Research (pp. 1369-1371). Dordrecht: Springer.

Ibrahim, B., Buffler, A., \& Lubben, F. (2009). Profiles of freshman physics students' views on the nature of science. Journal of Research in Science Teaching, 46(3), 248-264. https://doi.org/10.1002/tea.20219

Iipinge, S. M., \& Likando, G. N. (2012). The Educational assessment reforms in postindependence Namibia : A critical analysis, 9(2), 1-10.

Irzik, G., \& Nola, R. (2011). A Family Resemblance Approach to the Nature of Science for Science Education. Science and Education, 20(7), 591-607. ht tps://doi.org/10.1007/s11191-010-9293-4

Jansen, M., Scherer, R., \& Schroeders, U. (2015). Students' self-concept and self-efficacy 
in the sciences: Differential relations to antecedents and educational outcomes.

Contemporary Educational Psychology, 41, 13-24. h ttps://doi.org/10.1016/j.cedpsych.2014.11.002

Józsa, K., Kis, N., \& Barrett, K. C. (2018). Mastery motivation, parenting, and school achievement among Hungarian adolescents. European Journal of Psychology of Education, 34(2), 317-339. https://doi.org/10.1007/s10212-018-0395-8

Józsa, K., Kis, N., \& Huang, S.-Y. (2017). Mastery Motivation in School Subjects in Hungary and Taiwan. HERJ Hungarian Educational Research Journal, 7(2), 158177. https://doi.org/10.14413/HERJ/7/2/10

Kampourakis, K. (2016). The "general aspects" conceptualization as a pragmatic and effective means to introducing students to nature of science. Journal of Research in Science Teaching, 53(5), 667-682. https://doi.org/10.1002/tea.21305

Kandjeo-Marenga, H. (2011). Teaching and learning implications on group experiments and teacher demonstrations of process to teaching of process skills in biology: A case of two Namibian secondary schools. Analytical Reports in International Education, 1(4), 43-66. https://doi.org/10.3890/1542-3882-4-3

Khishfe, R. (2008). The development of seventh graders' views of nature of science. Journal of Research in Science Teaching, 45(4), 470-496. $\mathrm{h}$ ttps://doi.org/10.1002/tea.20230

Khishfe, R., \& Abd-El-Khalick, F. (2002). Influence of explicit and reflective versus implicit inquiry-oriented instruction on sixth graders' views of nature of science. Journal of Research in Science Teaching, 39(7), 551-578. htt ps://doi .org/10.1002/tea.10036

Khishfe, R., \& Lederman, N. (2007). Relationship between instructional context and views of nature of science. International Journal of Science Education, 29(8), 939961. https://doi.org/10.1080/09500690601110947

Kienhues, D., Bromme, R., \& Stahl, E. (2008). Changing epistemological beliefs: The unexpected impact of a short-term intervention. British Journal of Educational Psychology, 78(4), 545-565. https://doi.org/10.1348/000709907X268589

Kitchener, R. F. (2002). Folk epistemology: An introduction. New Ideas in Psychology, 20(2-3), 89-105. https://doi.org/10.1016/s0732-118x(02)00003-x

Kline, R. B. (2011). Principles and Practice of Structural Equation Modeling (3rd ed.). New York: The Guildford Press.

Kuhn, D. (1988). Cognitive development. In M. H. Bornstein (Ed.), Developmental Psychology: An advanced textbook (pp. 205-260). Hillsdale, NJ: Lawrence Erlbaum Associates Publishers.

Lawson, A. E., Banks, D. L., \& Logvin, M. (2007). Self-Efficacy, Reasoning Ability, and Achievement in College Biology. Journal of Research in Science Teaching, 44(5), 706-724. https://doi.org/10.1002/tea 
Leal-Soto, F., \& Ferrer-Urbina, R. (2017). Three-factor structure for Epistemic Belief Inventory: A cross-validation study. PLOS ONE, 12(3), 1-16. htt ps://doi. org/10.1371/journal.pone.0173295

Leden, L., Hansson, L., Redfors, A., \& Ideland, M. (2015). Teachers' Ways of Talking About Nature of Science and Its Teaching. Science and Education, 24(9-10), 11411172. https://doi.org/10.1007/s11191-015-9782-6

Lederman, J. S., Lederman, N. G., Bartos, S. A., Bartels, S. L., Meyer, A. A., \& Schwartz, R. S. (2014). Meaningful assessment of learners' understandings about scientific inquiry - The views about scientific inquiry (VASI) questionnaire. Journal of Research in Science Teaching, 51(1), 65-83. https://doi.o rg/10.1002/tea.21125

Lederman, N. G. (2006). Research on nature of science: reflections on the past, anticipations of the future. Asia-Pacific Forum on Science Learning and Teaching, 7(1), 1-11. Retrieved from https://www.ied.edu.hk/apfslt/download/v7 _issue1_files/foreword.pdf

Lederman, N. G., \& Abd-El-Khalick, F. (1998). Avoiding De-Natured Science: Activities that promote understandings of the nature of science. Chicago: Illinois Institute of Technology. https://doi.org/10.1007/0-306-47215-5_5

Lederman, N. G., Abd-El-Khalick, F., Bell, R. L., \& Schwartz, R. S. (2002). Views of Nature of Science Questionnaire: Toward Valid and Meaningful Assessment of Learners' Conceptions of Nature of Science. Journal of Research in Science Teaching, 39(6), 497-521. https://doi.org/10.1002/tea.10034

Lederman, N. G. (1992). Students' and teachers' conceptions of the nature of science: A review of the research. Journal of Research in Science Teaching, 29(4), 331-359. https://doi.org/10.1002/tea.3660290404

Lederman, N. G. (1999). Teachers' understanding of the nature of science and classroom practice: Factors that facilitate or impede the relationship. Journal of Research in Science Teaching, 36(8), 916-929. https://doi.org/10.1002/(SI CI)10982736(199910)36:8<916::AID-TEA2>3.0.CO;2-A

Lederman, N. G. (2007). Nature of science: Past, present and future. In S. K. Abell \& N. G. Lederman (Eds.), Handbook of research on science education (pp. 831-880). Mahwah, NJ,: Lawrence Erlbaum.

Lederman, N. G., Antink, A., \& Bartos, S. (2014). Nature of Science, Scientific Inquiry, and Socio-Scientific Issues Arising from Genetics: A Pathway to Developing a Scientifically Literate Citizenry. Science and Education, 23(2), 285-302. https://doi.org/10.1007/s11191-012-9503-3

Lederman, N. G., Lederman, J. S., \& Antink, A. (2013). Nature of Science and Scientific Inquiry as Contexts for the Learning of Science and Achievement of Scientific Literacy. International Journal of Education in Mathematics Science and Technology, 1(3), 138-147. https://doi.org/10.18404/ijemst.19784 
Lederman, N. G., Wade, P. D., \& Bell, R. L. (1998). Assessing the Nature of Science: What is the Nature of Our Assessments? Science and Education. https://doi.org/10.1023/A:1008601707321

Liang, J. C., \& Tsai, C. C. (2010). Relational analysis of college science-major students' epistemological. International Journal of Science Education, 32(17), 2273-2289. https://doi.org/10.1080/09500690903397796

Liu, S.-Y., \& Lederman, N. G. (2002). Taiwanese Gifted Students' Views of Nature of Science. School Science and Mathematics, 102, 114-123.

Malhotra, N. K., \& Dash, S. (2011). Marketing Research: An applied orientation. London: Pearson Publishing.

Marsh, H. W., \& Craven, R. G. (2006). Reciprocal Effects of Self- Concept and Performance From a Multidimensional Perspective: Beyond Seductive Pleasure and Unidimensional Perspectives. Perspective on Psychological Science, 1(2), 133-163.

Mathews, M. R. (1997). Editorial. Science \& Education, 6, 323-329.

Mathews, M. R. (2012). Changing the focus: From nature of science to features of science (FOS). In M. S. Khine (Ed.), Advances in nature of science research: Concepts and methodology (pp. 3-26). Dordrecht, The Netherlands: Springer.

Mazlo, J., Dormedy, D. F., Neimoth-Anderson, J. D., Urlacher, T., Carson, G. A., \& Kelter, P. B. (2002). Assessment of motivational methods in the general chemistry laboratory. Journalof College Science Teaching, 36, 318-321.

McComas, W. F. (1996). Ten Myths of Science: Reexamining What We Think We Know About the Nature of Science. School Science and Mathematics, 96(1), 10-16. https://doi.org/10.1111/j.1949-8594.1996.tb10205.x

McComas, W. F. (2008). Seeking historical examples to illustrate key aspects of the nature of science. Science and Education, 17(2-3), 249-263. htt ps://doi.org/10.1007/s11191-007-9081-y

McComas, W. F., Almazroa, H., \& Clough, M. P. (1998). The Nature of Science in Science Education: An Introduction. Science $\{\&\}$ Education. https ://doi.org/10.1023/A:1008642510402

McDonald, C. V. (2010). The influence of explicit nature of science and argumentation instruction on preservice primary teachers' views of nature of science. Journal of Research in Science Teaching, 47(9), 1137-1164. https://d oi.org/10.1002/tea.20377

Meichtry, Y. J. (1992). Influencing Student Understanding of the Nature of Science Data from a Case of Curriculum-Development. Journal of Research in Science Teaching, 29(4), 389-407. https://doi.org/10.1002/tea.3660290407

Meyling, H. (1997). How to change students' conceptions of the epistemology of science. Science \& Education. https://doi.org/10.1023/A:1017908916810 
Moss, D. M., Abrams, E. D., \& Robb, J. (2001). Examining student conceptions of the nature of science. International Journal of Science Education, 23(8), 771-790. https://doi.org/10.1080/09500690010016030

Muis, K. R., Bendixen, L. D., \& Haerle, F. C. (2006). Domain-generality and domainspecificity in personal epistemology research: Philosophical and empirical reflections in the development of a theoretical framework. Educational Psychology Review, 18(1), 3-54. https://doi.org/10.1007/s10648-006-9003-6

Murphy, P. K., Edwards, M. N., Buehl, M. M., \& Zeruth, J. A. (2007). Using the domainspecific beliefs questionnaire with adolescents enrolled in high-poverty, highminority schools: Examining psychometric properties. Journal of Experimental Education, 76(1), 3-25. https://doi.org/10.3200/JEXE.76.1.3-25

Muthén, L. K., \& Muthén, B. O. (2017). Mplus User's Guide (8th ed.). Los Angeles, CA: Muthén \& Muthén. https://doi.org/10.1111/j.1600-0447.2011.01711.X

Namibia. Ministry of Education [MoE]. (2010a). Junior Secondary Phase Life Science Syllabus. Okahandja: NIED.

Namibia. Ministry of Education [MoE]. (2010b). Junior Secondary Phase Physical Science Syllabus. Okahandja: NIED.

Namibia. Ministry of Education [MoE]. (2010c). Namibia Senior Secondary Certificate Biology Syllabus: Higher Level (Vol. 32). Okahandja: NIED. ht tps://do i.org/10.1136/adc.32.161.66

Namibia. Ministry of Education [MoE]. (2010d). Namibia Senior Secondary Certificate Physical Science Syllabus: Higher Level (Vol. 32). Okahandja: NIED. https://doi .org/10.1136/adc.32.161.66

Namibia. Ministry of Education [MoE]. (2010e). The national curriculum for basic education. Okahandja: NIED.

Namibia. Ministry of Education [MoE]. (2016). Senior Primary Phase Natural Science and Health Education Syllabus. Okahandja: NIED.

National Academy of Sciences. (2010). Expanding underrepresented minority participation: american's science and technology talent at the crossroads. Nas. Washignton DC: National Academies Press. https://doi.org/10.17226/12984

National Research Council. (2007). Taking Science to School: Learning and Teaching Science in Grades K-8. Washington, DC: National Academies Press.

National Research Council (NRC). (2000). Inquiry and the National Science Education Standards: A guide for teaching and learning. Washington, DC: National Academies Press. https://doi.org/10.17226/9596

Nemeth, M. B., \& Korom, E. (2012). Science literacy and the Application of Scientific knowledge. In B. Csapo \& G. Szabo (Eds.), Framework for Diagnostic Assessment of Science (pp. 55-87). Budapest: Nemzeti Tankonyvkiado Zrt. 
Niaz, M. (2008). What "ideas-about-science" should be taught in school science? A chemistry teachers' perspective. Instructional Science, 36(3), 233-249. https://doi.org/10.1007/s11251-007-9031-8

Nowak, K. H., Nehring, A., Tiemann, R., \& Upmeier Zu Belzen, A. (2013). Assessing students abilities in processes of scientific inquiry in biology using a paper-andpencil test. Journal of Biological Education, 47(3), 182-188. htt ps://doi .org/10.1080/00219266.2013.822747

O'connor, B. P. (2000). SPSS and SAS programs for determining the number of components using parallel analysis and Velicer's MAP test. Behavior Research Methods, Instruments, \& Computers, 32(3), 396-402. ht tps:/ /doi.org/10.3758/BF03200807

Ogunniyi, M. B. (1982). An Analysis of Prospective Science Teachers Understanding of the Nature of Science - Comment. Journal of Research in Science Teaching, 19(1), $25-32$.

Osborne, J., Collins, S., Ratcliffe, M., Millar, R., \& Duschl, R. (2003). What "ideasabout-science" should be taught in school science? A delphi study of the expert community. Journal of Research in Science Teaching, 40(7), 692-720. https://doi.org/10.1002/tea.10105

Paechter, M., Rebmann, K., Schloemer, T., Mokwinski, B., Hanekamp, Y., \& Arendasy, M. (2013). Development of the Oldenburg Epistemic Beliefs Questionnaire (OLEQ), a German questionnaire based on the Epistemic Belief Inventory (EBI). Current Issues in Education, 16(1), 1-18.

Paulsen, M. B., \& Feldman, K. A. (2007). The conditional and interaction effects of epistemological beliefs on the self-regulated learning of college students: Cognitive and behavioral strategies. Research in Higher Education, 48(3), 353-401. https://doi.org/10.1007/s11162-006-9029-0

Peffer, M. E., \& Ramezani, N. (2019). Assessing epistemological beliefs of experts and novices via practices in authentic science inquiry, 9(6), 3-23.

Peters-Burton, E. (2016). Scientists Taking a Nature of Science Course: Beliefs and Learning Outcomes of Career Switchers. School Science and Mathematics, 116(3), 148-163. https://doi.org/10.1111/ssm.12161

Peters, E. E. (2012). Developing Content Knowledge in Students Through Explicit Teaching of the Nature of Science: Influences of Goal Setting and Self-Monitoring. Science and Education, 21(6), 881-898. https://d oi.org/10.1007/s11191-009-92191

Piedmont, R. L. (2014). Inter-item correlations. In A. C. Michalos (Ed.), Encyclopedia of Quality of Life and Well-Being Research (pp. 3303-3304). Netherlands: Springer Netherlands.

Pintrich, Paul R. (2003). A Motivational Science Perspective on the Role of Student 
Motivation in Learning and Teaching Contexts. Journal of Educational Psychology, 95(4), 667-686. https://doi.org/10.1037/0022-0663.95.4.667

Pintrich, Paul R., \& Schunk, D. H. (1996). Motivation in education: Theory, research and application (2nd ed.). Englewood Cliffs, NJ: Merrill Company.

Pintrich, Paul R., \& Schunk, D. H. (2002). Motivation in education: Theory, Research, and Applications (2nd ed.). Columbus, Ohio: Merrill Prentice Hall.

Quigley, C., Pongsanon, K., \& Akerson, V. L. (2011). If We Teach Them, They Can Learn: Young Students Views of Nature of Science During an Informal Science Education Program. Journal of Science Teacher Education, 22(2), 129-149. https://doi.org/10.1007/s10972-010-9201-4

Rebelo-Pinto, T., Pinto, J. C., Rebelo-Pinto, H., \& Paiva, T. (2014). Validation of a threedimensional model about sleep: Habits, personal factors and environmental factors. Sleep Science, 7(4), 197-202. https://doi.org/10.1016/j.slsci.2014.12.002

Reilly-Shah, V. N. O. (2017). Factors influencing healthcare provider respondent fatigue answering a globally administered in-app survey. PeerJ, 5(3785). https://doi.org/10.7717/peerj.3785

Rüschenpöhler, L., \& Markic, S. (2019). Self-concept research in science and technology education-theoretical foundation, measurement instruments, and main findings. Studies in Science Education, 55(1), 37-68. https: //doi.org/10.1080/03057267.2019.1645533

Schraw, G., Bendixen, L. D., \& Dunkle, M. E. (2002). Development and validation of the Epistemic Belief Inventory (EBI). In K. Hofer \& P. R. Pintrich (Eds.), Personal epistemology: The psychology of beliefs about knowledge and knowing (pp. 261275). Mahwah, NJ, US: Lawrence Erlbaum Associates Publishers.

Schwartz, R. S., Lederman, N. G., \& Crawford, B. A. (2004). Developing views of nature of science in an authentic context: An explicit approach to bridging the gap between nature of science and scientific inquiry. Science Education, 88(4), 610-645. https://doi.org/10.1002/sce.10128

Simpkins, S. D., Davis-Kean, P. E., \& Eccles, J. S. (2006). Math and science motivation: A longitudinal examination of the links between choices and beliefs. Developmental Psychology, 42(1), 70-83. https:/ /doi.org/10.1037/0012-1649.42.1.70

Smith, M. U., \& Scharmann, L. C. (1999). Defining versus describing the nature of science: A pragmatic analysis for classroom teachers and science educators. Science Education, $\quad 83(4), \quad$ 493-509. https://doi.org/10.1002/(SICI)1098237X(199907)83:4<493::AID-SCE6>3.0.CO;2-U

Songer, N. B., \& Linn, M. C. (1991). How do students' views of science influence knowledge integration? Journal of Research in Science Teaching, 28(9), 761-784. https://doi.org/10.1002/tea.3660280905

Stanley, L. M., \& Edwards, M. C. (2016). Reliability and Model Fit, 76(6), 976-985. 
https://doi.org/10.1177/0013164416638900

Stathopoulou, C., \& Vosniadou, S. (2007). Exploring the relationship between physicsrelated epistemological beliefs and physics understanding. Contemporary Educational Psychology, 32(3), 255-281. https://doi.org/10.1016/j.cedp sych.2005.12.002

Streiner, D. L. (2003). Starting at the Beginning: An Introduction to Coefficient Alpha and Internal Consistency Starting at the Beginning: An Introduction to Coefficient Alpha and Internal Consistency. Journal of Personality Assessment, 80(1), 99-103. https://doi.org/10.1207/S15327752JPA8001

Summers, R., \& Abd-El-Khalick, F. (2017). Development and validation of an instrument to assess student attitudes toward science across grades 5 through 10. Journal of Research in Science Teaching, 55(2), 172-205. h ttps://doi.org/10.1002/tea.21416

Tala, S., \& Vesterinen, V. M. (2015). Nature of Science Contextualized: Studying Nature of Science with Scientists. Science and Education, 24(4), 435-457. https://doi.org/10.1007/s11191-014-9738-2

Teo, T. (2013). Examining the Psychometric Properties of the Epistemic Belief Inventory (EBI). Journal of Psychoeducational Assessment, 31(1), 72-79. https://doi.org/10.1177/0734282912449436

Thye, T. L., \& Kwen, B. H. (2003). Assessing the nature of science views of Singaporean pre-service teachers. Annual Conference of the New Zealand/Australian Association for Research in Education. November 30 - December 3, 2003, 29(109433), 1-11. https://doi.org/10.14221/ajte.2004v29n2.1

Trautwein, U., \& Lüdtke, O. (2007). Epistemological beliefs, school achievement, and college major: A large-scale longitudinal study on the impact of certainty beliefs. Contemporary Educational Psychology, 32(3), 348-366. https://doi.org/10.1016/ j.cedpsych.2005.11.003

Tsai, C. C., Jessie Ho, H. N., Liang, J. C., \& Lin, H. M. (2011). Scientific epistemic beliefs, conceptions of learning science and self-efficacy of learning science among high school students. Learning and Instruction, 21(6), 757-769. https://doi.org/10. /j.learninstruc.2011.05.002

Tuan, H. L., Chin, C. C., \& Shieh, S. H. (2005). The development of a questionnaire to measure students' motivation towards science learning. International Journal of Science Education, 27(6), 639-654.https://doi.org/10.1080/0950069042000323737

Turiman, P., Omar, J., Daud, A. M., \& Osman, K. (2012). Fostering the 21st Century Skills through Scientific Literacy and Science Process Skills. Procedia - Social and Behavioral Sciences, 59, 110-116. https://doi.org/ 10.1016/j.sb spro.201 2.09 .253

van Sonderen, E., Sanderman, R., \& Coyne, J. C. (2013). Ineffectiveness of Reverse Wording of Questionnaire Items: Let's Learn from Cows in the Rain. PLoS ONE, 8(7), 1-7. https://doi.org/10.1371/journal.pone.0068967 
Vesterinen, V. M., Aksela, M., \& Lavonen, J. (2013). Quantitative Analysis of Representations of Nature of Science in Nordic Upper Secondary School Textbooks Using Framework of Analysis Based on Philosophy of Chemistry. Science and Education, 22(7), 1839-1855. https://doi.org/10.1007/s11191-011-9400-1

Vhurumuku, E. (2010). The impact of explicit instruction on undergraduate students' understanding of the nature of science. African Journal of Research in Mathematics, Science and Technology Education, 14(1), 99-111. https://doi.org/10. 1080/10288457.2010.10740676

Vhurumuku, E., Holtman, L., Mikalsen, O., \& Kolsto, S. D. (2006). An investigation of Zimbabwe high school chemistry students' laboratory work-based images of the nature of science. Journal of Research in Science Teaching, 43(2), 127-149. https://doi.org/10.1002/tea.20098

Virginia Mathematics and Science Coalition. (2013). Teaching About Scientific Inquiry and the Nature of Science: Towards a more complete view of science. The Journal of Mathematics and Science: Collaborative Explorations, 13, 5-25.

Wang, C. L., \& Liou, P. Y. (2017). Students' motivational beliefs in science learning, school motivational contexts, and science achievement in Taiwan. International Journal of Science Education, 39(7), 898-917. https://doi.org/10.1080/ 09500693.2017.1310410

Weijters, B., Baumgartner, H., \& Schillewaert, N. (2013). Reversed item bias: An integrative model. Psychological Methods, 18(3), 320-334. https://doi.org/10.1037/ a0032121

Wellman, H. M. (1992). The child's theory of mind. Cambridge, MA: The MIT Press.

Wenning, C. J. (2006). Assessing nature-of-science literacy as one component of scientific literacy. Journal of Physics Teacher Education Online, 3, 3-14.

Wieland, A., Durach, C. F., Kembro, J., \& Treiblmaier, H. (2017). Statistical and judgmental criteria for scale purification. Supply Chain Management: An International Journal, 22(4), 321-328. https://doi.org/10.1108/SCM-07-2016-0230

Windschitl, M. (1999). A vision educators can put into practice: Portraying the constructivist classroom as a cultural system. School Science and Mathematics, 99(4), 189-196.

Wong, S. L., Hodson, D., Kwan, J., \& Yung, B. H. W. (2008). Turning crisis into opportunity: Enhancing student-teachers' understanding of nature of science and scientific inquiry through a case study of the scientific research in severe acute respiratory syndrome. International Journal of Science Education, 30(11), 14171439. https://doi.org/10.1080/09500690701528808

Worthington, R. L., \& Whittaker, T. A. (2006). Scale Development Research: A Content Analysis and Recommendations for Best Practices. The Counseling Psychologist, 34(6), 806-838. https://doi.org/10.1177/0011000006288127 
Yilmaz, H., \& Çava, P. H. (2007). Reliability and Validity Study of the Students ' Motivation toward Science Learning ( SMTSL ) Questionnaire. Elementary Education Online, 6(3), 430-440. Retrieved from http://ilkogretim-online.org.tr

Zusho, A., Pintrich, P. R., \& Coppola, B. (2003). Skill and will: The role of motivation and cognition in the learning of college chemistry. International Journal of Science Education, 25(9), 1081-1094. https://doi.org/10.1080/0950069 032000052207

\section{PUBLICATIONS RELATED TO THE DISSERTATION}

Shaakumeni, S. N. (2019). Exploring the factorability of the nature of science construct. 27th Annual Conference of the Southern African Association for Research in Mathematics, Science and Technology Education (SAARMSTE). Durban, South Africa. January 1417,2019

Shaakumeni, S. N. (2019). Assessing the factorability of the eight-dimension nature of science. 23rd Conference of the Junior Researchers of European Association for Research on Learning and Instruction (EARLI). Aachen, Germany. August 10-11, 2019.

Shaakumeni, S. N., \& Csapó, B. (2019). Exploring the Factorial Validity of the Beliefs about Nature of Science Questionnaire. Science Education International, 30(1), 38-44.

Shaakumeni, S. N. (2019). Assessing students' scientific epistemic beliefs. 17th Conference on Educational Assessment. Szeged, Hungary. April 11-13, 2019.

Shaakumeni, S. N. (2019). Assessing the suitability of the adapted scientific epistemic beliefs questionnaire in Namibia. Journal of Studies in Education, 9 (2).

Shaakumeni, S. N. (2019). Validation of an instrument to assess beliefs about nature of science and scientific inquiry in Namibia. European Journal Educational Sciences, 6 (2).

Shaakumeni, S. N. (2018). The nature of science conception: A review of literature. Reform Forum Journal of Educational Reform in Namibia, 26(1), 60-74.

Shaakumeni, S. N., \& Csapó, B. (2018). Exploring the possibility of assessing students' motivation to learn science in Namibia. 16th Conference on Educational Assessment. Szeged, Hungary. April 26-28, 2018.

Shaakumeni, S. N., \& Csapó, B. (2018). Examining the psychometric properties of an instrument for assessing motivation to learn science in Namibia. EDULEARN18: 10th International Conference on Education and New Learning Technologies. Palma de Mallorca, Spain. July 02-04, 2018.

Shaakumeni, S. N., \& Csapó, B. (2018). A cross-cultural validation of adapted questionnaire for assessing motivation to learn science. African Journal of Research in Mathematics, Science and Technology Education, 22 (3), 340-350. 


\section{APPENDICES}

\section{Appendix 1: Beliefs About Nature of Science Questionnaire and Scientific Inquiry (Study 1)}

Information: Nature of science is concerned with the values and beliefs that characterises scientific knowledge and its development. Each statement is about the characteristics of scientific knowledge. This is NOT a test and it's not an evaluation of your work. We are just looking for your views. Please circle your choice.

Gender: Male | Female

\section{Science subject taught: $\quad$ Biology/Life Science | Physical Science}

Location: $\quad$ Urban | Rural

Qualification: Degree | Diploma | Others (specify:

Science teaching experience: 0 -3years $\mid 3-5$ years $\mid$ 5-10years $\mid 10+$ years

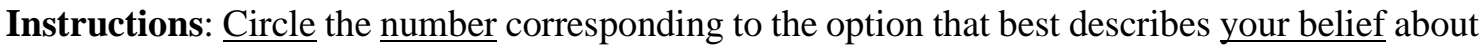
each statement. The options are $\underline{1=\text { Strongly Disagree }}, \underline{2=\text { Disagree }} ; \underline{3=\text { Not Sure }} ; \underline{4=\text { Agree }} ; \underline{5}$ = Strongly agree. There is no correct or wrong answer. The numbers are just labels, they do not mean any order of importance. Kindly respond to all statements.

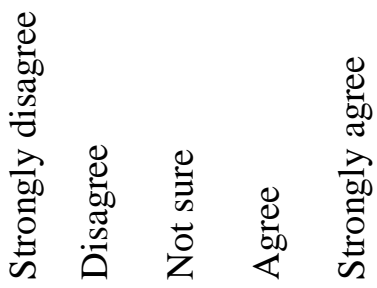

1. Scientific knowledge changes as we learn more about the natural $\begin{array}{lllll}1 & 2 & 3 & 4 & 5\end{array}$ world.

2. Scientific knowledge changes due to the changes in cultural $\quad \begin{array}{lllll}1 & 2 & 3 & 4 & 5\end{array}$ interests.

3. Scientific knowledge changes as scientists reconsider existing $\quad \begin{array}{lllll}1 & 2 & 3 & 4 & 5\end{array}$ evidence.

4. Scientific knowledge changes due to changes in social interests. $\begin{array}{llllll}1 & 2 & 3 & 4 & 5\end{array}$

5. Scientific knowledge changes due to advances in technology. $\begin{array}{llllll}1 & 2 & 3 & 4 & 5\end{array}$

$\begin{array}{llllll}\text { 6. Scientific laws and theories are not final, they change. } & 1 & 2 & 3 & 4 & 5\end{array}$

7. Experiments are not the only source of scientific evidence. $\quad \begin{array}{llllll}1 & 2 & 3 & 4 & 5\end{array}$ 
8. Experiments support rather than prove scientific claims. $\quad \begin{array}{llllll}1 & 2 & 3 & 4 & 5\end{array}$

9. Observations are used to make scientific claims. $\quad \begin{array}{llllll}1 & 2 & 3 & 4 & 5\end{array}$

10. Observations are also a source of scientific evidence. $\quad \begin{array}{lllll}1 & 2 & 3 & 4 & 5\end{array}$

11. Scientists do not use a single procedure called the scientific $\quad \begin{array}{llllll}1 & 2 & 3 & 4 & 5\end{array}$ method.

12. There is no single step-by-step scientific method that all $\quad \begin{array}{llllll}1 & 2 & 3 & 4 & 5\end{array}$ scientists follow.

13. Scientists use various methods in search of scientific $\quad \begin{array}{lllll}1 & 2 & 3 & 4 & 5\end{array}$ knowledge.

14. Scientific conclusions are influenced by scientists' personal $\quad \begin{array}{llllll}1 & 2 & 3 & 4 & 5\end{array}$ feelings.

15. Scientists' backgrounds, cultures and beliefs influence their $\begin{array}{llllll}1 & 2 & 3 & 4 & 5\end{array}$ work.

16. It is possible for scientists to look at the same evidence or set of $\begin{array}{llllll}1 & 2 & 3 & 4 & 5\end{array}$ data and come up with different conclusions.

17. Scientists use their creativity to analyse data. $\quad \begin{array}{llllll}1 & 2 & 3 & 4 & 5\end{array}$

18. Scientists use their creativity to interpret data. $\quad \begin{array}{llllll}1 & 2 & 3 & 4 & 5\end{array}$

19. Scientists use their creativity to invent explanations. $\quad \begin{array}{llllll} & 1 & 2 & 3 & 4 & 5\end{array}$

20. Models (e.g. atoms, species etc) are not exact copies of how $\begin{array}{llllll}1 & 2 & 3 & 4 & 5\end{array}$ things are in reality.

21. Scientists use imagination throughout the entire process of $\quad \begin{array}{llllll}1 & 2 & 3 & 4 & 5\end{array}$ investigation.

22. Science is influenced by religion. $\quad \begin{array}{lllll}1 & 2 & 3 & 4 & 5\end{array}$

23. Science is influenced by economic factors e.g. research funding $\begin{array}{llllll}1 & 2 & 3 & 4 & 5\end{array}$

24. The values of the culture determine how science is practiced. $\begin{array}{llllll}1 & 2 & 3 & 4 & 5\end{array}$

25. Science is influenced by cultures. $\quad \begin{array}{lllll}1 & 2 & 3 & 4 & 5\end{array}$

26. There is a difference between observations and inferences $\quad \begin{array}{llllll}1 & 2 & 3 & 4 & 5\end{array}$ (interpretations).

27. Observations are descriptions of the natural world obtained $\quad \begin{array}{llllll}1 & 2 & 3 & 4 & 5\end{array}$ using human senses.

28. Inferences are interpretations of observations that are not $\quad \begin{array}{llllll}1 & 2 & 3 & 4 & 5\end{array}$ accessible to human senses.

29. There is a difference between scientific theories and laws. $\quad \begin{array}{llllll}1 & 2 & 3 & 4 & 5\end{array}$

30. Scientific theories are inferred explanations of observable $\quad \begin{array}{lllll}1 & 2 & 3 & 4 & 5\end{array}$ phenomena. 
31. Scientific theories and laws are different kinds of scientific $\begin{array}{lllll}1 & 2 & 3 & 4 & 5\end{array}$ knowledge.

32. Scientific laws are descriptions of the relationship among $\begin{array}{lllll}1 & 2 & 3 & 4 & 5\end{array}$ observable phenomena.

33. Hypotheses do not become theories that in turn become laws. $\begin{array}{llllll}1 & 2 & 3 & 4 & 5\end{array}$

34. Theories do not become laws, even with additional evidence. $\begin{array}{llllll}1 & 2 & 3 & 4 & 5\end{array}$

35. Theories and laws are equally legitimate products of science. $\begin{array}{lllllll}1 & 2 & 3 & 4 & 5\end{array}$

36. All scientific investigations generally starts with a question. $\begin{array}{llllll}1 & 2 & 3 & 4 & 5\end{array}$

37. The method of investigations must be suitable for answering the $\begin{array}{llllll}1 & 2 & 3 & 4 & 5\end{array}$ question asked.

38. Scientific data is not the same as scientific evidence.

39. All investigations do not necessarily have to formally state a $\begin{array}{lllllll}1 & 2 & 3 & 4 & 5\end{array}$ hypothesis.

40. Research conclusions must be supported by the evidence from $\begin{array}{llllll}1 & 2 & 3 & 4 & 5\end{array}$ the data collected. 


\section{Appendix 2: Beliefs About Nature of Science Questionnaire (BANOS) (Study 2)}

Information: Nature of science is concerned with the values and beliefs that characterises scientific knowledge and its development. Each statement is about the characteristics of scientific knowledge. This is NOT a test and it's not an assessment of your school work. We are just looking for your views. Please circle your choice.

Gender: $\quad$ Male | Female

Age:

Location: Urban | Rural

Mother's level of education: Degree | Diploma | Matric | Below matric | I Don't know

Instructions: Circle the number corresponding to the option that best describes your belief about each statement. The options are $1=$ Strongly Disagree; $2=$ Disagree; $3=$ Not Sure; $4=$ Agree; 5 $=$ Strongly agree. There is no correct or wrong answer. Kindly respond to all statements.

1. Scientists can look at the same evidence or set of data and come up with different conclusions

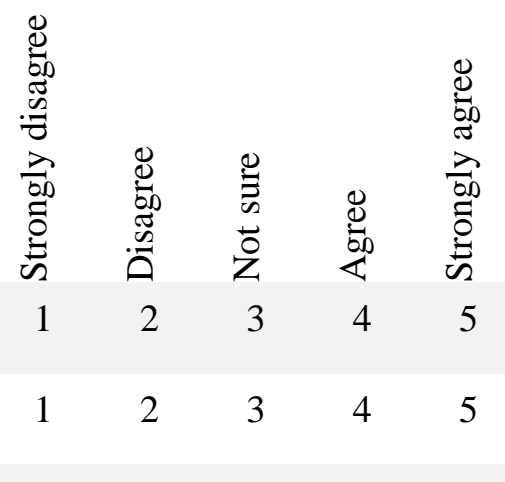

3. Scientists' backgrounds and beliefs influence their $\begin{array}{lllllll}1 & 2 & 3 & 4 & 5\end{array}$ work

4. Inferences are conclusions about observations that $\begin{array}{llllll}1 & 2 & 3 & 4 & 5\end{array}$ are not accessible to human senses

5. Science knowledge can change as scientists reconsider existing evidence

$\begin{array}{lllll}1 & 2 & 3 & 4 & 5\end{array}$

6. Scientific conclusions are influenced by scientists' $\quad \begin{array}{lllllll}1 & 2 & 3 & 4 & 5\end{array}$ personal feelings

7. Scientists use their creativity to analyse data $\quad \begin{array}{llllll}1 & 2 & 3 & 4 & 5\end{array}$

8. There is a difference between observations and $\quad \begin{array}{lllllll}1 & 2 & 3 & 4 & 5\end{array}$ inferences (conclusions)

9. Scientific evidence can be obtained from $\quad \begin{array}{lllllll}1 & 2 & 3 & 4 & 5\end{array}$ observations of the natural world

10. Scientists can use human senses to make scientific $\quad \begin{array}{lllllll}1 & 2 & 3 & 4 & 5\end{array}$ claims (observations)

11. Experiments support rather than prove scientific $\quad \begin{array}{lllllll}1 & 2 & 3 & 4 & 5\end{array}$ claims

12. Scientific theories are conclusions about observable phenomena

$\begin{array}{lllll}1 & 2 & 3 & 4 & 5\end{array}$


13. Experiments are not the only source of scientific evidence

14. There is no single step-by-step method that all scientists in the world follow

15. Scientists use different procedures to study the natural world

16. Various methods can be used in search of scientific knowledge

17. Scientific laws are descriptions of the relationship among observable phenomena

18. Theories do not become laws even with additional $\begin{array}{lllllll}1 & 2 & 3 & 4 & 5\end{array}$ evidence

19. Theories and laws are different kinds of scientific $\begin{array}{llllllll}1 & 2 & 3 & 4 & 5\end{array}$ knowledge

20. Science is influenced by cultures

21. Science is influenced by economic factors such as $\begin{array}{lllllll}1 & 2 & 3 & 4 & 5\end{array}$ research funding

22. The values of the culture determine how science is $\begin{array}{lllllll}1 & 2 & 3 & 4 & 5\end{array}$ practiced

23. Scientists use imagination throughout the entire $\quad \begin{array}{lllllll}1 & 2 & 3 & 4 & 5\end{array}$ process of investigation

24. Scientists use their creativity to interpret data

25. Models like atoms and species are products of human imagination

26. Some scientific ideas today were different in the past

27. Scientific ideas can change due to advances in technology

28. Scientific ideas in the science books can change $\begin{array}{lllllll}1 & 2 & 3 & 4 & 5\end{array}$ 


\section{Appendix 3: Adapted Students' Motivation Towards Science Learning (Study 3)}

This questionnaire contains statements about your willingness to learn science (Biology/Physical Science). We ask you to express your agreement on each statement. There are no "right" or "wrong" answers. We just need your opinion. Think about how well each statement describes your willingness to learn science in school. Ensure that you respond to all statements. Circle your choice.

Gender: $\quad$ Male | Female

Age:

Location: Urban | Rural

Mother's level of education: Degree | Diploma | Matric | Below matric | I don't know

Instructions: Circle the number corresponding to the option that best describes your belief about each statement. The options are $1=$ Never; $2=$ Rarely; $3=$ No opinion; $4=$ Usually; $5=$ Always.

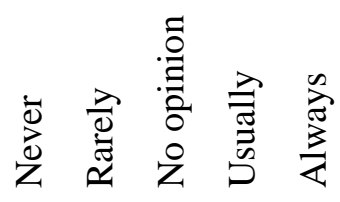

1. I am sure that I can understand science content even when it is $\begin{array}{lllll}1 & 2 & 3 & 4 & 5\end{array}$ difficult.

2. I am confident about understanding difficult science concepts. $\quad \begin{array}{llllll}1 & 2 & 3 & 4 & 5\end{array}$

3. I do not give up even when science activities are too difficult for $\begin{array}{llllll}1 & 2 & 3 & 4 & 5\end{array}$ me.

4. I prefer to think for myself rather than ask other people for help $\begin{array}{llllll}1 & 2 & 3 & 4 & 5\end{array}$ during science activities.

5. When I learn new science concepts, I connect them to my $\quad \begin{array}{lllll}1 & 2 & 3 & 4 & 5\end{array}$ previous understanding.

6. When I do not understand a science concept, I use other sources $\begin{array}{llllll}1 & 2 & 3 & 4 & 5\end{array}$ of information.

7. When I meet science concepts that I do not understand, I still try $\quad 1 \quad 2 \quad 2 \quad 3 \quad 4 \quad 5$ to learn them.

8. When I do not understand a science concept, I discuss with $\begin{array}{lllll}1 & 2 & 3 & 4 & 5\end{array}$ others to clarify my understanding.

9. I think learning science is important because I can use it in my $\begin{array}{lllll}1 & 2 & 3 & 4 & 5\end{array}$ life. 
10. I think learning science is important because it stimulates my $\quad \begin{array}{lllll}1 & 2 & 3 & 4 & 5\end{array}$ thinking.

11. I think it is important to learn science because it provides an $\quad \begin{array}{llllll}1 & 2 & 3 & 4 & 5\end{array}$ opportunity to satisfy my own curiosity.

12. I think it is important to participate in science activities during $\begin{array}{llllll}1 & 2 & 3 & 4 & 5\end{array}$ learning.

13. I feel very good when I get good marks in science tests.

14. I feel good when I am able to solve a difficult science task.

15. I feel good when my science teacher accepts my ideas during $\quad \begin{array}{llllll}1 & 2 & 3 & 4 & 5\end{array}$ science lessons.

16. I feel good when other learners accept my ideas during science $\begin{array}{llllll}1 & 2 & 3 & 4 & 5\end{array}$ lessons.

17. I am willing to participate in science lessons because the content $\begin{array}{llllll}1 & 2 & 3 & 4 & 5\end{array}$ is exciting.

18. I am willing to participate in science lessons because the teacher $\begin{array}{lllll}1 & 2 & 3 & 4 & 5\end{array}$ does not put a lot of pressure on me.

19. I am willing to participate in science lessons because the teacher $\begin{array}{lllll}1 & 2 & 3 & 4 & 5\end{array}$ pays attention to me.

20. I am willing to participate in science lessons because learners $\begin{array}{llllll}1 & 2 & 3 & 4 & 5\end{array}$ are involved in discussions. 


\section{Appendix 4: Adapted Scientific Epistemic Beliefs Questionnaire (SEBs) (Study 4)}

Information: This questionnaire seeks your beliefs about nature of scientific knowledge and learning. This is NOT a test and it's not an assessment of your school work. We are just looking for your views about science learning.

Please circle your choice and fill in your age.

Grade: $\quad 11 \quad 12$

Gender: $\quad$ Male | Female

Age:

Mother's level of education: Degree | Diploma | Matric | Below matric | I Don't know

Instructions: $\underline{\text { Circle }}$ the number corresponding to the option that best describes your belief about each statement. The options are $\mathbf{1}=$ Strongly Disagree $\mid \mathbf{2}=$ Disagree $\mid \mathbf{3}=$ Not Sure $\mid \mathbf{4}=$ Agree $\mid \mathbf{5}=$ Strongly agree. There is no correct or wrong answer. Please respond to all statements.

1. Everybody has to believe what scientists say.

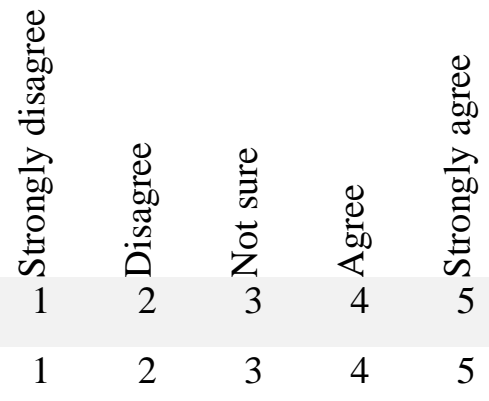

2. In science, you have to believe what the science $\begin{array}{lllllll}1 & 2 & 3 & 4 & 5\end{array}$ books say about things.

3. Whatever the teacher says in science class is $\quad \begin{array}{llllll}1 & 2 & 3 & 4 & 5\end{array}$ true.

4. If you read something in a science book, you $\quad \begin{array}{llllll}1 & 2 & 3 & 4 & 5\end{array}$ can be sure it is true.

5. All questions in science have one right answer. $\begin{array}{lllllll}1 & 2 & 3 & 4 & 5\end{array}$

6. The most important part of doing science is $\quad \begin{array}{llllll}1 & 2 & 3 & 4 & 5\end{array}$ coming up with the right answer.

7. Scientists know everything about science; there $\begin{array}{lllllll}1 & 2 & 3 & 4 & 5\end{array}$ is not much more to know.

8. Scientific knowledge is always true. $\quad \begin{array}{lllllll}1 & 2 & 3 & 4 & 5\end{array}$ 
9. Once scientists have the result from an

$\begin{array}{lllll}1 & 2 & 3 & 4 & 5\end{array}$

experiment, that is the only answer.

10. Some ideas in science today are different than $\begin{array}{llllll}1 & 2 & 3 & 4 & 5\end{array}$ what scientists used to think.

11. The ideas in science books sometimes change. $\begin{array}{lllllll}1 & 2 & 3 & 4 & 5\end{array}$

12. There are some questions that even scientists $\quad \begin{array}{lllllll}1 & 2 & 3 & 4 & 5\end{array}$ cannot answer.

13. Sometimes scientists change their minds about $\quad \begin{array}{llllll}1 & 2 & 3 & 4 & 5\end{array}$ what is true in science.

14. Existing ideas in science may change as $\quad \begin{array}{lllllll}1 & 2 & 3 & 4 & 5\end{array}$ scientists come up with new ones.

15. Scientific ideas may change because $\quad \begin{array}{llllll}1 & 2 & 3 & 4 & 5\end{array}$ technology may lead to new findings.

16. Ideas about science experiments come from $\quad \begin{array}{llllllll}1 & 2 & 3 & 4 & 5\end{array}$ being curious and thinking about how things work.

17. In science, there can be more than one way for $\begin{array}{lllllll}1 & 2 & 3 & 4 & 5\end{array}$ scientists to test their ideas.

18. One important part of science is doing $\quad \begin{array}{llllll}1 & 2 & 3 & 4 & 5\end{array}$ experiments to come up with new ideas about how things work.

19. Good answers are based on evidence from $\quad \begin{array}{lllllll}1 & 2 & 3 & 4 & 5\end{array}$ many different experiments.

20. Ideas in science can come from your own $\quad \begin{array}{llllll}1 & 2 & 3 & 4 & 5\end{array}$ questions and experiments.

21. It is good to try experiments more than once to $\begin{array}{lllllll}1 & 2 & 3 & 4 & 5\end{array}$ make sure of your results.

22. Good ideas in science can come from anybody, $\begin{array}{lllllll}1 & 2 & 3 & 4 & 5\end{array}$ not just from scientists. 


\section{Appendix 5: Ethical Clearance letter from the Institutional Review Board}

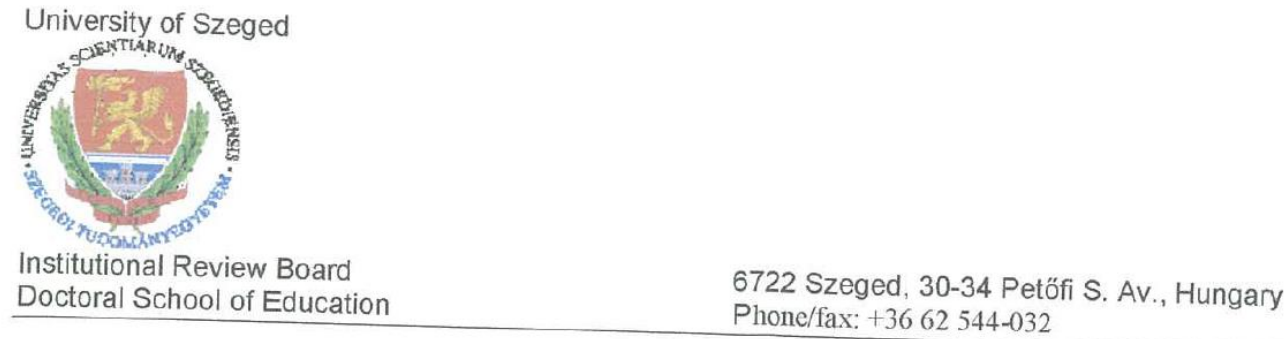

Simson Ndadaleka Shaakumeni

PhD Student: Doctoral School of Education

Reference number: $5 / 2016$

Subject: Ethical evaluation of a research project

E T H I CA L A P P R OVA L

The Insitutional Review Board (IRB) of the Doctoral School of Education, University of Szeged has recently reviewed your application for an ethical approval (Title of the Research Sub-Project: "Assessing science education student teachers' conception of scientific inquiry and the nature of science in Namíbia", senior researcher: Prof. Dr. Benő Csapó). This is a supplementary permission to "Assessing scientific literacy of junior and senior secondary students" to get an overall picture about scientific literature in a broad age group from elementary school children to student teachers. This proposal is also deemed to meet the requirements of the ethical conducts on social research with human subjects of the Doctoral School of Education, University of Szeged.

\section{IRB decision: approved}

Justification: The research project meets the requirements of the professional-ethical criteria of the social research identification subjects within the field of educational science. Participation in data collection is voluntary, the link to their identity. The students and their to this research, therefore students will be assigned codes without any Procedure of the data collection a me research project. or physical health. Data cannot be handled by persons to law, it does not have an impact on the students' mental

In a summary, full ethical approval has been granted.

We wish you all the best for the conduct of the project.

Date: 14th December, 2016

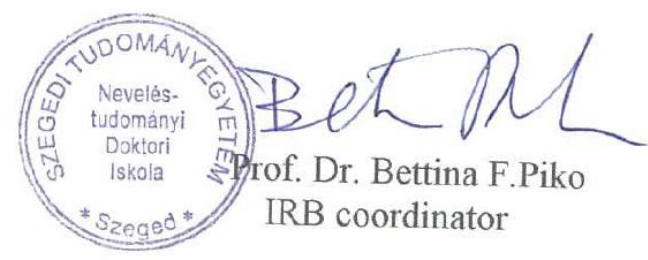




\section{Appendix 6: Permission letter from the Ministry of Education, Arts and Culture}

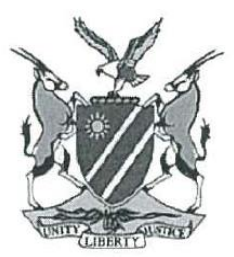

REPUBLIC OF NAMIBIA

\section{MINISTRY OF EDUCATION, ARTS AND CULTURE}

Tel: $+26461-2933200$

Fax: +264 61- 2933922

Enquiries: C. Muchila

Email:Cavin.Muchila@moe.gov.na

File no: $11 / 1 / 1$

Mr Simson N. Shaakumeni

Cell: +264811271427

Email: sshaakumeni@gmail.com

Dear Mr Shaakumeni
Luther Street Govt Office Park

Private Bag 13186

Windhoek

Namibia

\section{SUBJECT: PERMISSION TO CONDUCT RESEARCH IN IN THE MINISTRY OF EDUCATION}

Kindly be informed that permission to conduct research for your Doctoral Degree in the Ministry of Education, Arts and Culture is herewith granted. You are further requested to present the letter of approval to the Regional Directors to ensure that research ethics are adhered to and disruption of curriculum delivery is avoided.

Furthermore, we humbly request you to share your research findings with the ministry. You may contact Mr C. Muchila at the Directorate: Programmes and Quality Assurance (PQA) for provision of summary of your research findings.

I wish you the best in conducting your research and I look forward to hearing from you soon.

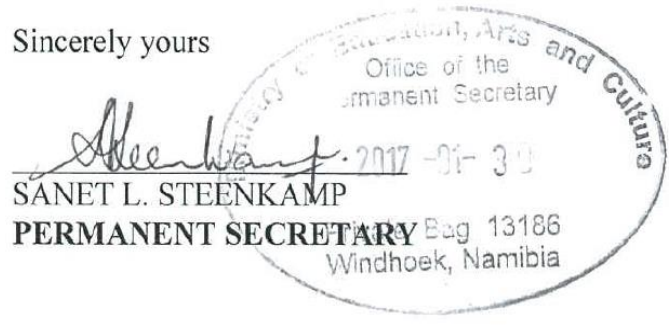

$\frac{30 \cdot 1 \cdot 17}{\text { Date }}$

All official correspondences must be addressed to the Permanent Secretary 


\title{
Appendix 7: Permission letter from the Regional Education Office
}

\author{
REPUBLIC OF NAMIBIA
}

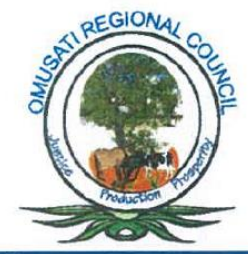

\section{OMUSATI REGIONAL COUNCIL}

\section{DIRECTORATE OF EDUCATION, ARTS AND CULTURE}

Team Work and Dedication for Quality Education

Tel: +26465251700

Fax: +26465 251722

Enq: Apollonia Hango
Private Bag 529

OUTAPI

28 June 2017

Mr. Simson N. Shaakumeni

Cell: 0811271427

Email: sshaakumeni@gmail.com

Subject: Permission to conduct research in the Ministry of Education, Arts and culture- Omusati Education Directorate

This letter serves to notify you (Simson N Shaakumeni) that permission has been granted to conduct a research in Omusati Education Directorate-Omusati Region. Please be informed that the research to be conducted at school shouid by no means whatsoever disrupt teaching and learning.

We hope and trust this exercise will enhance quality education in the Region.

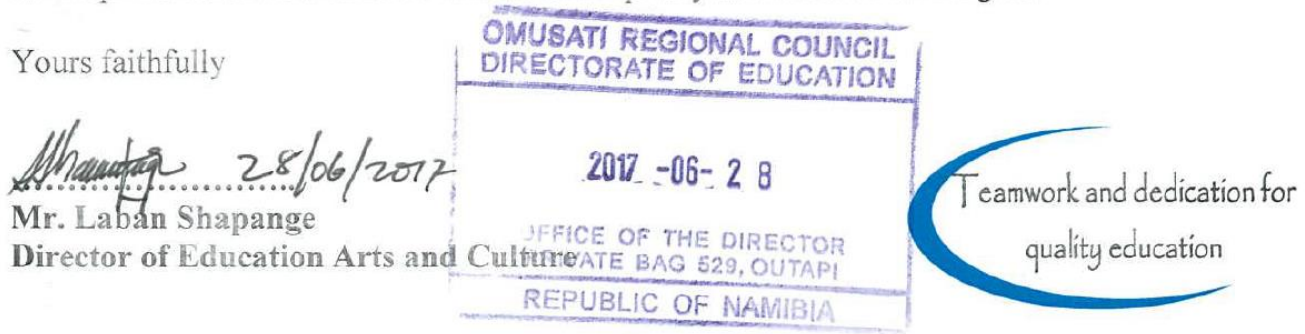




\section{Appendix 8: Information sheet and consent form}

Title of research project: Development, adaptation and validation of instruments for assessing Namibian students' beliefs about nature of science.

Hello, my name is Simson Ndadaleka Shaakumeni and I am conducting research towards a doctoral degree (Doctor of Philosophy-PhD) in science education. I am researching on the understanding of scientific inquiry and the nature of science among school senior secondary level students that have been learning science for more than 10 years of their basic education and I would like to invite you to participate in this project.

I am interested in finding out about students' understanding of scientific inquiry and nature of science as foundations of science learning. According to the Namibian science curriculum for basic education, scientific inquiry and the nature of science skills are not taught directly, they are expected to be incorporated in the teaching of other content areas. This study aims to find out how much scientific inquiry skills and knowledge of the nature of science had students learned at exit point of the basic education phase of the Namibian education system.

Please understand that you do not have to participate, your participation is voluntary. The choice to participate is yours alone. If you choose not to participate, there will be no negative consequence. If you choose to participate, but wish to withdraw at any time, you will be free to do so without negative consequence. However, I would be thankful if you would assist me by answering some questions using a computer.

I would like you to respond to less than 40 questions all together. It should take you about 30 minutes. This project is not going to cost you anything other than your precious time. I am a student as well and for this reason I am unable to pay you for participating. I am humbly requesting you to assist without expecting any payment from me.

By participating in this project, you may not feel any direct benefit however; your participation to the best of your ability means a lot to the outcome of this research, in terms of its contribution to the knowledge of science learning in Namibia's basic education. This task can serve as a refresher for your knowledge about scientific inquiry 
and the nature of science that you should have gained during your over ten years of learning science during your basic education to date.

This research study does not pose any risk to you or the school in general nor does it harm your privacy. Your participation in this research is anonymous. It is not important to identify you in this research so your name or any of your identity is not needed. You will be assigned codes without any link to your identity. The university's identity will also be withheld and findings will be reported as that of senior secondary school students.

The information that you will provide will be handled securely. The results of this research will be published in responsible journals and conferences after they are reviewed and found fit for publication. This will be done as part of the requirements for awarding a PhD qualification at the Doctoral School of Education in the University of Szeged.

If you have concerns about this research, its risks and benefits or about your rights as a research participant in this study, you may contact my supervisor Prof. Dr. Benő Csapó at this email address: csapo@edpsy.u-szeged.hu.

Alternatively, you may write to the Chairperson of the Institutional Review Board of the University of Szeged:

Prof. Dr. Bettina F. Piko, MD, PhD, Dsc

Professor of Behavioral Sciences and Community Health

Department of Behavioral Sciences

University of Szeged

6722 Szeged, Szentharomsag Street 5.

Hungary

Email: fuzne.piko.bettina@med.u-szeged.hu 


\section{INFORMED CONSENT FORM}

\begin{tabular}{|c|c|c|}
\hline Please tick $(\checkmark)$ yes or no & YES & NO \\
\hline $\begin{array}{l}\text { I have read and I understand the provided information and have had the opportunity } \\
\text { to ask questions }\end{array}$ & & \\
\hline $\begin{array}{l}\text { I understand that my participation is voluntary and that I am free to withdraw at any } \\
\text { time, without giving a reason and without cost or any negative consequences }\end{array}$ & & \\
\hline I understand that I will be given a copy of this consent form & & \\
\hline I voluntarily agree to take part in this study & & \\
\hline
\end{tabular}

Participant's signature

Date

Researcher's signature

Date 


\section{Appendix 9: Data Analyses Clearance}

Study 1: Inter-item Correlations

\begin{tabular}{|c|c|c|c|c|c|c|c|c|}
\hline & Item1 & Item2 & Item3 & Item4 & Item5 & Item6 & Item7 & Item8 \\
\hline Item2 & .588 & & & & & & & \\
\hline Item3 & .917 & .568 & & & & & & \\
\hline Item4 & .462 & .776 & .501 & & & & & \\
\hline Item5 & .880 & .559 & .854 & .557 & & & & \\
\hline Item6 & .157 & -.152 & .094 & -.072 & .100 & & & \\
\hline Item7 & .031 & -.134 & .001 & -.007 & .023 & .255 & & \\
\hline Item8 & -.246 & -.212 & -.199 & -.139 & -.241 & .063 & .586 & \\
\hline Item9 & .816 & .517 & .818 & .416 & .711 & .353 & .178 & -.161 \\
\hline Item 10 & .072 & -.079 & -.040 & -.186 & .065 & -.014 & .482 & .158 \\
\hline Item11 & .370 & .143 & .282 & -.031 & .273 & .297 & .145 & -.090 \\
\hline Item12 & .845 & .468 & .824 & .422 & .835 & .291 & .156 & -.186 \\
\hline Item 13 & .410 & .093 & .430 & .264 & .464 & .537 & .456 & .077 \\
\hline Item14 & .586 & .444 & .569 & .446 & .477 & .216 & .308 & -.107 \\
\hline Item 15 & .515 & .335 & .595 & .411 & .497 & .206 & .263 & .064 \\
\hline Item16 & .621 & .270 & .625 & .359 & .580 & .262 & .132 & .103 \\
\hline Item17 & .550 & .209 & .494 & .302 & .518 & .441 & .555 & .260 \\
\hline Item 18 & .129 & .039 & .121 & -.041 & .208 & .369 & .435 & .111 \\
\hline Item19 & .309 & .100 & .163 & .127 & .235 & .471 & .421 & -.054 \\
\hline Item 21 & .479 & .434 & .350 & .340 & .430 & .324 & .213 & -.121 \\
\hline Item 22 & .434 & .260 & .322 & .172 & .432 & .520 & .061 & -.038 \\
\hline Item 23 & .636 & .429 & .667 & .314 & .680 & .158 & .105 & -.065 \\
\hline Item24 & .694 & .372 & .677 & .283 & .705 & .171 & .088 & -.125 \\
\hline Item 25 & .535 & .168 & .590 & .208 & .640 & .481 & .354 & .183 \\
\hline Item 26 & .170 & .042 & .179 & .054 & .126 & .521 & .140 & -.075 \\
\hline Item 27 & .109 & .120 & .004 & .172 & .140 & .323 & .407 & .249 \\
\hline Item 28 & .677 & .525 & .696 & .381 & .717 & .271 & .016 & -.057 \\
\hline Item 29 & .764 & .495 & .759 & .361 & .761 & .290 & .203 & .020 \\
\hline
\end{tabular}




\begin{tabular}{|c|c|c|c|c|c|c|c|c|}
\hline Item30 & .389 & .101 & .360 & .228 & .442 & .187 & .389 & .226 \\
\hline Item31 & .750 & .518 & .761 & .446 & .795 & .190 & .090 & -.067 \\
\hline Item32 & .694 & .411 & .756 & .443 & .761 & .166 & .019 & -.088 \\
\hline Item33 & .476 & .529 & .548 & .660 & .585 & .106 & .191 & .219 \\
\hline Item34 & .306 & .099 & .290 & .115 & .288 & .332 & .364 & .285 \\
\hline Item35 & .849 & .420 & .812 & .317 & .787 & .268 & .038 & -.096 \\
\hline
\end{tabular}

\begin{tabular}{|c|c|c|c|c|c|c|c|c|c|c|}
\hline Item9 & Item10 & Item11 & Item12 & Item13 & Item14 & Item15 & Item16 & Item17 & Item18 & Item19 \\
\hline \multicolumn{11}{|l|}{.126} \\
\hline .465 & .583 & & & & & & & & & \\
\hline .834 & .189 & .442 & & & & & & & & \\
\hline .612 & .042 & .183 & .531 & & & & & & & \\
\hline .766 & .066 & .341 & .620 & .630 & & & & & & \\
\hline .677 & .213 & .257 & .606 & .568 & .451 & & & & & \\
\hline .716 & -.045 & .123 & .657 & .570 & .640 & .511 & & & & \\
\hline .687 & .183 & .227 & .624 & .661 & .657 & .469 & .795 & & & \\
\hline .253 & .373 & .243 & .394 & .391 & .243 & .310 & .086 & .363 & & \\
\hline .489 & .397 & .316 & .408 & .537 & .447 & .483 & .425 & .632 & .314 & \\
\hline .252 & .037 & .212 & .404 & .289 & .323 & -.082 & .299 & .240 & .302 & .182 \\
\hline .595 & .088 & .320 & .618 & .429 & .599 & .316 & .475 & .558 & .319 & .550 \\
\hline .501 & .080 & .225 & .599 & .417 & .360 & .232 & .483 & .430 & .382 & .392 \\
\hline .689 & .154 & .281 & .802 & .434 & .583 & .429 & .651 & .533 & .435 & .208 \\
\hline .759 & .112 & .227 & .841 & .485 & .599 & .506 & .621 & .497 & .357 & .254 \\
\hline .590 & .041 & .243 & .733 & .727 & .462 & .556 & .500 & .549 & .555 & .260 \\
\hline .346 & .106 & .293 & .418 & .348 & .431 & .026 & .396 & .397 & .231 & .330 \\
\hline .217 & .416 & .322 & .301 & .311 & .150 & .251 & .066 & .324 & .216 & .509 \\
\hline .760 & .171 & .430 & .856 & .344 & .490 & .477 & .650 & .561 & .346 & .280 \\
\hline .823 & .225 & .394 & .891 & .443 & .555 & .536 & .651 & .639 & .382 & .390 \\
\hline .488 & .323 & .418 & .567 & .415 & .527 & .349 & .515 & .567 & .168 & .360 \\
\hline .792 & .160 & .370 & .928 & .443 & .599 & .562 & .692 & .568 & .366 & .307 \\
\hline
\end{tabular}




\begin{tabular}{|c|c|c|c|c|c|c|c|c|c|c|}
\hline .735 & .115 & .354 & .880 & .388 & .541 & .535 & .688 & .528 & .286 & .260 \\
\hline .560 & .077 & .217 & .569 & .425 & .450 & .587 & .461 & .422 & .180 & .113 \\
\hline .506 & .329 & .573 & .499 & .573 & .509 & .443 & .540 & .580 & .207 & .476 \\
\hline .782 & .160 & .405 & .932 & .420 & .582 & .525 & .709 & .598 & .267 & .325 \\
\hline
\end{tabular}

\begin{tabular}{|c|c|c|c|c|c|c|c|c|c|c|c|c|c|c|}
\hline Item 20 & Item 21 & Item22 & Item 23 & Item24 & Item 25 & Item 26 & Item 27 & Item 28 & Item29 & Item30 & Item31 & Item32 & Item33 & Item34 \\
\hline \multicolumn{15}{|l|}{.639} \\
\hline .788 & .727 & & & & & & & & & & & & & \\
\hline .543 & .572 & .639 & & & & & & & & & & & & \\
\hline .483 & .603 & .670 & .889 & & & & & & & & & & & \\
\hline .406 & .372 & .556 & .672 & .687 & & & & & & & & & & \\
\hline .531 & .386 & .581 & .473 & .335 & .360 & & & & & & & & & \\
\hline .234 & .425 & .403 & .132 & .203 & .304 & .398 & & & & & & & & \\
\hline .460 & .544 & .633 & .815 & .780 & .612 & .460 & .226 & & & & & & & \\
\hline .383 & .572 & .608 & .848 & .848 & .687 & .393 & .337 & .915 & & & & & & \\
\hline .164 & .350 & .377 & .538 & .575 & .502 & .497 & .475 & .538 & 609 & & & & & \\
\hline .443 & .572 & .619 & .883 & .881 & .721 & .411 & .291 & .910 & .945 & .624 & & & & \\
\hline .342 & .453 & .519 & .844 & .830 & .666 & .407 & .231 & .881 & .899 & .661 & .953 & & & \\
\hline .094 & .220 & .195 & .485 & .509 & .587 & .118 & .355 & .579 & .618 & .497 & .677 & .640 & & \\
\hline .176 & .364 & .334 & .465 & .424 & .527 & .412 & .401 & .462 & .485 & .739 & .501 & .510 & .422 & \\
\hline .405 & .526 & .587 & .768 & .798 & .667 & .402 & .241 & .841 & .873 & .514 & .902 & .851 & .535 & .447 \\
\hline
\end{tabular}


Study 1: Reliability Tests

\section{Reliability Statistics}

Cronbach's

\begin{tabular}{cc} 
Alpha & $\mathrm{N}$ of Items \\
\hline .962 & 35 \\
\hline
\end{tabular}

\section{Item-Total Statistics}

\begin{tabular}{lcc}
\hline & $\begin{array}{c}\text { Corrected Item-Total } \\
\text { Correlation }\end{array}$ & $\begin{array}{c}\text { Cronbach's Alpha if } \\
\text { Item Deleted }\end{array}$ \\
\hline $\begin{array}{l}\text { Scientific knowledge changes as we } \\
\text { learn more about the natural world. }\end{array}$ & .753 & .960 \\
$\begin{array}{l}\text { Scientific knowledge changes due to } \\
\text { the changes in cultural interests. }\end{array}$ & .440 & .961 \\
$\begin{array}{l}\text { Scientific knowledge changes as } \\
\text { scientists reconsider existing }\end{array}$ & & .960 \\
evidence. \\
$\begin{array}{l}\text { Scientific knowledge changes due to } \\
\text { changes in social interests. }\end{array}$ \\
$\begin{array}{l}\text { Scientific laws and theories are not } \\
\text { final, they can change. }\end{array}$ \\
$\begin{array}{l}\text { Science does not depend on } \\
\text { experiments only to get evidence } \\
\text { about the natural world. }\end{array}$ \\
$\begin{array}{l}\text { Science cannot prove anything but is } \\
\text { still valuable. }\end{array}$ \\
$\begin{array}{l}\text { Science experiments cannot prove a } \\
\text { scientific theory true. }\end{array}$
\end{tabular}


Scientific conclusions are influenced by scientists' personal feelings.

Scientists' backgrounds, cultures and beliefs influence their work.

It is possible for scientists to look at

the same evidence or set of data and come up with different conclusions.

Scientists use their creativity to analyse data.

Scientists use their creativity to interpret data.

Models (e.g. atoms, species etc) are not exact copies of how things are in reality.

Scientists use imagination throughout the entire process of investigation

Science is influenced by sociocultural elements e.g. religion, economic factors etc.

The values of the culture determine how science is practiced.

Science is influenced by cultures.

There is a difference between

Observations are descriptions of the natural world obtained using human senses.

Inferences are interpretations of

observations that are not accessible to human senses.

There is a difference between scientific theories and laws.

A scientific law is not a theory that has been proven true.

Theories (e.g. kinetic) become laws (e.g. Boyle's) when supporting evidence is found.

Theories and laws are different kinds of scientific knowledge.

Theories do not become laws even with additional evidence. 
All scientific investigations generally start with a question.

The method of investigations must be suitable for answering the question asked.

Scientific data is not the same as scientific evidence.

All investigations do not necessarily have to formally state a hypothesis.

Research conclusions must be supported by the evidence from the data collected.

Study 2: Reliability Tests

\section{Reliability Statistics}

Cronbach's

\begin{tabular}{cc} 
Alpha & N of Items \\
\hline .870 & 16 \\
\hline
\end{tabular}

Item-Total Statistics

\begin{tabular}{lcc}
\hline & $\begin{array}{c}\text { Corrected Item-Total } \\
\text { Correlation }\end{array}$ & $\begin{array}{c}\text { Cronbach's Alpha if } \\
\text { Item Deleted }\end{array}$ \\
\hline $\begin{array}{l}\text { Some scientific ideas today were } \\
\text { different in the past. }\end{array}$ & .419 & .866 \\
$\begin{array}{l}\text { Scientific ideas can change due to } \\
\text { advances in technology. }\end{array}$ & .432 & .866 \\
$\begin{array}{l}\text { Scientists use different procedures to } \\
\text { study the natural world. }\end{array}$ & .567 & .861 \\
$\begin{array}{l}\text { There is no single step-by-step method } \\
\text { that all scientists in the world follow. }\end{array}$ & .483 & .864 \\
$\begin{array}{l}\text { Scientific laws are descriptions of the } \\
\text { relationship among observable } \\
\text { phenomena. }\end{array}$ & .555 & .861 \\
$\begin{array}{l}\text { Scientists' backgrounds and beliefs } \\
\text { influence their work. }\end{array}$ & .539 & .861 \\
$\begin{array}{l}\text { Scientists can look at the same } \\
\text { evidence or set of data and come up } \\
\text { with different conclusions. }\end{array}$ & & .522 \\
\end{tabular}


Scientists use their creativity to analyse data.

Science is influenced by economic factors such as research funding.

The values of the culture determine how science is practiced.

Science is influenced by cultures.

Experiments are not the only source of scientific evidence.

Experiments support rather than prove scientific claims.

Scientists can use human senses to make scientific claims (observations).

Models like atoms and species are products of human imagination.

Scientific theories are conclusions about observable phenomena.

Study 2: Confirmatory factor analysis data

UNIVARIATE HIGHER-ORDER MOMENT DESCRIPTIVE STATISTICS

\begin{tabular}{ccccc}
\hline Variable/ & Mean/ & Skewness/ & Minimum/ \% with & Percentiles \\
Sample Size & Variance & Kurtosis & Maximum Min/Max & $20 \% / 60 \%$ \\
$40 \% / 80 \%$ Median & & & & \\
\hline
\end{tabular}

\begin{tabular}{llllllll} 
ITEM2 & 3.112 & -0.075 & 1.000 & $7.84 \%$ & 2.000 & 3.000 & 3.000 \\
\multirow{2}{*}{357.000} & 1.399 & -1.103 & 5.000 & $11.76 \%$ & 4.000 & 4.000 & \\
ITEM4 & 3.132 & 0.176 & 1.000 & $4.76 \%$ & 2.000 & 2.000 & 3.000 \\
357.000 & 1.481 & -1.238 & 5.000 & $17.65 \%$ & 4.000 & 4.000 & \\
ITEM5 & 3.176 & -0.328 & 1.000 & $21.01 \%$ & 1.000 & 3.000 & 4.000 \\
357.000 & 2.151 & -1.397 & 5.000 & $19.89 \%$ & 4.000 & 4.000 & \\
ITEM6 & 2.852 & -0.013 & 1.000 & $24.93 \%$ & 1.000 & 2.000 & 3.000
\end{tabular}




\begin{tabular}{|c|c|c|c|c|c|c|c|}
\hline 357.000 & 1.947 & -1.375 & 5.000 & $12.32 \%$ & 4.000 & 4.000 & \\
\hline ITEM7 & 2.938 & -0.177 & 1.000 & $21.85 \%$ & 1.000 & 2.000 & 3.000 \\
\hline 357.000 & 1.811 & -1.324 & 5.000 & $10.08 \%$ & 4.000 & 4.000 & \\
\hline ITEM9 & 3.599 & -0.520 & 2.000 & $25.77 \%$ & 2.000 & 4.000 & 4.000 \\
\hline 357.000 & 1.080 & -1.003 & 5.000 & $16.25 \%$ & 4.000 & 4.000 & \\
\hline ITEM10 & 3.325 & -0.474 & 1.000 & $15.41 \%$ & 2.000 & 4.000 & 4.000 \\
\hline 357.000 & 1.978 & -1.245 & 5.000 & $20.73 \%$ & 4.000 & 5.000 & \\
\hline ITEM13 & 3.059 & -0.132 & 1.000 & $14.01 \%$ & 2.000 & 2.000 & 3.000 \\
\hline 357.000 & 1.691 & -1.256 & 5.000 & $13.17 \%$ & 4.000 & 4.000 & \\
\hline ITEM14 & 3.275 & -0.390 & 1.000 & $12.61 \%$ & 2.000 & 3.000 & 4.000 \\
\hline 357.000 & 1.762 & -1.186 & 5.000 & $17.37 \%$ & 4.000 & 4.000 & \\
\hline ITEM15 & 3.246 & -0.423 & 1.000 & $17.09 \%$ & 2.000 & 3.000 & 4.000 \\
\hline 357.000 & 1.889 & -1.157 & 5.000 & $18.21 \%$ & 4.000 & 4.000 & \\
\hline ITEM17 & 3.042 & -0.274 & 1.000 & $21.57 \%$ & 1.000 & 3.000 & 3.000 \\
\hline 357.000 & 1.900 & -1.300 & 5.000 & $12.89 \%$ & 4.000 & 4.000 & \\
\hline ITEM19 & 2.908 & 0.084 & 1.000 & $12.89 \%$ & 2.000 & 2.000 & 3.000 \\
\hline 357.000 & 1.479 & -1.069 & 5.000 & $10.08 \%$ & 3.000 & 4.000 & \\
\hline ITEM20 & 3.025 & -0.066 & 1.000 & $12.04 \%$ & 2.000 & 3.000 & 3.000 \\
\hline 357.000 & 1.498 & -1.071 & 5.000 & $11.48 \%$ & 4.000 & 4.000 & \\
\hline ITEM21 & 2.776 & 0.182 & 1.000 & $17.09 \%$ & 2.000 & 2.000 & 3.000 \\
\hline 357.000 & 1.530 & -1.040 & 5.000 & $9.24 \%$ & 3.000 & 4.000 & \\
\hline ITEM25 & 3.129 & -0.214 & 1.000 & $15.69 \%$ & 2.000 & 3.000 & 3.000 \\
\hline 357.000 & 1.821 & -1.253 & 5.000 & $16.53 \%$ & 4.000 & 4.000 & \\
\hline ITEM26 & 3.412 & -0.686 & 1.000 & $10.36 \%$ & 2.000 & 4.000 & 4.000 \\
\hline 357.000 & 1.475 & -0.642 & 5.000 & $14.57 \%$ & 4.000 & 4.000 & \\
\hline
\end{tabular}


THE MODEL ESTIMATION TERMINATED NORMALLY

MODEL FIT INFORMATION

Number of Free Parameters

58

Loglikelihood

$\begin{array}{ll}\text { H0 Value } & -8507.862 \\ \text { H1 Value } & -8252.309\end{array}$

Information Criteria

Akaike (AIC) $\quad 17131.724$

Bayesian (BIC) $\quad 17356.633$

Sample-Size Adjusted BIC $\quad 17172.630$

$\left(\mathrm{n}^{*}=(\mathrm{n}+2) / 24\right)$

Chi-Square Test of Model Fit

$\begin{array}{lr}\text { Value } & 511.107 \\ \text { Degrees of Freedom } & 94 \\ \text { P-Value } & 0.0000\end{array}$

RMSEA (Root Mean Square Error Of Approximation)
Estimate
0.111
90 Percent C.I.
$0.102 \quad 0.121$
Probability RMSEA $<=.05$ 0.000 
CFI/TLI

CFI $\quad 0.831$

$\begin{array}{ll}\text { TLI } & 0.785\end{array}$

SRMR (Standardized Root Mean Square Residual)

Value $\quad 0.067$

MODEL RESULTS

Two-Tailed

Estimate S.E. Est./S.E. P-Value

EMPIRI BY

$\begin{array}{lllll}\text { ITEM7 } & 1.000 & 0.000 & 999.000 & 999.000 \\ \text { ITEM5 } & 1.043 & 0.095 & 10.970 & 0.000 \\ \text { ITEM6 } & 1.092 & 0.082 & 13.358 & 0.000 \\ \text { ITEM17 } & 0.880 & 0.087 & 10.150 & 0.000 \\ \text { ITEM25 } & 0.968 & 0.084 & 11.466 & 0.000\end{array}$

SOCIO BY

$\begin{array}{lllll}\text { ITEM21 } & 1.000 & 0.000 & 999.000 & 999.000\end{array}$

$\begin{array}{lllll}\text { ITEM20 } & 1.006 & 0.077 & 13.101 & 0.000\end{array}$

$\begin{array}{lllll}\text { ITEM19 } & 0.912 & 0.072 & 12.688 & 0.000\end{array}$ 
SUBJECTI BY

$\begin{array}{ccccc}\text { ITEM13 } & 1.000 & 0.000 & 999.000 & 999.000 \\ \text { ITEM14 } & 0.994 & 0.077 & 12.893 & 0.000 \\ \text { ITEM15 } & 0.897 & 0.082 & 10.913 & 0.000 \\ & & & & \\ \text { SCIMETH BY } & & & & \\ \text { ITEM9 } & 1.000 & 0.000 & 999.000 & 999.000 \\ \text { ITEM10 } & 1.227 & 0.105 & 11.690 & 0.000 \\ \text { ITEM26 } & 1.108 & 0.114 & 9.678 & 0.000\end{array}$

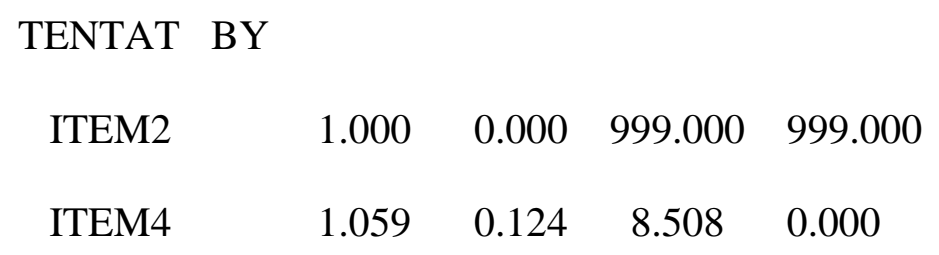

SOCIO WITH

$\begin{array}{lllll}\text { EMPIRI } & 0.401 & 0.068 & 5.880 & 0.000\end{array}$

\section{SUBJECTI WITH}

$\begin{array}{lllll}\text { EMPIRI } & 0.549 & 0.078 & 6.999 & 0.000 \\ \text { SOCIO } & 0.538 & 0.078 & 6.921 & 0.000\end{array}$

\section{SCIMETH WITH}

$\begin{array}{lllll}\text { EMPIRI } & 0.408 & 0.062 & 6.572 & 0.000 \\ \text { SOCIO } & 0.423 & 0.060 & 7.054 & 0.000\end{array}$


$\begin{array}{lllll}\text { SUBJECTI } & 0.574 & 0.069 & 8.276 & 0.000\end{array}$

$\begin{array}{lcccc}\text { TENTAT WITH } & & & & \\ \text { EMPIRI } & 0.292 & 0.065 & 4.471 & 0.000 \\ \text { SOCIO } & 0.344 & 0.073 & 4.694 & 0.000 \\ & & & & \\ \text { SUBJECTI } & 0.499 & 0.076 & 6.587 & 0.000 \\ \text { SCIMETH } & 0.351 & 0.061 & 5.757 & 0.000\end{array}$

Intercepts

$\begin{array}{lllll}\text { ITEM2 } & 3.112 & 0.063 & 49.709 & 0.000 \\ \text { ITEM4 } & 3.132 & 0.064 & 48.617 & 0.000 \\ \text { ITEM5 } & 3.176 & 0.078 & 40.923 & 0.000 \\ \text { ITEM6 } & 2.852 & 0.074 & 38.611 & 0.000 \\ \text { ITEM7 } & 2.938 & 0.071 & 41.252 & 0.000 \\ \text { ITEM9 } & 3.599 & 0.055 & 65.429 & 0.000 \\ \text { ITEM10 } & 3.325 & 0.074 & 44.664 & 0.000 \\ \text { ITEM13 } & 3.059 & 0.069 & 44.442 & 0.000 \\ \text { ITEM14 } & 3.275 & 0.070 & 46.607 & 0.000 \\ \text { ITEM15 } & 3.246 & 0.073 & 44.633 & 0.000 \\ \text { ITEM17 } & 3.042 & 0.073 & 41.696 & 0.000 \\ \text { ITEM19 } & 2.908 & 0.064 & 45.175 & 0.000 \\ \text { ITEM20 } & 3.025 & 0.065 & 46.702 & 0.000 \\ \text { ITEM21 } & 2.776 & 0.065 & 42.408 & 0.000 \\ \text { ITEM25 } & 3.129 & 0.071 & 43.810 & 0.000 \\ \text { ITEM26 } & 3.412 & 0.064 & 53.084 & 0.000\end{array}$




$\begin{array}{lcccc}\text { Variances } & & & & \\ \text { EMPIRI } & 0.946 & 0.132 & 7.182 & 0.000 \\ \text { SOCIO } & 0.931 & 0.118 & 7.898 & 0.000 \\ \text { SUBJECTI } & 0.997 & 0.129 & 7.715 & 0.000 \\ \text { SCIMETH } & 0.599 & 0.087 & 6.913 & 0.000 \\ \text { TENTAT } & 0.870 & 0.135 & 6.459 & 0.000\end{array}$

Residual Variances

\begin{tabular}{lllll} 
ITEM2 & 0.530 & 0.101 & 5.219 & 0.000 \\
ITEM4 & 0.506 & 0.111 & 4.544 & 0.000 \\
ITEM5 & 1.121 & 0.107 & 10.488 & 0.000 \\
ITEM6 & 0.819 & 0.089 & 9.170 & 0.000 \\
ITEM7 & 0.865 & 0.086 & 10.088 & 0.000 \\
ITEM9 & 0.481 & 0.060 & 8.063 & 0.000 \\
ITEM10 & 1.076 & 0.111 & 9.713 & 0.000 \\
ITEM13 & 0.694 & 0.078 & 8.907 & 0.000 \\
ITEM14 & 0.777 & 0.082 & 9.490 & 0.000 \\
ITEM15 & 1.087 & 0.098 & 11.039 & 0.000 \\
ITEM17 & 1.168 & 0.100 & 11.677 & 0.000 \\
ITEM19 & 0.705 & 0.072 & 9.795 & 0.000 \\
ITEM20 & 0.557 & 0.070 & 7.970 & 0.000 \\
ITEM21 & 0.599 & 0.069 & 8.652 & 0.000 \\
ITEM25 & 0.935 & 0.087 & 10.701 & 0.000 \\
\hline & 0.740 & 0.084 & 8.805 & 0.000 \\
\hline
\end{tabular}


STANDARDIZED MODEL RESULTS

STDYX Standardization

Two-Tailed

\section{Estimate S.E. Est./S.E. P-Value}

EMPIRI BY

$\begin{array}{lllll}\text { ITEM7 } & 0.723 & 0.033 & 21.779 & 0.000 \\ \text { ITEM5 } & 0.692 & 0.035 & 19.523 & 0.000 \\ \text { ITEM6 } & 0.761 & 0.031 & 24.345 & 0.000 \\ \text { ITEM17 } & 0.621 & 0.039 & 16.121 & 0.000 \\ \text { ITEM25 } & 0.698 & 0.034 & 20.465 & 0.000\end{array}$

SOCIO BY

$\begin{array}{lllll}\text { ITEM21 } & 0.780 & 0.030 & 25.733 & 0.000 \\ \text { ITEM20 } & 0.793 & 0.031 & 25.806 & 0.000 \\ \text { ITEM19 } & 0.723 & 0.034 & 21.247 & 0.000\end{array}$

SUBJECTI BY

$\begin{array}{lllll}\text { ITEM13 } & 0.768 & 0.031 & 24.619 & 0.000 \\ \text { ITEM14 } & 0.748 & 0.032 & 23.379 & 0.000 \\ \text { ITEM15 } & 0.651 & 0.038 & 17.192 & 0.000\end{array}$

SCIMETH BY 


$\begin{array}{lllll}\text { ITEM9 } & 0.745 & 0.038 & 19.676 & 0.000 \\ \text { ITEM10 } & 0.675 & 0.040 & 16.683 & 0.000 \\ & & & & \\ \text { ITEM26 } & 0.706 & 0.040 & 17.508 & 0.000\end{array}$

TENTAT BY

$\begin{array}{lllll}\text { ITEM2 } & 0.788 & 0.047 & 16.829 & 0.000\end{array}$

$\begin{array}{lllll}\text { ITEM4 } & 0.811 & 0.047 & 17.195 & 0.000\end{array}$

SOCIO WITH

$\begin{array}{lllll}\text { EMPIRI } & 0.427 & 0.057 & 7.473 & 0.000\end{array}$

\begin{tabular}{lllll}
\multicolumn{2}{l}{ SUBJECTI WITH } & & & \\
EMPIRI & 0.565 & 0.050 & 11.268 & 0.000 \\
SOCIO & 0.559 & 0.052 & 10.663 & 0.000
\end{tabular}

SCIMETH WITH

$\begin{array}{lllll}\text { EMPIRI } & 0.542 & 0.054 & 10.101 & 0.000\end{array}$

$\begin{array}{lllll}\text { SOCIO } & 0.567 & 0.056 & 10.042 & 0.000\end{array}$

$\begin{array}{lllll}\text { SUBJECTI } & 0.743 & 0.046 & 16.030 & 0.000\end{array}$

TENTAT WITH

\begin{tabular}{lrrrr} 
EMPIRI & 0.322 & 0.061 & 5.318 & 0.000 \\
SOCIO & 0.382 & 0.063 & 6.069 & 0.000 \\
SUBJECTI & 0.536 & 0.055 & 9.818 & 0.000 \\
SCIMETH & 0.486 & 0.060 & 8.042 & 0.000 \\
\hline
\end{tabular}


Intercepts

$\begin{array}{lllll}\text { ITEM2 } & 2.631 & 0.112 & 23.536 & 0.000 \\ \text { ITEM4 } & 2.573 & 0.110 & 23.417 & 0.000 \\ \text { ITEM5 } & 2.166 & 0.097 & 22.374 & 0.000 \\ \text { ITEM6 } & 2.044 & 0.093 & 21.972 & 0.000 \\ \text { ITEM7 } & 2.183 & 0.097 & 22.427 & 0.000 \\ \text { ITEM9 } & 3.463 & 0.140 & 24.737 & 0.000 \\ \text { ITEM10 } & 2.364 & 0.103 & 22.930 & 0.000 \\ \text { ITEM13 } & 2.352 & 0.103 & 22.900 & 0.000 \\ \text { ITEM14 } & 2.467 & 0.106 & 23.181 & 0.000 \\ \text { ITEM15 } & 2.362 & 0.103 & 22.926 & 0.000 \\ \text { ITEM17 } & 2.207 & 0.098 & 22.498 & 0.000 \\ \text { ITEM19 } & 2.391 & 0.104 & 22.999 & 0.000 \\ \text { ITEM20 } & 2.472 & 0.107 & 23.193 & 0.000 \\ \text { ITEM21 } & 2.244 & 0.099 & 22.607 & 0.000 \\ \text { ITEM25 } & 2.319 & 0.102 & 22.812 & 0.000 \\ \text { ITEM26 } & 2.809 & 0.118 & 23.868 & 0.000\end{array}$

\begin{tabular}{lcccc} 
Variances & & & & \\
EMPIRI & 1.000 & 0.000 & 999.000 & 999.000 \\
SOCIO & 1.000 & 0.000 & 999.000 & 999.000 \\
SUBJECTI & 1.000 & 0.000 & 999.000 & 999.000 \\
SCIMETH & 1.000 & 0.000 & 999.000 & 999.000 \\
TENTAT & 1.000 & 0.000 & 999.000 & 999.000 \\
\hline
\end{tabular}


Residual Variances

\begin{tabular}{lllll} 
ITEM2 & 0.379 & 0.074 & 5.125 & 0.000 \\
ITEM4 & 0.342 & 0.077 & 4.463 & 0.000 \\
ITEM5 & 0.521 & 0.049 & 10.628 & 0.000 \\
ITEM6 & 0.421 & 0.048 & 8.846 & 0.000 \\
ITEM7 & 0.478 & 0.048 & 9.962 & 0.000 \\
ITEM9 & 0.446 & 0.056 & 7.908 & 0.000 \\
ITEM10 & 0.544 & 0.055 & 9.946 & 0.000 \\
ITEM13 & 0.411 & 0.048 & 8.572 & 0.000 \\
ITEM14 & 0.441 & 0.048 & 9.219 & 0.000 \\
ITEM15 & 0.576 & 0.049 & 11.656 & 0.000 \\
ITEM17 & 0.615 & 0.048 & 12.857 & 0.000 \\
ITEM19 & 0.477 & 0.049 & 9.675 & 0.000 \\
ITEM20 & 0.372 & 0.049 & 7.629 & 0.000 \\
ITEM21 & 0.392 & 0.047 & 8.284 & 0.000 \\
ITEM25 & 0.513 & 0.048 & 10.793 & 0.000 \\
\hline & 0.502 & 0.057 & 8.812 & 0.000 \\
\hline
\end{tabular}

R-SQUARE

Observed

Two-Tailed

\begin{tabular}{lrrrr}
\hline Variable & Estimate & S.E. Est./S.E. & P-Value \\
& & & & \\
& & & & \\
ITEM2 & 0.621 & 0.074 & 8.414 & 0.000 \\
ITEM4 & 0.658 & 0.077 & 8.598 & 0.000
\end{tabular}




\begin{tabular}{lllll} 
ITEM5 & 0.479 & 0.049 & 9.761 & 0.000 \\
ITEM6 & 0.579 & 0.048 & 12.172 & 0.000 \\
ITEM7 & 0.522 & 0.048 & 10.890 & 0.000 \\
ITEM9 & 0.554 & 0.056 & 9.838 & 0.000 \\
ITEM10 & 0.456 & 0.055 & 8.341 & 0.000 \\
ITEM13 & 0.589 & 0.048 & 12.310 & 0.000 \\
ITEM14 & 0.559 & 0.048 & 11.690 & 0.000 \\
ITEM15 & 0.424 & 0.049 & 8.596 & 0.000 \\
ITEM17 & 0.385 & 0.048 & 8.060 & 0.000 \\
ITEM19 & 0.523 & 0.049 & 10.624 & 0.000 \\
ITEM20 & 0.628 & 0.049 & 12.903 & 0.000 \\
ITEM21 & 0.608 & 0.047 & 12.867 & 0.000 \\
ITEM25 & 0.487 & 0.048 & 10.232 & 0.000 \\
ITEM26 & 0.498 & 0.057 & 8.754 & 0.000 \\
\hline
\end{tabular}

Study 3: Reliability Tests

\section{Reliability Statistics}

\begin{tabular}{cc}
\hline $\begin{array}{c}\text { Cronbach's } \\
\text { Alpha }\end{array}$ & N of Items \\
\hline .790 & 19 \\
\hline
\end{tabular}

\section{Item-Total Statistics}

Corrected Item- Cronbach's Alpha

Total Correlation if Item Deleted

I am sure that I can understand science content even when it is difficult.

I am confident about understanding difficult science concepts.

I always try to understand science concepts.
.417

.770

.451

.463
.768

.767 
I try to understand by myself rather than ask for help with science tasks.

When I learn new science concepts, I connect them to my previous understanding.

When I do not understand a science concept, I use other sources of information.

When I meet science concepts that I do not understand, I still try to learn them.

When I do not understand a science concept, I discuss with others to clarify my understanding.

I think learning science is important because it stimulates my thinking.

I think it is important to learn science because it provides an opportunity to satisfy my own curiosity.

I think it is important to participate in science activities during learning.

I feel very good when I get good marks in science tests.

I feel good when I am able to solve a difficult science task.

I feel good when my science teacher accepts my ideas during science lessons.

I feel good when other learners accept my ideas during science lessons.

I am willing to participate in science lessons because the content is exciting.

I am willing to participate in science lessons because the teacher does not put a lot of pressure on me.

I am willing to participate in science lessons because the teacher pays attention to me.

I am willing to participate in science lessons because learners are involved in discussions.

Study 3: Confirmatory factor analysis data

Model Fit Summary

CMIN

\begin{tabular}{lrrrrr}
\hline Model & NPAR & CMIN & DF & P & CMIN/DF \\
\hline Default model & 49 & 217.139 & 141 & .000 & 1.540 \\
Saturated model & 190 & .000 & 0 & & \\
\hline
\end{tabular}




\begin{tabular}{lrrrrr}
\hline Model & NPAR & CMIN & DF & P & CMIN/DF \\
\hline Independence model & 19 & 1631.943 & 171 & .000 & 9.544 \\
\hline
\end{tabular}

RMR, GFI

\begin{tabular}{lrrrr}
\hline Model & RMR & GFI & AGFI & PGFI \\
\hline Default model & .031 & .939 & .917 & .697 \\
Saturated model & .000 & 1.000 & & \\
Independence model & .135 & .574 & .527 & .517 \\
\hline
\end{tabular}

Baseline Comparisons

\begin{tabular}{lrrrrr}
\hline Model & $\begin{array}{r}\text { NFI } \\
\text { Delta1 }\end{array}$ & $\begin{array}{r}\text { RFI } \\
\text { rho1 }\end{array}$ & $\begin{array}{r}\text { IFI } \\
\text { Delta2 }\end{array}$ & $\begin{array}{r}\text { TLI } \\
\text { rho2 }\end{array}$ & CFI \\
\hline Default model & .867 & .839 & .949 & .937 & .948 \\
Saturated model & 1.000 & & 1.000 & & 1.000 \\
Independence model & .000 & .000 & .000 & .000 & .000 \\
\hline
\end{tabular}

RMSEA

\begin{tabular}{lrrrr}
\hline Model & RMSEA & LO 90 & HI 90 & PCLOSE \\
\hline Default model & .039 & .029 & .049 & .962 \\
Independence model & .156 & .149 & .163 & .000 \\
\hline
\end{tabular}

Scalar Estimates (Group number 1 - Default model)

Maximum Likelihood Estimates

Regression Weights: (Group number 1 - Default model)

\begin{tabular}{lrlrrrrr}
\hline & & & Estimate & \multicolumn{1}{c}{ S.E. } & \multicolumn{1}{c}{ C.R. } & P & Label \\
\hline LES20 & $<---$ & LES & 1.000 & & & & \\
LES19 & $<---$ & LES & .988 & .090 & 10.938 & $* * *$ & \\
LES18 & $<---$ & LES & .924 & .097 & 9.549 & $* * *$ & \\
LES17 & $<---$ & LES & .916 & .086 & 10.662 & $* * *$ & \\
SE4 & $<---$ & SE & 1.000 & & & & \\
SE3 & $<---$ & SE & 1.636 & .285 & 5.748 & $* * *$ & \\
SE2 & $<---$ & SE & 2.082 & .345 & 6.030 & $* * *$ & \\
SE1 & $<---$ & SE & 2.056 & .344 & 5.979 & $* * *$ & \\
ALS8 & $<---$ & ALS & 1.000 & & & & \\
ALS7 & $<---$ & ALS & .640 & .074 & 8.647 & $* * *$ & \\
ALS6 & $<---$ & ALS & .756 & .086 & 8.818 & $* * *$ & \\
ALS5 & $<---$ & ALS & .626 & .075 & 8.377 & $* * *$ & \\
AG16 & $<---$ & AG & 1.000 & & & &
\end{tabular}




\begin{tabular}{lllrrrrr}
\hline & & & \multicolumn{1}{c}{ Estimate } & \multicolumn{1}{l}{ S.E. } & C.R. & P & Label \\
\hline AG15 & $<---$ & AG & 1.765 & .369 & 4.779 & $* * *$ & \\
AG14 & $<---$ & AG & 2.212 & .520 & 4.253 & $* * *$ & \\
AG13 & $<---$ & AG & 1.653 & .389 & 4.252 & $* * *$ & \\
SLV12 & $<---$ & SLV & 1.000 & & & & \\
SLV11 & $<---$ & SLV & 1.358 & .208 & 6.522 & $* * *$ & \\
SLV10 & $<---$ & SLV & 1.480 & .227 & 6.535 & $* * *$ & \\
\hline
\end{tabular}

Standardized Regression Weights: (Group number 1 - Default model)

\begin{tabular}{lllr}
\hline & & & Estimate \\
\hline LES20 & $<---$ & LES & .716 \\
LES19 & $<--$ & LES & .729 \\
LES18 & $<--$ & LES & .606 \\
LES17 & $<---$ & LES & .698 \\
SE4 & $<---$ & SE & .363 \\
SE3 & $<---$ & SE & .621 \\
SE2 & $<---$ & SE & .792 \\
SE1 & $<---$ & SE & .731 \\
ALS8 & $<---$ & ALS & .785 \\
ALS7 & $<---$ & ALS & .577 \\
ALS6 & $<---$ & ALS & .593 \\
ALS5 & $<---$ & ALS & .553 \\
AG16 & $<---$ & AG & .292 \\
AG15 & $<---$ & AG & .517 \\
AG14 & $<---$ & AG & .664 \\
AG13 & $<---$ & AG & .661 \\
SLV12 & $<---$ & SLV & .488 \\
SLV11 & $<---$ & SLV & .651 \\
SLV10 & $<---$ & SLV & .663 \\
\hline
\end{tabular}

Study 4: Reliability Tests

\section{Reliability Statistics}

Cronbach's

\begin{tabular}{cc} 
Alpha & N of Items \\
\hline .701 & 22 \\
\hline
\end{tabular}

\section{Item-Total Statistics}




\begin{tabular}{|c|c|c|}
\hline & $\begin{array}{c}\text { Corrected Item-Total } \\
\text { Correlation } \\
\end{array}$ & $\begin{array}{l}\text { Cronbach's Alpha if } \\
\text { Item Deleted }\end{array}$ \\
\hline $\begin{array}{l}\text { Everybody has to believe what } \\
\text { scientists say. }\end{array}$ & .271 & .678 \\
\hline $\begin{array}{l}\text { In science, you have to believe what } \\
\text { the science books say about things. }\end{array}$ & .215 & .687 \\
\hline $\begin{array}{l}\text { Whatever the teacher says in science } \\
\text { class is true. }\end{array}$ & .217 & .684 \\
\hline $\begin{array}{l}\text { If you read something in a science } \\
\text { book, you can be sure it is true. }\end{array}$ & .234 & .682 \\
\hline $\begin{array}{l}\text { All questions in science have one right } \\
\text { answer. }\end{array}$ & .238 & .681 \\
\hline $\begin{array}{l}\text { The most important part of doing } \\
\text { science is coming up with the right } \\
\text { answer. }\end{array}$ & .249 & .682 \\
\hline $\begin{array}{l}\text { Scientists know everything about } \\
\text { science; there is not much more to }\end{array}$ & & \\
\hline know. & .264 & .679 \\
\hline Scientific knowledge is always true. & .285 & .677 \\
\hline $\begin{array}{l}\text { Once scientists have the result from an } \\
\text { experiment, that is the only answer. }\end{array}$ & .222 & .683 \\
\hline $\begin{array}{l}\text { Some ideas in science today are } \\
\text { different than what scientists used to }\end{array}$ & & \\
\hline think. & .276 & .678 \\
\hline $\begin{array}{l}\text { The ideas in science books sometimes } \\
\text { change. }\end{array}$ & .272 & .680 \\
\hline $\begin{array}{l}\text { There are some questions that even } \\
\text { scientists cannot answer. }\end{array}$ & .267 & .679 \\
\hline $\begin{array}{l}\text { Sometimes scientists change their } \\
\text { minds about what is true in science. } \\
\text { Existing ideas in science may change }\end{array}$ & .230 & .682 \\
\hline $\begin{array}{l}\text { as scientists come up with new ones. } \\
\text { Scientific ideas may change because }\end{array}$ & .300 & .676 \\
\hline $\begin{array}{l}\text { technology may lead to new findings. } \\
\text { Ideas about science experiments come } \\
\text { from being curious and thinking about }\end{array}$ & .302 & .676 \\
\hline how things work. & .304 & .676 \\
\hline $\begin{array}{l}\text { In science, there can be more than one } \\
\text { way for scientists to test their ideas. } \\
\text { One important part of science is doing } \\
\text { experiments to come up with new ideas }\end{array}$ & .258 & .680 \\
\hline about how things work. & .233 & .682 \\
\hline
\end{tabular}


Good answers are based on evidence

from many different experiments.

Ideas in science can come from your

own questions and experiments.

It is good to try experiments more than

once to make sure of your results.

Good ideas in science can come from anybody, not just from scientists.

Study 4: Confirmatory factor analysis data

Model Fit Summary

CMIN

\begin{tabular}{lrrrrr}
\hline Model & NPAR & CMIN & DF & P & CMIN/DF \\
\hline Default model & 48 & 460.452 & 183 & .000 & 2.516 \\
Saturated model & 231 & .000 & 0 & & \\
Independence model & 21 & 6505.362 & 210 & .000 & 30.978 \\
\hline
\end{tabular}

RMR, GFI

\begin{tabular}{lrrrr}
\hline Model & RMR & GFI & AGFI & PGFI \\
\hline Default model & .026 & .957 & .946 & .758 \\
Saturated model & .000 & 1.000 & & \\
Independence model & .188 & .515 & .467 & .468 \\
\hline
\end{tabular}

Baseline Comparisons

\begin{tabular}{lrrrrr}
\hline Model & $\begin{array}{r}\text { NFI } \\
\text { Delta1 }\end{array}$ & $\begin{array}{r}\text { RFI } \\
\text { rho1 }\end{array}$ & $\begin{array}{r}\text { IFI } \\
\text { Delta2 }\end{array}$ & $\begin{array}{r}\text { TLI } \\
\text { rho2 }\end{array}$ & CFI \\
\hline Default model & .929 & .919 & .956 & .949 & .956 \\
Saturated model & 1.000 & & 1.000 & & 1.000 \\
Independence model & .000 & .000 & .000 & .000 & .000 \\
\hline
\end{tabular}

RMSEA

\begin{tabular}{lrrrr}
\hline Model & RMSEA & LO 90 & HI 90 & PCLOSE \\
\hline Default model & .040 & .036 & .045 & 1.000 \\
Independence model & .178 & .175 & .182 & .000 \\
\hline
\end{tabular}


Scalar Estimates (Group number 1 - Default model)

Maximum Likelihood Estimates

Regression Weights: (Group number 1 - Default model)

\begin{tabular}{|c|c|c|c|c|c|c|c|}
\hline & & & Estimate & S.E. & C.R. & $\mathrm{P}$ & Label \\
\hline $\mathrm{S} 1$ & $<--$ & Sour & 1.000 & & & & \\
\hline $\mathrm{S} 2$ & $<--$ & Sour & 1.465 & .078 & 18.824 & $* * *$ & \\
\hline S3 & $<---$ & Sour & .920 & .057 & 16.041 & $* * *$ & \\
\hline $\mathrm{S} 4$ & $<---$ & Sour & 999 & .056 & 17.718 & $* * *$ & \\
\hline $\mathrm{C} 5$ & $<--$ & Certi & 1.000 & & & & \\
\hline C6 & $<--$ & Certi & 1.697 & .087 & 19.404 & $* * *$ & \\
\hline $\mathrm{C} 7$ & $<--$ & Certi & .943 & .064 & 14.640 & $* * *$ & \\
\hline $\mathrm{C} 8$ & $<---$ & Certi & 1.269 & .067 & 18.837 & $* * *$ & \\
\hline C9 & $<--$ & Certi & 1.051 & .067 & 15.673 & $* * *$ & \\
\hline D10 & $<--$ & Deve & 1.000 & & & & \\
\hline D11 & $<--$ & Deve & .551 & .039 & 14.303 & $* * *$ & \\
\hline D12 & $<---$ & Deve & 1.012 & .050 & 20.095 & $* * *$ & \\
\hline D13 & $<--$ & Deve & .818 & .050 & 16.482 & $* * *$ & \\
\hline D14 & $<--$ & Deve & 1.033 & .051 & 20.300 & $* * *$ & \\
\hline D15 & $<--$ & Deve & 1.014 & .049 & 20.574 & $* * *$ & \\
\hline $\mathrm{J} 16$ & $<---$ & Justi & 1.000 & & & & \\
\hline $\mathrm{J} 17$ & $<---$ & Justi & .930 & .059 & 15.841 & $* * *$ & \\
\hline $\mathrm{J} 18$ & $<--$ & Justi & 1.094 & .062 & 17.634 & $* * *$ & \\
\hline J19 & $<---$ & Justi & 1.091 & .067 & 16.316 & $* * *$ & \\
\hline $\mathbf{J} 20$ & $<---$ & Justi & .819 & .060 & 13.700 & $* * *$ & \\
\hline $\mathrm{J} 21$ & $<---$ & Justi & 1.149 & .065 & 17.664 & $* * *$ & \\
\hline
\end{tabular}

Standardized Regression Weights: (Group number 1 - Default model)

\begin{tabular}{lllr}
\hline & & & Estimate \\
\hline S1 & $<---$ & Sour & .675 \\
S2 & $<---$ & Sour & .816 \\
S3 & $<---$ & Sour & .625 \\
S4 & $<---$ & Sour & .709 \\
C5 & $<---$ & Certi & .653 \\
C6 & $<---$ & Certi & .820 \\
C7 & $<---$ & Certi & .559 \\
C8 & $<---$ & Certi & .772 \\
C9 & $<---$ & Certi & .606 \\
D10 & $<---$ & Deve & .744 \\
D11 & $<---$ & Deve & .506 \\
D12 & $<---$ & Deve & .714 \\
D13 & $<---$ & Deve & .583 \\
\hline
\end{tabular}




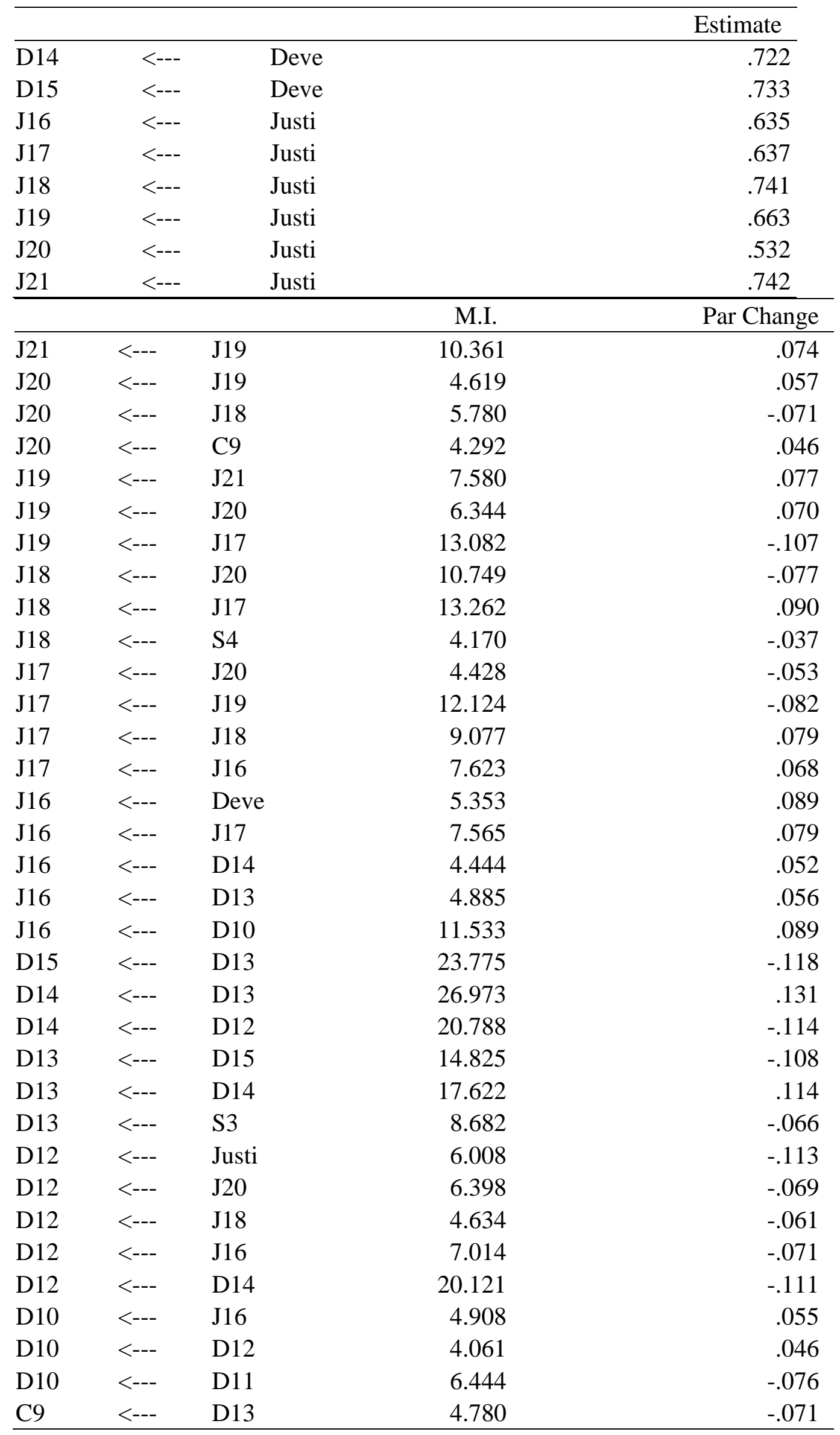




\begin{tabular}{lllrr}
\hline & & & M.I. & Par Change \\
\hline C8 & $<---$ & S3 & 6.393 & .054 \\
C7 & $<---$ & C5 & 6.282 & -.077 \\
C7 & $<---$ & S1 & 6.248 & .065 \\
C6 & $<---$ & S3 & 8.077 & -.074 \\
C5 & $<---$ & D11 & 4.618 & .076 \\
C5 & $<---$ & C7 & 7.914 & -.067 \\
S3 & $<---$ & Justi & 5.761 & .147 \\
S3 & $<---$ & J16 & 6.946 & .094 \\
S3 & $<---$ & D13 & 16.681 & -.137 \\
S2 & $<---$ & J16 & 5.966 & -.092 \\
S2 & $<---$ & D13 & 4.385 & .075 \\
S1 & $<---$ & C7 & 7.516 & .077 \\
\hline
\end{tabular}

